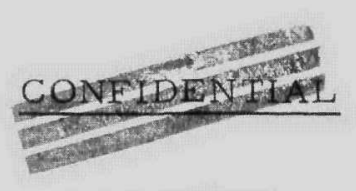

Report No. BMI-1208

C-83 Reactors-Special Features of Military Package Power Reactors $(\mathrm{M}-3679$, 19th Ed. $)$

Contract No. W-7405-eng-92

EVALUATION OF REACTOR CORE MATERIALS

FOR A GAS-COOLED REACTOR EXPERIMENT

by

Donald L. Keller

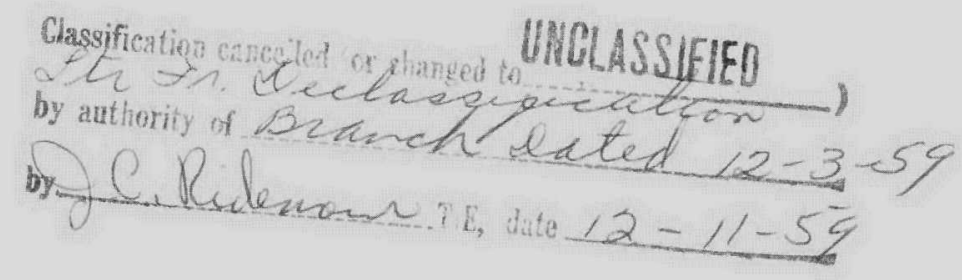

July 11,1957

\title{
RESTRIGTED D A T A
}

This document containgrestricted data as defined in the Atomic Energy Act of 1954. If transmittal or disclosure of its contents in any manner to an unauthorized person is prohibited.

BAT TELLE MEMORIAL INSTITUTE 505 King Avenue

Columbus 1, Ohio 


\section{DISCLAIMER}

This report was prepared as an account of work sponsored by an agency of the United States Government. Neither the United States Government nor any agency Thereof, nor any of their employees, makes any warranty, express or implied, or assumes any legal liability or responsibility for the accuracy, completeness, or usefulness of any information, apparatus, product, or process disclosed, or represents that its use would not infringe privately owned rights. Reference herein to any specific commercial product, process, or service by trade name, trademark, manufacturer, or otherwise does not necessarily constitute or imply its endorsement, recommendation, or favoring by the United States Government or any agency thereof. The views and opinions of authors expressed herein do not necessarily state or reflect those of the United States Government or any agency thereof. 


\section{DISCLAIMER}

Portions of this document may be illegible in electronic image products. Images are produced from the best available original document. 


\title{
TABLE OF CONTENTS
}

\begin{abstract}
. . . . . . . . . . . . . . . . . . . . 5
INTRODUCTION

DESIGN CONSIDERATIONS . . • . . . . . . . . . . . . . . . . 8

DEVELOPMENT OF HYDRIDE MODERATORS . . . . . . . . . . . 10

Reference Moderator . . . . . . . . . . . . . . 10

Temperature Distribution Through Moderator Bonding . . . . . . 12

Reactions of Hydrides With Nitrogen . . . . . . . . . . . . 14

Compatibility of Zirconium and Calcium Hydrides With

Several Metallic Materials . . . . . . . . . . . . 16

Thermal Conductivity of Calcium Hydride . . . . . . . . . . . 18

Mechanical Properties of Delta-Phase Zirconium Hydride . . . . 19

Fabrication of Zirconium Hydride . . . . . . . . . . . . 23

Cladding and Bond Evaluation . . . . . . . . . . . . 25
\end{abstract}

DEVELOPMENT OF CONTROL MATERIALS . . . . . . . . . . . . 28

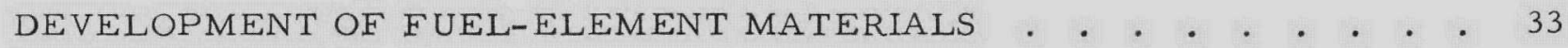

Fabrication of Reference Fuel Elements and Subassemblies . . . . . 33

Preparation of Enriched Uranium-Niobium and Uranium-Molybdenum

Irradiation Samples . . . . . . . . . . . . . . . 43

Calrod Fabrication . . . . . . . . . . . . . . . . 44

RADIATION-EFFECTS PROGRAM . . . . . . . . . . . . . . . 47

Survey of Radiation Stability of Fuel Elements of Interest to GCRE . . 47

Postirradiation Heat-Treatment Study of KAPL UO 2 Cermets . . . . 51

Preliminary Irradiation and Evaluation of Reference-Type

Fuel-Element Specimens . . . . . . . . . . . . . . 54

Irradiation of GCRE Reference-Fuel Specimens . . . . . . . . . 61

Evaluation of Alternate Fuels . . . . . . . . . . . . . . 62

Release of Fission Products From the Reference Fuel Element . . . . 62

NITROGEN-COOLANT STUDIES . . . . . . . . . . . . . . . . 63

Resistance of Materials to Nitriding . . . . . . . . . . . 63

Radiation-Induced Nitriding . . . . . . . . . . . . . . . . 74

Thermodynamic Considerations . . . . . . . . . . . 79

IN-PILE-LOOP FACILITY AT THE BRR . . . . . . . . . . . . . 86

Loop-Design Specifications . . . . . . . . . . . . . . . 86

Description of the Loop . . . . . . . . . . . . . . 87

Out-of-Pile Test Program . . . . . . . . . . . . . . 95

Present Status and Future Plans . . . . . . . . . . . . . 96 


\title{
EVALUATION OF REACTOR CORE MATERIALS FOR A GAS-COOLED REACTOR EXPERIMENT
}

\author{
Donald L. Keller
}

\begin{abstract}
An evaluation of core materials for a 2-megawatt gas-cooled reactor (GCRE) is being made. Work on the zirconium hydride moderator has been confined to the high-hydrogen or delta-phase material. Methods for preparing sound hydride bodies of the high-hydrogen composition have been developed. Both solid hydride and hydride powder compacts are being clad by a pressure-bonding technique. The hot hardness, tensile strength, thermal conductivity, thermal-expansion coefficient, and dissociation pressure of the delta-phase material are being determined. Control-material development has been directed at rare-earth-oxide dispersions in Nichrome $V$ or cobalt alloys. The reference fuel element is dispersed- $\mathrm{UO}_{2}$ in stainless steel. Studies include work on fabrication techniques and irradiation damage, and physical-and mechanical-property determinations. Several alternate fuels are being investigated. Gas-coolant studies involve nitrogen-metal and ammonia-metal reactions at $1500 \mathrm{~F}$. Several additives to retard nitriding are being investigated. An in-pile-loop facility for testing GCRE reference materials is being constructed for operation in the Battelle Research Reactor.
\end{abstract}

\section{INTRODUCTION}

On February 1, 1956, Battelle was awarded a contract by the Army Reactor Branch (APB) to select, develop, and test core materials which could be used successfully in conducting a Gas Cooled Reactor Experiment (GCRE). The prime objective of the GCRE would be to evaluate small portable reactor systems for military application.

In order to initiate the materials studies at Battelle, the following specifications for a Core I system were submitted by the APB:

$\begin{array}{ll}\text { Power level } & 2 \text { megawatts } \\ \text { Gas-inlet temperature } & 700 \mathrm{~F} \\ \text { Gas-exit temperature } & 1150 \mathrm{~F} \\ \text { Gas coolant } & \text { Nitrogen, air, or } \mathrm{CO}_{2} \\ \text { Operating pressure } & 200 \mathrm{psi}, \text { maximum } \\ \text { Core-pressure drop } & 10 \mathrm{psi}, \text { maximum } \\ \text { Core lifetime } & 10,000 \mathrm{hr} \\ \text { Coolant flow rate } & 16.6 \mathrm{lb} \mathrm{per} \mathrm{sec.}\end{array}$


Other pertinent characteristics are:

(1) The core shall be small, a 2-ft right cylinder about $2 \mathrm{ft}$ high, and contain a critical mass not exceeding $15 \mathrm{~kg}$.

(2) The plant shall be small and capable of transportation on a trailer truck.

(3) Permanent shielding will not be complete, a part of the biological shielding being provided from materials available in the field.

(4) Access to the turbine will not be essential.

With these specifications as limiting conditions, Battelle embarked upon a program to choose a set of core materials best suited for the GCRE concept from the standpoint of proposed time schedule, cost, and performance reliability. It was further recognized that the number of materials and material combinations were many. In order to concentrate attention, it was both desirable and necessary to select reference materials for the major reactor components with, in some cases, one or two alternate choices. These reference selections could only be made after a detailed survey of the most promising materials which had been demonstrated to be compatible, from both an engineering and a physics standpoint, with the GCRE specifications.

This survey constituted the first phase of the Battelle GCRE program and is reported in BMI-1133, entitled "Survey and Selection of Materials for Programmatic Evaluation for a Gas-Cooled Reactor Experiment". As a result of this study and related experience with reactor materials of the general type of interest, reference and alternate materials were selected for the major reactor-core components. These are listed below.

Gas coolant

Reference

Fuel element

Reference

Alternates

Control rod

Reference

Alternate

Moderator

Reference

Alternate
Nitrogen-7-1/2 volume per cent hydrogen plus approximately 1 volume per cent ammonia resulting from thermal equilibrium

Stainless steel-dispersed $\mathrm{UO}_{2}$ fuel element clad with Nichrome $\mathrm{V}$ for maximum resistance to nitriding

Solid $\mathrm{UO}_{2}$ pin-type elements

KAPL annularly loaded $\mathrm{UO}_{2}$ pin-type elements

Molybdenum $-20 \mathrm{w} / \mathrm{o}$ uranium and niobium-20

w/o alloy elements

Zirconium-1 w/o uranium hydride element

Haynes Stellite Alloy No. 25

Rare-earth-oxide dispersed in stainless steeltype alloy

Zirconium hydride

Calcium hydride

CONFIDENTIAL 
7

The present report is concerned with the GCRE activities at Battelle during approximately the 7 month' period following the first report of this series, BMI- 1133 . It is primarily concerned with a detailed evaluation of the reference materials as well as of the impact of one material upon the other.

In addition to the materials studies, some design work was continued to aid in the evaluation of alternate fuel and control materials. Also, the design and construction of an in-pile-loop facility for testing reference fuel-element subassemblies in the Battelle Research Reactor moved toward completion during the period covered.

As a result of the work described in this report, modifications were required on some of the reference materials while others could be specified in more detail.

Gas coolant

Reference

Nitrogen $-7-1 / 2$ volume per cent hydrogen-1 volume per cent ammonia plus approximately 0.1 to 0.5 volume per cent $\mathrm{H}_{2} \mathrm{O}$ vapor added to prevent nitriding.

Fuel element

Reference

Core

Cladding

Over-all dimensions

50-mil-thick Type 347 stainless steel plus $25 \mathrm{w} / \mathrm{o} \mathrm{UO}_{2}$

5 mils of Type 347 stainless steel

1 by 24 by 0,060 in.; seven of these flat plates are spaced 100 mils apart and brazed into side plates forming a 1-in.-square subassembly 24 in. long

\section{Alternates}

Same materials as previously described

Control rod

Reference

Rare-earth-oxide dispersion in a stainless steel, Nichrome V, or cobalt-base-alloy matrix

Moderator

Reference

Delta-phase zirconium hydride with a composition of approximately $\mathrm{ZrH}_{1.6}$

As a final word, it should be emphasized that all mention of a reference system for the GCRE in this report is the Battelle concept of core materials most compatible with the reactor specifications submitted by the Army Reactor Branch at the onset of this program. During the preparation of this report, the prime contractor for the GCRE presented several conceptual designs for a GCRE. One was similar to the Battelle concept; however, since there has been a recent relaxation in both the core-volume and critical-mass specifications, a broader choice of core materials (particularly moderator) was possible. 


\section{DESIGN CONSIDERATIONS}

H. M. Epstein, R. F. Redmond, J. W. Chastain

The purpose of this phase of the program was to perform preliminary evaluations of proposed fuel materials from a reactor-physics and an engineering standpoint. As reported previously in BMI-1133, the reference fuel system was evaluated on this basis. Since that time, some alternate fuel materials and configurations have been studied and the essential results are given here. As in BMI-1133, certain parameters have been specified for all calculations. These are:

$\begin{array}{ll}\text { Core diameter } & 2 \mathrm{ft} \\ \text { Core length } & 2 \mathrm{ft} \\ \text { Power } & 2 \text { megawatts } \\ \text { Moderator } & \mathrm{ZrH} 1.6 \\ \text { Fuel cladding thickness } & 0.005 \mathrm{in} . \\ \text { Moderator cladding thickness } & 0.030 \mathrm{in} . \\ \text { Outlet temperature } & 1150 \mathrm{~F} \\ \text { Inlet temperature } & 755 \mathrm{~F} \\ \text { Coolant } & \text { Nitrogen } \\ \text { Pressure drop } & 5 \mathrm{psi} \\ \text { Reflector savings } & 10 \mathrm{~cm} .\end{array}$

The systems studied are characterized briefly and the critical-mass range is given in the following list:

(1) Seven-plate subassemblies similar to the reference design except that niobium-10 to $20 \mathrm{w} / \mathrm{o}$ uranium alloy replaced the reference-design fuel material. Critical masses range from 13 to $17 \mathrm{~kg}$ of uranium-235, depending on whether the cladding is stainless steel or Nichrome V.

(2) Small rods using a $\mathrm{UO}_{2}$ fuel of medium-to-low enrichment. Critical masses range from 13 to $19 \mathrm{~kg}$ of uranium-235, depending upon whether the cladding is stainless steel or Nichrome V. Resonance capture by uranium-238 was not considered.

(3) Small rods using a fully enriched $\mathrm{UO}_{2}$ fuel diluted with $\mathrm{ZrO}_{2}$. Critical masses range from 12 to $19 \mathrm{~kg}$ of uranium-235, depending upon whether the cladding is stainless steel or Nichrome V. 


\section{CONFIDENTIAL}

9

(4) A homogeneous mixture of uranium and zirconium hydride. Critical masses range from 6 to $8 \mathrm{~kg}$ of uranium-235, depending upon the cladding material.

Some conclusions were drawn on the basis of these studies. These are:

(1) If Nichrome $\mathrm{V}$ is to be used as the cladding material, the fuel inventory will probably have to be above $15 \mathrm{~kg}$ unless a core design is employed which approaches a homogeneous distribution of fuel in the moderator.

(2) Rods offer no apparent advantage when compared with plates.

(3) The use of low-enrichment fuel does not appear attractive.

(4) The use of stainless steel as a cladding material gives an appreciable savings in critical mass.

In addition to these studies on alternate fuel materials, further studies were directed toward a complete evaluation of the reactor-physics and heat-transfer aspects of the reference reactor system. The reference reactor system employs a stainless steel- $\mathrm{UO}_{2}$ fuel material and a zirconium hydride moderator.

The effects of fuel concentration, plate thickness, coolant-channel size, core size, and reflector savings on reactivity, fuel inventory, pressure drop, and maximum fuel temperature were studied. Fuel-element designs were considered which would minimize flux depressions and power variations. 


\title{
DEVELOPMENT OF HYDRIDE MODERATORS
}

\author{
J. B. Vetrano
}

During the period covered by the previous survey report (BMI-1133) a preliminary evaluation of the materials problems likely to be encountered in developing a moderator for the GCRE was conducted, and pertinent materials information was gathered. It was concluded from this survey that the material which would be most suitable for development in this application was zirconium hydride, and, since the allowed rate of effort would not be sufficient to study all possible materials, the decision was taken to gather as much pertinent information as possible within the limitations of time and budget on zirconium hydride alone. This is what has been done in the intervening period, and the results of these investigations are related in this report.

The initial programs which were undertaken were not aimed at the fabrication of a subassembly of specified size and shape since the programs all preceded detailed design studies, but, rather, a research approach was taken in which probable materials problems were anticipated and studied. It was realized that certain basic information on properties of zirconium hydride, such as hardness, tensile strength, thermal conductivity, coefficient of expansion, and dissociation pressure, would be needed regardless of the final design. Also, it would be necessary to know something of the chemical and metallurgical reactivity of the hydride to gases and metals with which it would likely come into contact either by design or accident. Finally, with this basic background information, fabrication studies could be conducted which would lead to information on the size of subassemblies which could possibly be fabricated and the methods required. Programs to answer all of these problems have been initiated, and those which have progressed to a point where more than preliminary information is available are reported here.

\section{Reference Moderator}

J. B. Vetrano

In BMI-1133 the qualifications for a moderator in the gas-cooled reactor were discussed in the light of the known properties of possibly suitable materials. It was shown that the properties of metal hydrides, and especially zirconium hydride and calcium hydride, most nearly fulfilled the specifications for a moderator in the gascooled reactor. Of these two materials, zirconium hydride has been chosen as the reference moderator on the basis of its higher $N_{H}$, greater metallic character, and nonhydroscopic nature. Zirconium hydride is a many-faced species, and when one speaks of zirconium hydride it is necessary to identify the particular hydrogen/zirconium ratio in point, and the metallurgical phase designation of that material. The following discussion will be concerned with the properties of the various phases of zirconium hydride with reference as to how well these properties satisfy the requirements of the GCRE. 
Beta-Phase Zirconium Hydride

The phase boundary of beta zirconium hydride is temperature as well as composition dependent, but, in general, the lower composition limit is established by a hydrogen/zirconium atomic ratio of about 0.01 and the higher composition limit at about 1.0. The physical and mechanical properties of this material are well established as it has been given serious consideration for use at temperatures higher than those specified for the GCRE.

A serious limitation on the use of beta-phase zirconium hydride in the GCRE, however, is the composition limits imposed by the phase diagram and by the temperature of operation. From available P-C $-\mathrm{T}$ data it $\mathrm{can}$ be shown that the highest composition which can be maintained at $1000 \mathrm{~F}$ while still remaining in the beta phase is $\mathrm{ZrH}_{0.6}$. This material would have a dissociation pressure of $2.4 \times 10^{-4} \mathrm{~atm}$. The zirconium hydride having this same dissociation pressure at $1500 \mathrm{~F}$ would be $\mathrm{ZrH}_{0.013}$. The generally low $\mathrm{N}_{\mathrm{H}}$ values as sociated with these low hydrogen/zirconium ratios and the excessive concentration gradients established under thermal gradients make the use of beta-phase zirconium hydride extremely unattractive in the temperature range of operation of the GCRE.

Delta-Phase Zirconium Hydride

There exists at compositions between $\mathrm{ZrH}_{1} .46$ and $\mathrm{ZrH}_{1} .60$ a delta-phase region. This region merges into an epsilon phase at only slightly higher compositions, and the phase boundaries defining both of these regions are nearly independent of temperature. The two phase delta-epsilon region is so small that it may be neglected and all compositions above $\mathrm{ZrH}_{1.46}$ treated essentially as one phase.

The hydride of this composition is a brittle material, and would probably be difficult to fabricate. Mechanical tests conducted at Battelle have confirmed this. However, delta-phase zirconium hydride would make a very good moderator because of its high hydrogen content. Its $\mathrm{N}_{\mathrm{H}}$ value at room temperature would be from about 5.5 to 7.0. Furthermore, since the phase boundaries are independent of temperature, thermal cycling of the material will not cause any phase changes, and the imposition of large thermal gradients will not cause the extreme composition gradients associated with phase changes. There will be some hydrogen migration with temperature however, but this will be comparatively minor. From available P-C-T and density data it is calculated that the composition gradient caused by a thermal gradient of from 1000 to $1500 \mathrm{~F}$ at a hydrogen partial pressure on 1 atm would not exceed a change from approximately $\mathrm{ZrH}_{1.6}$ to $\mathrm{ZrH}_{1.9}$ and correspond to a density change of no more than $0.15 \mathrm{~g}$ per $\mathrm{cm}$.

\section{Beta-Delta Two-Phase Region}

There exists the possibility of fabricating a moderator from delta-phase zirconium hydride to take advantage of the greater workability of the material, and then using it in a temperature range in which the beta-phase is thermodynamically unstable. This is not an overly attractive possibility, however, since as the metastable material slowly reverts to an equilibrium state by a mechanism whose rate is determined primarily by 
the diffusior rate of the hydrogen in zirconium, beta-delta two-phase regions will be formed. These regions will be particularly sensitive to hydrogen migration, since a minute change in temperature can cause a marked composition change. This in turn is manifested as a density change, or, in other words, there is a swelling or contracting of the element. Furthermore, the hydrogen shift would result in nonuniform moderating properties of the system.

\section{Dissociation-Pressure Data}

The above discussion of the relative merits of the delta-phase versus beta-phase zirconium hydride is based largely upon what is known of the zirconium-hydrogen system. Since the literature does contain conflicting information on this system, and since a thorough knowledge of the system is so vital to the prediction of the behavior of a zirconium hydride moderator, a few check points in the expected range of operation of the GCRE are being determined and will be reported at a later time.

\section{Temperature Distribution Through Moderator Bonding}

H. M. Epstein, R. E. Redmond, and J. W. Chastain, Jr.

Significant quantities of heat are generated within the moderator. Since the reference moderator is a hydride, and hydrides are unstable with respect to dissociation at elevated temperatures, it is necessary to determine the heat-transfer properties of the clad element required to keep the center temperature below a value at which the dissociation pressure becomes excessive. The heat-transfer properties are dictated largely by the diameter of the moderator core and the size of gaps and voids between the core and the cladding.

In order to determine the extent of the temperature rise in an imperfectly bonded element, a series of calculations was carried out for a flat-plate zirconium hydride moderator, clad with 5 mils of molybdenum and 20 mils of stainless steel, and with a hydrogen film of variable thickness between the moderator and molybdenum. Keeping the surface temperature of the stainless steel constant at $1150 \mathrm{~F}$ (the exit temperature of the coolant gas), while varying the thickness of the hydrogen film and the thickness of the zirconium hydride plate, the temperature at the core of the moderator was calculated.

It was further assumed that the thermal conductivity of the hydride would be about $13 \mathrm{Btu} /(\mathrm{hr})(\mathrm{ft})(\mathrm{F})$, and that the gamma heating per unit mass in the GCRE would be approximately the same as in the MTR for the same power level. The total heating in the moderator is the sum of the gamma heating and the heating due to moderation of fast neutrons. The maximum energy expended in the moderator was estimated to be 6 w per $\mathrm{cm}^{3}$.

To interpret the results of the calculations, which are given in Table 1 it should be borne in mind that the maximum center temperature which can be tolerated in the 


\section{CONFIDENTIAL}

13

TABLE 1. TEMPERATURE-DISTRIBUTION CALCULATIONS

\begin{tabular}{|c|c|c|c|c|}
\hline \multicolumn{2}{|c|}{ Thickness } & \multirow{2}{*}{\multicolumn{3}{|c|}{ Temperature at Indicated Point, F }} \\
\hline \multirow{3}{*}{$\begin{array}{l}\text { Zirconium } \\
\text { Hydride } \\
\text { Plate, in. }\end{array}$} & \multirow{3}{*}{$\begin{array}{l}\text { Hydrogen } \\
\text { Film, } \\
\text { mils }\end{array}$} & & & \\
\hline & & Center of & Hydride-Hydrogen & Hydrogen-Molybdenum \\
\hline & & Hydride & Interface & Interface \\
\hline \multirow[t]{6}{*}{4} & 0 & 1784 & 1163 & 1163 \\
\hline & 0.1 & 1818 & 1197 & 1163 \\
\hline & 1 & 2127 & 1506 & 1163 \\
\hline & 2 & 2472 & 1851 & 1163 \\
\hline & 5 & 3494 & 2873 & 1163 \\
\hline & 10 & 5214 & 4593 & 1163 \\
\hline \multirow[t]{6}{*}{2} & 0 & 1312 & 1157 & 1157 \\
\hline & 0.1 & 1329 & 1174 & 1157 \\
\hline & 1 & 1444 & 1329 & 1157 \\
\hline & 2 & 1656 & 1501 & 1157 \\
\hline & 5 & 2168 & 2015 & 1157 \\
\hline & 10 & 3032 & 2877 & 1157 \\
\hline \multirow[t]{6}{*}{1.5} & 0 & 1242 & 1155 & 1155 \\
\hline & 0.1 & 1255 & 1168 & 1155 \\
\hline & 1 & 1370 & 1283 & 1155 \\
\hline & 2 & 1499 & 1412 & 1155 \\
\hline & 5 & 1882 & 1795 & 1155 \\
\hline & 10 & 2525 & 2438 & 1155 \\
\hline \multirow[t]{6}{*}{1} & 0 & 1192 & 1153 & 1153 \\
\hline & 0.1 & 1200 & 1161 & 1153 \\
\hline & 1 & 1278 & 1239 & 1153 \\
\hline & 2 & 1364 & 1325 & 1153 \\
\hline & 5 & 1621 & 1582 & 1153 \\
\hline & 10 & 2052 & 2013 & 1153 \\
\hline \multirow[t]{6}{*}{0.5} & 0 & 1162 & 1152 & 1152 \\
\hline & 0.1 & 1166 & 1156 & 1152 \\
\hline & 1 & 1205 & 1195 & 1152 \\
\hline & 2 & 1248 & 1238 & 1152 \\
\hline & 5 & 1376 & 1366 & 1152 \\
\hline & 10 & 1591 & 1581 & 1152 \\
\hline \multirow[t]{6}{*}{0.25} & 0 & 1153 & 1151 & 1151 \\
\hline & 0.1 & 1155 & 1153 & 1151 \\
\hline & 1 & 1174 & 1172 & 1151 \\
\hline & 2 & 1196 & 1194 & 1151 \\
\hline & 5 & 1260 & 1258 & 1151 \\
\hline & 10 & 1367 & 1365 & 1151 \\
\hline
\end{tabular}


reference zirconium hydride moderator is $1650 \mathrm{~F}$; however, from the standpoint of hydrogen migration, a more desirable peak temperature would be 1300 to $1400 \mathrm{~F}$. From Table 1, hydride bodies $2 \mathrm{in.}$ thick can meet this requirement only if gap spacings are held to 1 mil or less. This is considerably better than a "force fit" and calls for a good mechanical or a metallurgical bond between the cladding and the hydride body. To achieve this, Battelle has developed a pressure-bonding technique which is reported in a later section.

Reactions of Hydrides With Nitrogen

J. B. Vetrano and J. F. Foster

There was some concern that, if a clad zirconium or calcium hydride moderator in the GCRE developed a failure in service, the nitrogen coolant would displace the hydride hydrogen with the resultant loss of the moderating properties of the element, and with the possible propagation of the failure due to the differences in mechanical and physical properties of the hydride and nitride. Samples of the hydrides which were being considered for use as moderators in the GCRE were exposed to the reference coolant gas at the probable temperature and pressure of operation. On the basis of the thermodynamic properties of the hydrides and nitrides involved, it would be expected that there would be nearly 100 per cent displacement of the hydrogen by nitrogen. Experimentally, however, it was found that equilibrium was attained only slowly in the case where calcium hydride was the condensed phase, and that trace oxidative impurities in the gas nearly completely protected the zirconium hydride from attack by the nitrogen under the experimental conditions.

\section{Experimental Work}

A sample of the material to be tested was placed in a Vycor boat in a $250-\mathrm{cm}^{3}-$ capacity microbomb. After introducing the required gas mixture to a precalculated pressure, the bomb was heated to the reaction temperature (1000 to $1500 \mathrm{~F}$ ) and pressure (140 to 215 psia) and maintained under these conditions for a measured time. The furnace was air quenched and the condensed phase was examined and analyzed for nitrogen and hydrogen.

The nitrogen gas used in the experiments was an oil-pumped grade of nominal 99.7 volume per cent purity, while the hydrogen was the extra-dry grade of nominal 99.9 volume per cent purity. The ammonia was anhydrous. None of the gases was further purified.

The calcium hydride was of 98.4 volume per cent purity as determined by a hydrogen-evolution analysis, and the zirconium hydride was hafnium free.

\section{Results}

The experimental results are shown in Table 2 . 
TABLE 2. RESULTS OF NITRIDING EXPERIMENTS

\begin{tabular}{|c|c|c|c|c|c|c|c|c|}
\hline \multirow[b]{2}{*}{ Run } & \multirow{2}{*}{$\begin{array}{l}\text { Starting } \\
\text { Material }\end{array}$} & \multirow{2}{*}{$\begin{array}{c}\text { Tempera- } \\
\text { ture, } F\end{array}$} & \multirow{2}{*}{$\begin{array}{c}\text { Pressure, } \\
\text { psia }\end{array}$} & \multirow{2}{*}{$\begin{array}{l}\text { Time, } \\
\text { hr }\end{array}$} & \multicolumn{3}{|c|}{$\begin{array}{l}\text { Gas Composition, } \\
\text { volume per cent }\end{array}$} & \multirow{2}{*}{$\begin{array}{l}\text { Nitrogen in } \\
\text { Product, w/o }\end{array}$} \\
\hline & & & & & $\mathrm{N}_{2}$ & $\mathrm{H}_{2}$ & $\mathrm{NH}_{3}$ & \\
\hline 1 & $\mathrm{ZrH}_{1.0}$ & 1130 & 214 & 28 & 90.9 & 9.1 & -- & 0.007 \\
\hline 2 & $\mathrm{CaH}_{2}$ & 1060 & 200 & 118 & 90.7 & 9.3 & -- & 5.6 \\
\hline 3 & $\mathrm{ZrH}_{1.1}$ & 1020 & 206 & 118 & 92.4 & -- & 7.6 & 0.006 \\
\hline 4 & $\mathrm{ZrH}_{1.1}$ & -- & 210 & 136 & 98.5 & -- & 1.5 & 1.1 \\
\hline 6 & $\mathrm{ZrH}_{1.1}$ & 1400 & 125 & 99 & 95.8 & 2.3 & 1.9 & 0.01 \\
\hline 7 & $\mathrm{ZrH}_{1.1}$ & 1500 & 140 & 216 & 96.1 & 2.4 & 1.5 & 0.039 \\
\hline 8 & $\mathrm{Zr}$ metal & 1540 & 165 & 80 & 96.0 & 2.4 & 1.5 & 0.053 \\
\hline
\end{tabular}

In Run 2 a sample of minus 4 plus 40 mesh calcium hydride was exposed to a mixture of nitrogen and hydrogen at a temperature of $1060 \mathrm{~F}$ and a total pressure of 200 psia. After $118 \mathrm{hr}$ of this treatment, it was found that the condensed phase had changed composition from the starting $98.4 \mathrm{w} / 0 \mathrm{CaH}_{2}$ to $64.3 \mathrm{w} / \mathrm{o} \mathrm{CaH}_{2}-29.7 \mathrm{w} / \mathrm{o}$ $\mathrm{Ca}_{3} \mathrm{~N}_{2}$. Although the hydride had not completely nitrided, the attack was extensive.

Very little attack was noted on the zirconium hydride exposed to a variety of nitriding atmospheres at various conditions. The one exception to this was in Run 4 where, after running for about 4 to 5 days at $1000 \mathrm{~F}$, the temperature controller developed a fault and the temperature rose to $2300 \mathrm{~F}$ for an undetermined length of time. The zirconium hydride absorbed nitrogen corresponding to about 8.3 per cent of theroretical for $\mathrm{ZrN}$.

The one sample of zirconium metal exposed for comparison suffered only slight attack by the nitriding atmosphere.

\section{Discussion}

From a combination of thermal data and dissociation-pressure data, the standard free-energy change for the equation

$$
3 \mathrm{CaH}_{2}+\mathrm{N}_{2}=\mathrm{Ca}_{3} \mathrm{~N}_{2}+3 \mathrm{H}_{2}
$$

was calculated to be $-100,331 \mathrm{cal}$ per mole at $1000 \mathrm{~F}$ and $-62,821 \mathrm{cal}$ per mole at $1500 \mathrm{~F}$, from which the respective equilibrium constants (Keq) are calculated to be $1.1 \times 10^{27}$ at $1000 \mathrm{~F}$ and $4.0 \times 10^{12}$ at $1500 \mathrm{~F}$. 
Similarly, the standard free-energy change for the equation

$$
\mathrm{ZrH}+1 / 2 \mathrm{~N}_{2}=\mathrm{ZrN}+1 / 2 \mathrm{H}_{2}
$$

was calculated to be $-57,268 \mathrm{cal}$ per mole at $1000 \mathrm{~F}$ and $-54,114 \mathrm{cal}$ per mole at $1500 \mathrm{~F}$. The equilibrium constant is therefore $2.6 \times 10^{15}$ at $100 \mathrm{~F}$ and $7.8 \times 10^{10}$ at $1500 \mathrm{~F}$.

It is therefore apparent that at these temperatures nitrogen should nearly completely displace hydrogen from either of these hydrides. This point was not verified experimentally. It is postulated that two factors were operating to reduce the nitriding. The first of these was the absence of an active nitriding species. In the experiments where small amounts of ammonia were added to provide this active species, it is likely that the ammonia completely dissociated in the static system even before the reaction temperature was attained, leaving only sluggishly reactive molecular nitrogen. The second factor retarding the nitriding was probably the presence of traces of oxygen or water vapor. It has now been established that minute amounts of water greatly retard the nitriding of metals, even when exposed to such vigorous nitriding reagents as ammonia (BMI-1162).

\section{Conclusion}

Failure of a zirconium hydride moderator by nitriding through a pinhole defect in the cladding will not be a serious problem if ammonia is nonexistent in the coolant (or at a low level) and if traces of moisture or oxygen are present.

Failure of a calcium hydride moderator by nitriding, on the other hand, would be a serious problem.

Compatibility of Zirconium and Calcium Hydrides With Several Metallic Materials

A. F. Gerds and M. W. Mallett

Zirconium hydride is the reference and calcium hydride the alternate moderator for the GCRE. Both of these materials have certain desirable properties, such as moderately low cost, relatively low neutron cross sections, and high $\mathrm{N}_{\mathrm{H}}$ values. In order for these materials to be used most successfully as moderators, it is necessary to isolate them from the gaseous coolant by means of a material that is relatively inert to both the hydride and the coolant and improves the structual qualities of hydride body.

The solid-solid reaction between the hydrides of zirconium and calcium and the metallic materials listed in Table 3 was studied at $1700 \mathrm{~F}$. A few experiments also were performed at $1450 \mathrm{~F}$. Cup-shaped elements were machined from the metals, filled with solid or powdered hydrides, capped, and welded tight. After machining the welded ends flat, the elements were heated under a pressure of argon in graphite restraining dies. The extent of reaction was determined on the basis of metallographic examinations of cross sections of the reacted elements.

\section{CONFIDENTIAL}

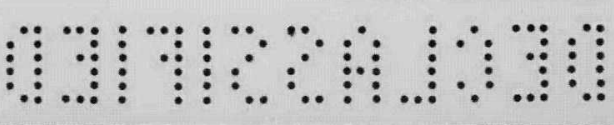


TABLE 3. COMBINATIONS OF HYDRIDES AND POSSIBLE CLADDING MATERIALS TESTED AT $1700 \mathrm{~F}$

\begin{tabular}{|c|c|c|c|}
\hline \multirow[b]{2}{*}{ Cladding Material } & \multicolumn{3}{|c|}{ Moderator Material } \\
\hline & $\overline{\mathrm{ZrH}}$ & $\mathrm{ZrH}_{1.8}$ & $\overline{\mathrm{CaH}_{2}}$ \\
\hline Molybdenum & $x(a)$ & $\mathbf{x}$ & $x(a)$ \\
\hline Chromium & $\mathrm{x}$ & & $\mathrm{x}$ \\
\hline Copper & & $\mathrm{x}$ & $\mathrm{x}$ \\
\hline Niobium & 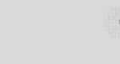 & $\mathrm{x}$ & $\mathrm{x}$ \\
\hline Armco iron & $x^{(a)}$ & $\mathrm{x}$ & $x(a)$ \\
\hline Nickel & $\mathrm{x}$ & $\mathrm{x}$ & $\mathrm{x}$ \\
\hline Type 303 stainless steel & & $\mathrm{x}$ & \\
\hline Type 347 stainless steel & & $\mathrm{x}$ & \\
\hline Type 446 stainless steel & $\mathrm{x}$ & $\mathrm{x}$ & $\mathrm{x}$ \\
\hline Nichrome & & $\mathrm{x}$ & . \\
\hline Nichrome V & $x(a)$ & $\mathrm{x}$ & $x(a)$ \\
\hline Inconel & & $\mathrm{x}$ & \\
\hline
\end{tabular}

(a) Tested at $1450 \mathrm{~F}$ in addition to $1770 \mathrm{~F}$.

Calcium hydride reacted extensively with Nichrome V and Armco iron but very little, if any, with molybdenum after heating in intimate contact with each material at $1450 \mathrm{~F}$ for about 1 week. At $1700 \mathrm{~F}$, molybdenum showed the least reaction with calcium hydride, while Type 446 stainless steel, chromium, and niobium reacted only very slightly more than molybdenum in similar tests. Armco iron and Nichrome were less resistant to attack by calcium hydride than the above-named metallic materials. Copper, nickel, and Nichrome $V$ showed the most reaction when tested in contact with calcium hydride at $1700 \mathrm{~F}$.

At $1450 \mathrm{~F}$, Armco iron appeared to react only very slightly if at all with $\mathrm{ZrH}$. Molybdenum and Nichrome $\mathrm{V}$ showed slight evidence of reaction on the basis of tests of about 1 week in duration. At $1700 \mathrm{~F}$, Type 446 stainless steel, chromium, molybdenum, and Armco iron showed the least reaction with $\mathrm{ZrH}$. Nichrome and nickel showed slight evidence of interaction.

No compatibility studies were made with $\mathrm{ZrH}_{1.8}$ at $1450 \mathrm{~F}$. Molybdenum, Type 446 stainless steel, and niobium showed the least interaction when in contact with 


\section{CONFIDENTIAL}

$\mathrm{ZrH}_{1.8}$ at $1700 \mathrm{~F}$. Armco iron, containing carbon which entered by diffusion from the graphite restraining die, showed only slight evidence of reaction. Somewhat more extensive reactions were observed between $\mathrm{ZrH}_{1} .8$ and Types 303 and 347 stainless steel, nickel, Inconel, Nichrome V, and Nichrome. Copper reacted quite severely with $\mathrm{ZrH}_{1.8}$ at $1700 \mathrm{~F}$.

Thermal Conductivity of Calcium Hydride

H. W. Deem, A. R. Noe, C. F. Lucks, and R. B. Fischer

In order to estimate the temperature drop through a moderator compacted from calcium hydride, it is necessary to know its thermal conductivity. This information was not available, and consequently it was measured as part of the program on determining materials properties of the alternate moderator.

\section{Apparatus and Method}

The method used consists of heating the top face of the specimen, measuring the temperature gradient through the specimen, and determining the rate of heat flow through the specimen by means of a guarded heat-flow meter of Armco iron on the bottom face of the specimen. Heat is introduced at a constant rate at the top face of the specimen from a resistance heater powered by a constant-voltage source. Heat is removed at the same constant rate from the bottom of the heat-flow meter by a watercooled heat sink through which temperature-controlled water flows at a constant rate. When thermal-equilibrium conditions are obtained, the thermal conductivity of the specimen is calculated from its thermal gradient and the heat flow as measured in the Armco iron standard.

Disks of Refrasil (essentially, a silica-fiber cloth) were used between the specimen and heater and between the specimen and Armco iron heat-flow meter to provide a uniform thermal contact over the surface areas. More layers of Refrasil were used under the specimen (between it and the heat-flow meter) than above it. This permitted the specimen to reach higher temperatures without excessive heat flows.

The specimen of calcium hydride used for the thermal-conductivity measurements was a 3-in.-diameter by 1.12 -in. -thick compact weighing $185 \mathrm{~g}$. It was compacted from minus 40-mesh calcium hydride of a commercial grade using a $21,000-p s i$ compacting pressure. Although actual compacting was done in air, the loading of the die and the weighing of the materials were accomplished in an inert-atmosphere dry box. All subsequent handling of the material was planned to avoid undue exposure to the air.

The entire thermal-conductivity assembly was placed in an atmosphere can with an O-ring-gasketed cover. Provision was made to supply the chamber with either argon or hydrogen. Gas pressure of about 1.6 psig was maintained on the specimen during the measurements by a mercury bubble bottle in the exhaust line. 
Commonly used thermocouples cannot be used at elevated temperatures in a reducing atmosphere without changing calibration. A Driver-Harris Company experimental thermocouple, composed of DH Alloys No. 242 and No. 33, which are essentially nickel-20 w/o chromium and nickel, was used. A calibration was made of the DriverHarris thermocouple wire as received and on two of the three specimen thermocouples after the run. The difference between the thermocouples before and after their exposure to hydrogen was negligible and within the limits of calibration errors. The thermocouple in the hottest region in the specimen was frozen and could not be removed after the run.

Results

Four thermal equilibria were obtained. Each thermal equilibrium gave two thermal-conductivity values for the calcium hydride, each at a different mean temperature. Table 4 shows the observed thermal conductivities for the four thermal equilibria. The heat flows were too low for good accuracy in thermal Equilibrium 1 and, therefore, these values should have less weight than those obtained in thermal Equilibria 2, 3, and 4. Table 5 shows interpolated thermal-conductivity values at selected temperatures. The values in Table 5 are estimated to be not in error by more than 10 per cent. Some error could result from the uncertainty of the thermal conductivity of the Armco iron used as a standard. Some error could, also, result from the uncertainty of thermocouple locations in the specimen, from radial-heat flows, and from errors in temperature measurements.

\section{Mechanical Properties of Delta-Phase Zirconium Hydride}

J. E. Campbell, J. B. Vetrano, and J. F. Foster

Prior to the initiation of this study, the only information available on the mechanical properties of delta-phase zirconium hydride was the qualitative observation that it was a brittle material. During the course of this investigation, the Vickers hardness of hydrided zirconium was measured in the temperature range of 1000 to $1500 \mathrm{~F}$. Comparison measurements were made at room temperature by both the Vickers and Tukon methods. The ultimate tensile strength of the material was also measured at elevated temperatures.

\section{Hardness}

The Vickers hardness measurements were made with a specially constructed apparatus which utilized the normal Vickers indentor but which also provided for heating and for maintaining a controlled gaseous atmosphere. The measurements at elevated temperatures were made in a flowing-gas stream containing a partial pressure of hydrogen just sufficient to balance the dissociation pressure of the hydride at the particular temperature in question. 
CONFIDENTIAL

20

TABLE 4. OBSERVED THERMAL CONDUCTIVITY OF CALCIUM HYDRIDE

\begin{tabular}{ccc}
\hline \hline Equilibrium & Mean Temperature, & $\begin{array}{c}\text { Thermal Conductivity, } \\
\text { Btu/(hr)(ft)(F) }\end{array}$ \\
\hline 1 & 846 & 0.507 \\
1 & 651 & 0.562 \\
2 & 1177 & 0.554 \\
2 & 901 & 0.544 \\
3 & 1440 & 0.669 \\
3 & 1116 & 0.579 \\
4 & 1535 & 0.568 \\
4 & 1166 & 0.596 \\
\hline \hline
\end{tabular}

TABLE 5. INTERPOLATED THERMALCONDUCTIVITY VALUES OF

CALCIUM HYDRIDE AT

SELECTED TEMPERATURES

\begin{tabular}{cc}
\hline $\begin{array}{c}\text { Temperature, } \\
\text { F }\end{array}$ & $\begin{array}{c}\text { Thermal Conductivity, } \\
\text { Btu/(hr)(ft)(F) }\end{array}$ \\
\hline $600(\mathrm{a})$ & 0.500 \\
800 & 0.527 \\
1000 & 0.553 \\
1200 & 0.580 \\
1400 & 0.606 \\
$1600(\mathrm{a})$ & 0.633 \\
\hline \hline
\end{tabular}

(a) Extrapolated. 


\section{1}

The results of the hardness measurements are reported in Table 6 and plotted in Figure 1. The one point which falls far below the curve is actually beta-phase zirconium hydride and was included in the measurements only for comparison.

TABLE 6. DELTA-PHASE ZIRCONIUM HYDRIDE HARDNESS

\begin{tabular}{lcccc}
\hline \hline Composition & $\begin{array}{c}\text { Temperature, } \\
\text { Foom }\end{array}$ & $\begin{array}{c}\text { Atmosphere } \\
\text { volume } \\
\text { per cent }\end{array}$ & $\begin{array}{c}\text { Hardness, } \\
\text { kg per mm } \mathrm{m}^{2}\end{array}$ & Apparatus \\
\hline $\mathrm{ZrH}_{1.60}$ & Room & $100 \mathrm{Air}$ & 209 & Vickers \\
$\mathrm{ZrH}_{1.90}$ & 1020 & $100 \mathrm{H}$ & 126 & Vickers \\
$\mathrm{ZrH}_{1.93}$ & 1031 & $10 \mathrm{H}-90 \mathrm{He}$ & Vickers \\
$\mathrm{ZrH}_{1.88}$ & 1148 & $100 \mathrm{H}$ & 46.7 & Vickers \\
$\mathrm{ZrH}_{1.88}$ & 1310 & $10 \mathrm{H}-90 \mathrm{He}$ & Vickers \\
$\mathrm{ZrH}_{1.60}$ & 1490 & $100 \mathrm{H}$ & 46.5 & Vickers \\
$\mathrm{ZrH}_{1.60}$ & 1508 & $10 \mathrm{H}-90 \mathrm{He}$ & 42.5 & Vickers \\
$\mathrm{ZrH}_{0.80}$ & Rickers \\
\hline \hline
\end{tabular}

Tensile Strength

The hydride specimens utilized were of flat plate with over-all dimensions of about 0.1 by 2 by $0.5 \mathrm{in}$. They were held in the test rig by pins resting against the shoulder of the specimens where they necked down to the test section.

A specially designed capsule was used to contain the samples on the testing machine. This allowed for controlled heating of the specimens as well as the maintenance of a controlled atmosphere to prevent decomposition of the hydride.

Major difficulties were encountered in mounting the samples in the testing machine because of their brittleness. Several specimens were broken even before a load was applied. Only two specimens were successfully tested and the results are shown in Table 7. 


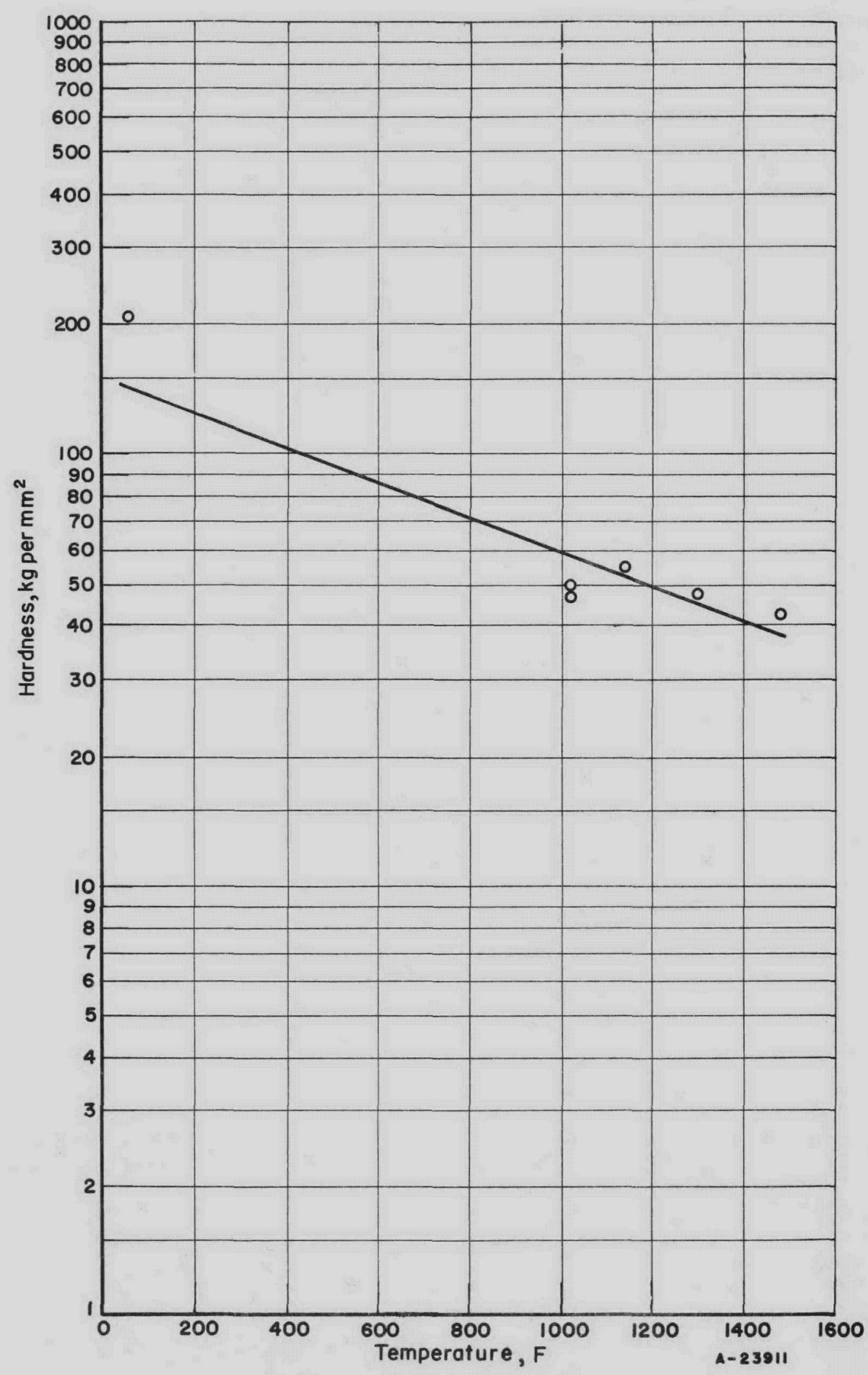

FIGURE 1. HARDNESS OF ZIRCONIUM HYDRIDE CONFIDENTIAL

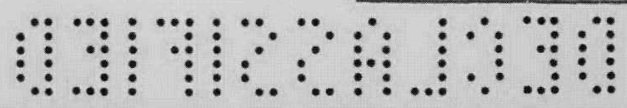




\begin{tabular}{|c|c|c|}
\hline & \multicolumn{2}{|c|}{ Specimen } \\
\hline & 1 & 2 \\
\hline Composition & $\mathrm{ZrH}_{1.80}$ & $\mathrm{ZrH}_{1.80}$ \\
\hline Testing Temperature, $F$ & 1130 & 1275 \\
\hline Atmosphere, volume per cent & $90 \mathrm{He}-10 \mathrm{H}$ & $100 \mathrm{H}$ \\
\hline Test-Section Dimensions, in. & $0.1298 \times 0.0742$ & $0.129 \times 0.0711$ \\
\hline Test-Section Area, in. ${ }^{2}$ & 0.00963 & 0.00923 \\
\hline Maximum Load, lb & 93.5 & 37.5 \\
\hline Tensile Strength, psi & 9700 & 4060 \\
\hline Elongation, per cent & 0 & 0 \\
\hline
\end{tabular}

Fabrication of Zirconium Hydride

J. B. Vetrano and J. F. Foster

A program was undertaken to supply zirconium hydride for the various experiments being conducted and to study the factors affecting cracking of specimens hydrided to the delta phase.

\section{$\underline{\text { Apparatus }}$}

There are two fundamentally different methods available for hydriding metals. In the first, a flowing stream of hydrogen is passed over a specimen held at a known temperature, and in the second, a static method, controlled amounts of hydrogen are introduced to the metal in a closed system. The latter method was chosen for this study because control of the final composition of the hydride is more easily attained in a closed system. The apparatus used for these studies is shown in Figure 2 .

In order to successfully hydride zirconium it is imperative that all traces of oxygen and nitrogen be removed from the hydrogen gas. Trace quantities of these gases will react at the surface of the zirconium to form barrier layers which inhibit the diffusion of hydrogen through the metal and greatly retard the hydriding rate.

The hydrogen-purification system used in this study consists of a commercial Deoxo purifier in series with a calcium hydride bed heated to $1350 \mathrm{~F}$, and a liquidnitrogen-cooled cold trap. The Deoxo purifier converts any oxygen present to water vapor, which is then decomposed to hydrogen in the calcium hydride bed. The heated 
calcium hydride also absorbs any nitrogen present in the gas stream. The cold trap serves to remove any moisture which may be swept through the calcium hydride. This particular purification system is well adapted to large-scale commercial processing since the materials involved are relatively inexpensive and since it can be operated continuously.

\title{
Experimental
}

Surface preparation of the samples prior to hydriding is very important since light oxide or grease films will inhibit hydriding. The standard procedure adopted for this study has been to lightly abrade the specimens with 120-grit aluminum oxide paper after they have been machined to the proper dimensions. They are then degreased by soaking in hexane, weighed, and immediately introduced into the furnace. If it is impossible to introduce the samples after weighing they are stored in hexane until ready for use.

With the samples in place and the furnace tube sealed to the line, the system is evacuated through the mechanical fore pump and mercury-diffusion pump and tested for leaks. If no leaks are found the furnace is heated to about 1850 to $1900 \mathrm{~F}$ while pumping. Purified hydrogen is then slowly admitted from the reservoirs as the temperature is gradually dropped to about $1450 \mathrm{~F}$. This cycle varies, but generally is around $7 \mathrm{hr}$ in the current operations. By knowing the volume, temperatures, and pressures in the different parts of the system it is possible to keep a hydrogen balance, and this is done to determine the composition of the condensed phase at any particular time. When the desired composition has been attained, the furnace is isolated from the reservoir and allowed to cool at its normal cooling rate.

The above description is of a typical hydriding cycle. Other cycles which vary the temperature and time of hydriding, and the rate of cooling to room temperature have also been investigated in an attempt to reduce the cracking in the specimens hydrided to the delta phase. As yet these experiments have not given consistent results. When two runs are closely duplicated there is no assurance that the specimens in each will be cracked comparably. Furthermore, it is sometimes observed that certain specimens in a given run will be uncracked while the neighboring specimens in the same run are cracked, even though the temperature gradient in the hydriding zone of the furnace does not exceed $25 \mathrm{~F}$.

\section{Cladding and Bond Evaluation}

\author{
S. J. Paprocki, E. S. Hodge, \\ and C. B. Boyer
}

For successful operation in the GCRE, the zirconium hydride moderator has to be clad with a material that possesses high-temperature properties to structurally reinforce the hydride and to protect it from attack by the reactor coolant. In addition, a metallurgical bond or a bond nearly equivalent in heat-transfer characteristics must be formed between the cladding and hydride to keep the hydride below a temperature at which the dissociation pressure would be excessive. The bond must also possess 
resistance to thermal cycling, as extensive thermal cycling of the material is anticipated.

Zirconium hydride possesses some undesirable qualities that make it difficult to clad for high-temperature service. At $1500 \mathrm{~F}$, the hydride has a dissociation pressure of approximately $1 \mathrm{~atm}$. The dissociation pressure increases sharply with an increase in temperature, consequently, during fabrication above $1500 \mathrm{~F}$, internal pressures within the clad system may lead to deformation or rupture of the cladding material. In addition, its apparent brittleness renders it more difficult to fabricate and clad by conventional techniques. These undesirable qualities of the hydride require that the cladding be done by some unconventional method. The technique of pressure bonding, which is more adaptable to cladding of brittle materials, and during which outside pressure would be exerted on the cladding at all stages of bonding, is receiving a maximum amount of effort. In this technique, the bonding components are assembled, sealed in an evacuated can, and the can simultaneously subjected to external pressure during heating to elevated bonding temperatures, while at bonding temperature, and during cooling to room temperature. This technique has been successfully utilized for the bonding of various fuel and control systems.

Initial investigations indicated that bonds formed between the zirconium hydride and the stainless steel would be brittle. This is to be expected because brittle intermetallics are formed when zirconium is bonded to stainless steel. In the event the hydride does not form similar brittle intermetallics with stainless steel, the bond is still anticipated to be brittle because of the inherent brittle nature of the hydride.

If the bond produced between the cladding and core possesses low thermal-shock resistance and fails during thermal cycling, it will be necessary to improve the properties of the bond by introducing ductile interface layers between the cladding and core. Another possible technique would involve a mechanical interlock between the cladding and core. Refractory-metal barrier layers are receiving the major emphasis because they do not form low-melting eutectics with the cladding or core and are less likely to form intermetallic compounds with the cladding and core. If intermetallic compounds do form, and they fail during thermal cycling and heat treating, a mechanically keyed metallurgical bond will be investigated. It is planned to investigate techniques for mechanically keying the cladding to the hydride during pressure bonding at temperature. Such a metallurgical bond may remain intact by being keyed in spite of some bond rupture along the core-to-cladding interface or barrier layer-to-core or cladding interface; consequently, such a bond may be more capable of resisting thermal stresses. The cladding will be keyed by the introduction of surface imperfections in the hydride subsequent to pressure bonding. The pressure-bonding operation utilizes a uniform pressure at all points on the entire cladding surface and should flow the cladding into the core imperfections.

Initial attempts have been made to bond zirconium hydride with stainless steel by pressure bonding to form a metallurgical bond between core and cladding. Sufficient data have not been obtained from these specimens to determine if a metallurgical bond is capable of withstanding the moderator-operation conditions. In order to expedite this investigation, a more extensive and comprehensive program has been formulated to develop techniques for cladding of delta-phase zirconium hydride. In addition, techniques for limited machining of zirconium hydride specimens have been developed, and 
as a result it is now possible to more closely control the core-to-cladding tolerances prior to pressure bonding.

Test specimens are being fabricated using partially machined zirconium hydride rod. The specimens consist of 0.250 -in. -diameter by 0.750 -in. - long rods closely fit into Type 304 or 347 stainless steel jackets with and without barrier layers. Barrierlayer materials being studied include molybdenum and niobium, and composite barrier layers of molybdenum and niobium with copper. Three sets of these test specimens will be bonded at 10,000 psi under varied conditions of time and temperature. The pressurebonded specimens will be evaluated to determine if direct cladding of the hydride is feasible, or if a barrier layer is significantly better or if it will be necessary to have a keyed metallurgical bond.

All of the specimens will be evaluated by microscopic examination, mechanical bend-and-peel test, and by heat-treatment and thermal-cycling tests.

The program in progress is arranged to produce sufficient specimens to evaluate several cladding techniques for preparing stainless steel-clad zirconium hydride for moderator applications. The most suitable method obtained from this investigation will be used to prepare in-pile-loop test specimens. 
This phase of the program is concerned with the development of a suitable control material for the GCRE. During the initial stage of the program, the following control systems received consideration: cobalt alloys, boron metal and compounds dispersed in stainless steel, cadmium sulfide dispersed in nickel, rare-earth oxides dispersed in stainless steel or cobalt, and rare-earth oxides or cadmium sulfide contained in stainless steel cans. Of these systems, the rare-earth oxide dispersions in a hightemperature steel or cobalt-base alloy were selected for development.

A system consisting of europium oxide dispersed in Nichrome V or Type 347 stainless steel, clad with the same materials, appears to be the most desirable control system of those that were considered. Europium is one of the most expensive of the potential rare-earth materials; however, it has many advantages. It is a much more effective neutron absorber than samarium or gadolinium, since all of the europium isotopes are absorbers and only a relatively small percentage of control effectiveness is lost by burnout. The use of europium instead of samarium or gadolinium will result in a saving in fabrication cost because less material will be required, assuming that a maximum dispersion loading governed by fabrication will be utilized. Another advantage results from the lower volume of control material that will be required.

This system should possess the necessary control effectiveness, stability under irradiation, and structural strength. The choice between Type 347 stainless steel and Nichrome $V$ for the matrix and cladding material will be governed by the corrosion resistance of these materials to the coolant gas. Ultimately, it may prove desirable to protect the surfaces of the control rod by use of a protective coating such as copper.

Fabrication studies were conducted with the use of a samarium oxide-gadolinium oxide mixture as a substitute for europium oxide. This cornmercially available rareearth oxide mixture was extremely fine; well below minus 325 mesh. In order to obtain a more fabricable coarse product, the fine powder was pressed into a compact and sintered in a hydrogen furnace at $2750 \mathrm{~F}$ for $2 \mathrm{hr}$. After sintering, the compact was crushed, and a minus 100 plus 270 -mesh powder fraction was separated for use in the fabrication studies.

Compacts consisting of a mixture of samarium oxide-gadolinium oxide dispersed in Nichrome V or Type 347 stainless steel were prepared by a duplex cold- and hotpressing technique. A loading of from 10 to $30 \mathrm{w} / 0$ rare-earth oxide was employed. The initial green compacts were prepared by cold pressing the mixed powders under a 50-tsi pressure. These green compacts were then inserted into steel packs coated with magnesium oxide. The pacts were sealed by welding in an inert atmosphere, heated to $1800 \mathrm{~F}$, and press forged at pressures of 200 and $250 \mathrm{tsi}$ with intermediate heating between press operations. These pressed compacts were utilized for nitriding and rollcladding studies.

The roll-cladding operation was performed at a temperature of $2000 \mathrm{~F}$, utilizing a total reduction of $3-1 / 2$ to 1 . Figures 3 and 4 are photomicrographs of Nichrome Vand Type 347 -clad stainless steel specimens. Extensive stringering has been encountered, as the oxide apparently flows readily at the rolling temperature. Since the CONFIDENTIAL 


\section{9}

Type 347 stainless steel

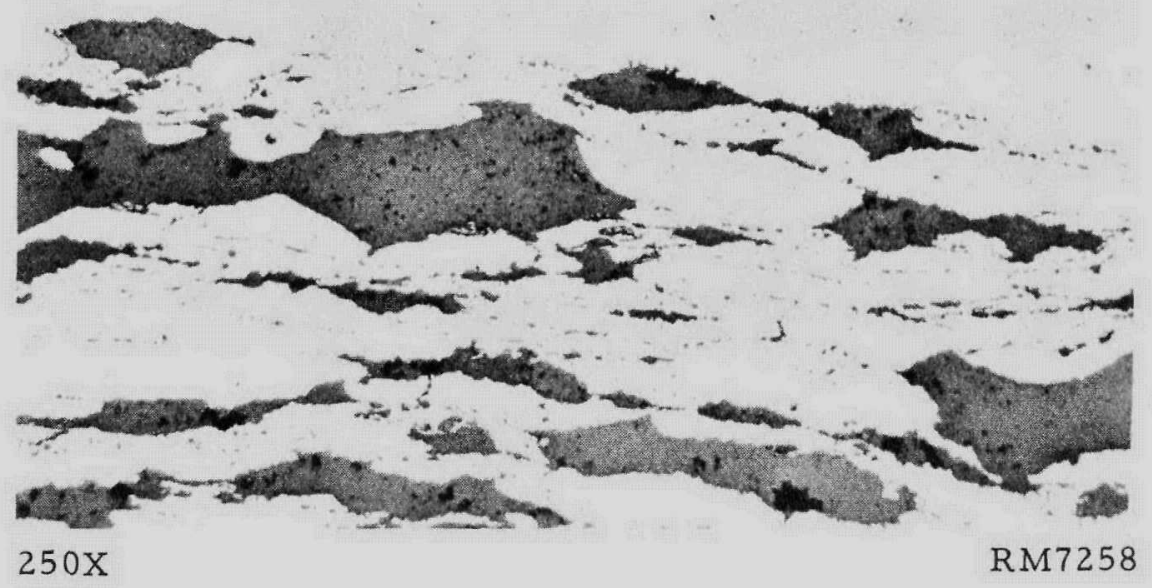

Type 347 stainless steel$30 \mathrm{w} / 0 \mathrm{Sm}_{2} \mathrm{O}_{3}-\mathrm{Gd}_{2} \mathrm{O}_{3}$

FIGURE 3. TRANSVERSE SECTION THROUGH A TYPE 347 STAINLESS STEEL$30 \mathrm{w} / 0 \mathrm{Sm}_{2} \mathrm{O}_{3}-\mathrm{Gd}_{2} \mathrm{O}_{3}$ CLAD WITH TYPE 347 STAINLESS STEEL AT $2000 \mathrm{~F}$

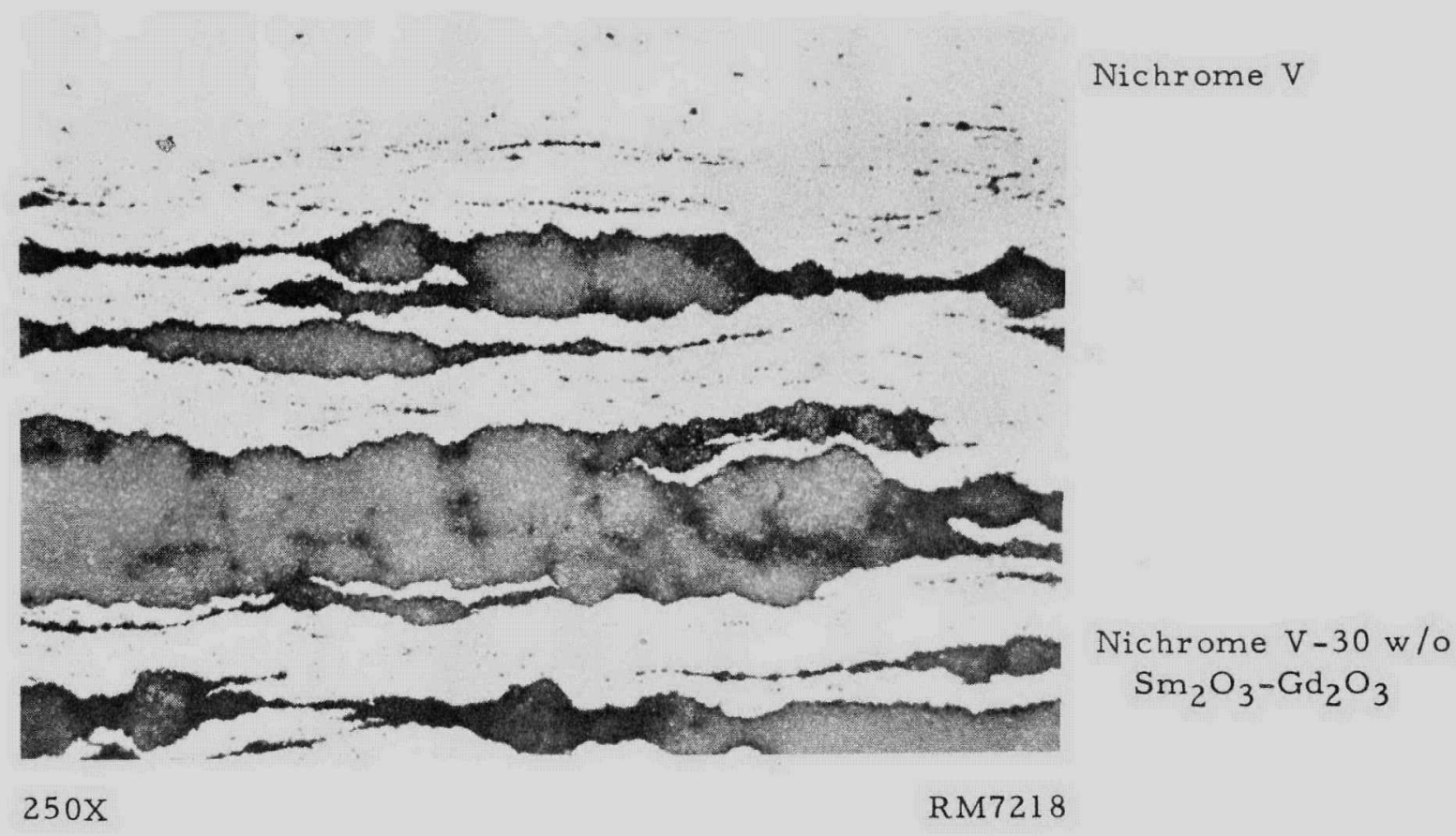

FIGURE 4. TRANSVERSE SECTION THROUGH A NICHROME V-30 w/o $\mathrm{Sm}_{2} \mathrm{O}_{3}-\mathrm{Gd}_{2} \mathrm{O}_{3}$ SPECIMEN ROLL CLAD WITH NICHROME V AT $2000 \mathrm{~F}$ 
rare-earth elements absorb neutrons by an $n, \gamma$ reaction, no significant radiation damage is anticipated, and, consequently, this stringering is not considered to be a serious problem from that standpoint. However, extensive stringering of this sort has a pronounced effect on the transverse strength of the material, and, consequently, fabrication investigations are being continued with the objective of reducing the stringering.

Although the rare-earth oxide is expected to be stable under irradiation, it is planned to irradiate specimens of Nichrome V-30 w/o europium oxide at $1500 \mathrm{~F}$. The specimens will be clad and evaluated on the basis of structural and dimensional changes.

Another control system receiving considerable attention combines a dispersion of europium oxide in a cobalt matrix clad with a cobalt alloy. This combination results in an effective control material. The cobalt is a good absorber in the epithermal region and the europium possess excellent absorption in the thermal region. Cobalt-base alloys such as Stellite 25 also possess high-temperature strength and relatively excellent resistance to nitriding. Compacts consisting of a Stellite or cobalt matrix with a dispersion of rare-earth oxide have been prepared by the same techniques utilized for the preparation of the stainless steel and Nichrome V-base materials. The pressed compacts were utilized in nitriding and roll-cladding studies. Photomicrographs of pressed compacts are shown in Figures 5 and 6.

Specimens incorporating a core of cobalt-10 w/o samarium oxide-gadolinium oxide and a cladding of Stellite 25 were roll clad at 1900 and $2150 \mathrm{~F}$. Satisfactory bonding was obtained between core and cladding on the flat surface of the specimens; however, incomplete bonding occurred at the ends of the cores. An attempt is being made to eliminate end effects by changes in the design of the roll packs and fabrication schedule. Figure 7 shows a photomicrograph of a specimen roll clad at $1900 \mathrm{~F}$. Hardness data were obtained for cobalt and several of the cobalt-base dispersions over a temperature range from 500 to $1500 \mathrm{~F}$. The results are shown in Table 8.

TABLE 8. HARDNESS DATA FOR COBALT AND COBALT-BASE SYSTEMS

\begin{tabular}{lccrr}
\hline \hline & \multicolumn{3}{c}{ Average Hardness at Indicated Temperature, DPHN } \\
\cline { 2 - 5 } \multicolumn{1}{c}{ Description of Specimens } & $500 \mathrm{~F}$ & $750 \mathrm{~F}$ & $1250 \mathrm{~F}$ & $1500 \mathrm{~F}$ \\
\hline Cobalt & -- & 141 & 43.5 & 30.9 \\
Cobalt-10 w/o $\mathrm{Sm}_{2} \mathrm{O}_{3}-\mathrm{Gd}_{2} \mathrm{O}_{3}$ & -- & 138 & 48.9 & 31.4 \\
Cobalt-30 w/o $\mathrm{Sm}_{2} \mathrm{O}_{3}-\mathrm{Gd}_{2} \mathrm{O}_{3}$ & 201 & -- & 71.4 & 60.3 \\
Stellite $31-10 \mathrm{w} / 0 \mathrm{Sm}_{2} \mathrm{O}_{3}-\mathrm{Gd}_{2} \mathrm{O}_{3}$ & -- & 339 & 232 & 138 \\
\hline \hline
\end{tabular}

An evaluation of the stainless, Nichrome V, and cobalt systems is being conducted to determine the relative control effectiveness of each system. At the present time, it is planned to irradiate only Nichrome V-clad Nichrome V-europium oxide specimens. In the event the cobalt system proves to be more desirable, representative specimens of this sytem will also be irradiated. Ultimately, it is planned to obtain mechanical and physical properties for the primary system selected on the basis of control effectiveness and resistance to nitriding. 


\section{CONFIDENTIAL}

\section{1}

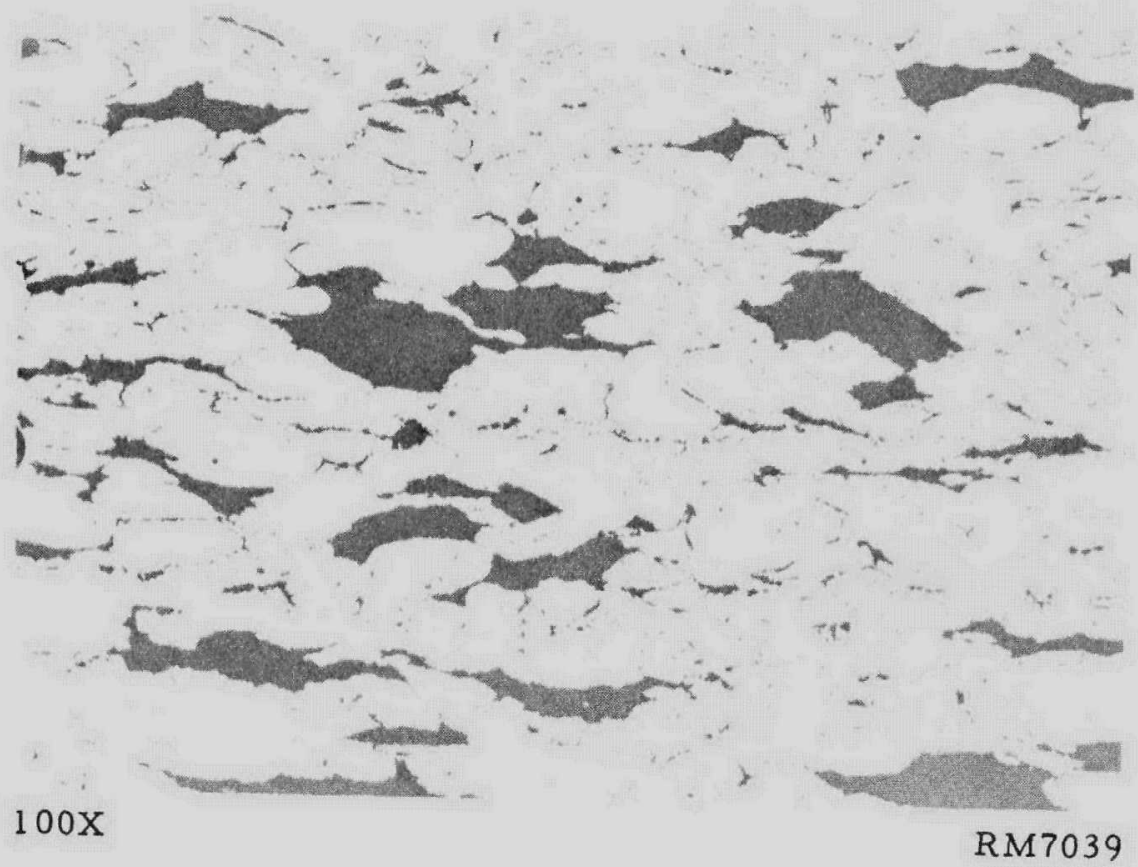

FIGURE 5. COMPACT OF STELLITE $31-10 \mathrm{w} / 0 \mathrm{Sm}_{2} \mathrm{O}_{3}-\mathrm{Gd}_{2} \mathrm{O}_{3} \mathrm{HOT}$
PRESSED AT $1800 \mathrm{~F}$

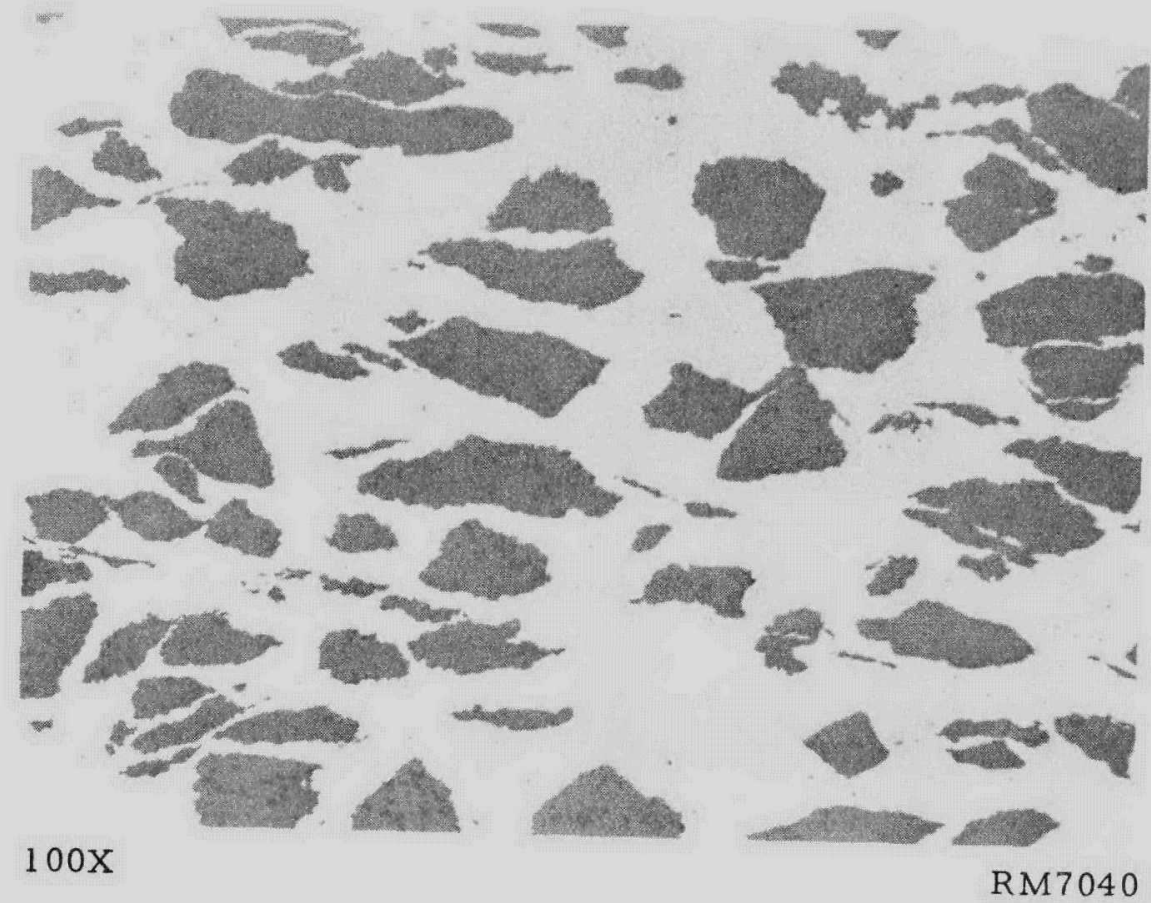

FIGURE 6. COMPACT OF COBALT-30 w/o $\mathrm{Sm}_{2} \mathrm{O}_{3}-\mathrm{Gd}_{2} \mathrm{O}_{3} \mathrm{HOT}$
PRESSED AT $1800 \mathrm{~F}$ 


\section{CONFIDENTIAL}

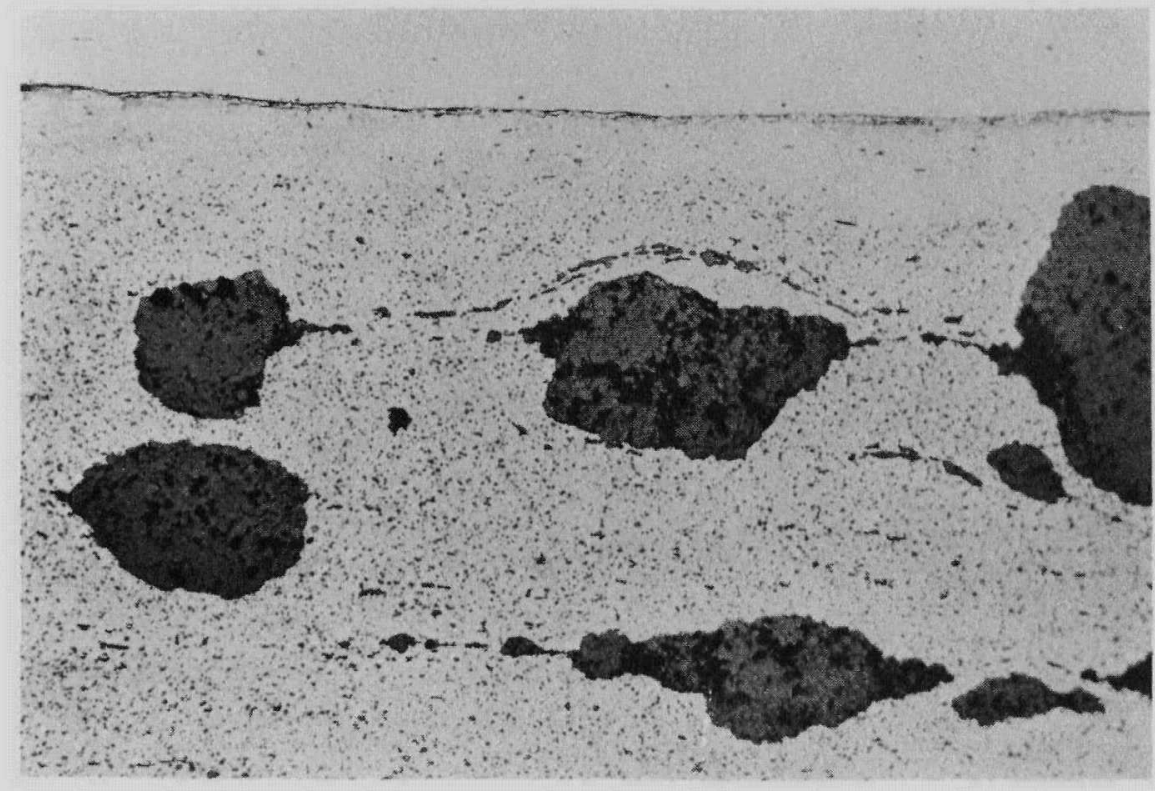

Haynes Stellite 25

Cobalt-1 $0 \mathrm{w} / 0 \mathrm{Sm}_{2} \mathrm{O}_{3}-\mathrm{Gd}_{2} \mathrm{O}_{3}$

$250 \mathrm{X}$

RM6699

FIGURE 7. TRANSVERSE SECTION THROUGH A COBALT-10 w/o $\mathrm{Sm}_{2} \mathrm{O}_{3}-\mathrm{Gd}_{2} \mathrm{O}_{3}$ SPECIMEN ROLL CLAD WITH STELLITE 25 AT $1900 \mathrm{~F}$ 
The reference fuel element for the GCRE is a Type 347 stainless steel-dispersed $\mathrm{UO}_{2}$ element. The exact dimensions and fuel loadings are listed in the "Introduction" of this report. The main reasons for its choice as the reference fuel material are its relatively low fabrication costs and its good mechanical and chemical stability at high temperatures. Its most marginal property is its resistance to radiation damage under proposed GCRE conditions which call for an average burnup of approximately 10 per cent of the uranium-235 at fuel-element surface temperatures of $1500 \mathrm{~F}$. This unfortunate characteristic is mainly responsible for a rather broad radiation-effects program, which is covered in the next section, and the alternate fuel-element program, which encompasses several very divergent fuel-element types. Activities on alternate fuels include the preparation and irradiation of molybdenum and niobium-20 w/o uranium al-

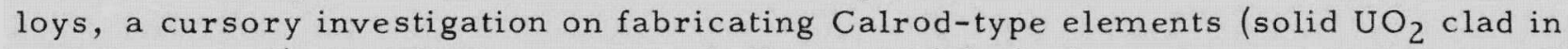
stainless steel), a radiation survey of all potential fuel-element types, and the postirradiation heat treatment of $\mathrm{KAPL} \mathrm{UO} 2$ cermet fuel elements. In addition to these studies, the development of (zirconium-1 w/o uranium) hydride alloys and the postirradiation heat treatment of KAPL $\mathrm{UO}_{2}$ annularly loaded fuel pins have been initiated.

Fabrication of Reference Fuel Elements and Subassemblies

S. J. Paprocki, D. L. Keller, G. W. Cunningham, J. B. Fox, and D. E. Lozier

Although extensive development work has been done on the stainless steel- $\mathrm{UO}_{2}$ fuel plates at Battelle and at several other laboratories, a development program is required to select the type of $\mathrm{UO}_{2}$, the matrix powder, the cladding materials, the method of core preparation, and the exact rolling procedures which will give a stainless-UO 2 fuel element of the proper fuel content with sufficient strength to withstand mechanical stresses and maximum resistance to irradiation damage. Brazing studies are required in order to select a satisfactory brazing alloy and determine the most feasible brazing procedure which will provide a subassembly with sufficient strength to withstand operational stresses. In support of the irradiation-damage program it is necessary to prepare small-scale clad fuel plates by the same techniques used to prepare full-size fuel elements.

\section{Fuel-Element Fabrication}

In the production of reference fuel-element plates, it is desirable to produce a plate with a core of evenly dispersed $\mathrm{UO}_{2}$ particles in a stainless steel matrix and a plate with uniform thickness of cladding which is metallurgically bonded to the core. Several variables such as type of $\mathrm{UO}_{2}$ powder, type of stainless powder, $\mathrm{UO}_{2}$ particle size, core-compacting procedures, rolling temperature, type of furnace atmosphere when rolling, reduction ratios and reduction per pass, and cold-rolling and annealing procedures have been considered. 
Because of its high density and closely controlled particle size, the hydrothermalprocess fully enriched $\mathrm{UO}_{2}$ was selected as the reference fuel. Although the $\mathrm{UO}_{2}$ can be prepared by Oak Ridge with an oxygen-uranium ratio very close to $2.0 / 1$, the material actually supplied for use in the first loop subassembly has an oxygen-uranium ratio of $2.12 / 1$ (based on the uranium analysis furnished by Oak Ridge). Battelle petrographic analyses indicate that the powder is very dense with less than 1 per cent porosity or impurities, but with 15 to 20 volume per cent of a secondary phase. X-ray diffraction methods have verified the presence of this phase and have established it as $\mathrm{U}_{4} \mathrm{O}_{9}$.

Selection of Type 347 stainless steel for the matrix and cladding materials in preference to other stainless alloys was based primarily on the mechanical properties at $1500 \mathrm{~F}$. In addition to Type 347 stainless steel, Nichrome V has been considered for cladding and a limited number of plates have been prepared with a Nichrome V cladding and a stainless steel- $\mathrm{UO}_{2}$ core. However, since stainless steel was selected as the reference material, a more extensive investigation has been conducted on the stainlessclad stainless $-\mathrm{UO}_{2}$ core system.

Either prealloyed Type 347 stainless powder or a mixture of elemental chromium, iron, and nickel powders may be used for the core matrix. In general, the elemental mixture is more ductile and, consequently, there is less fracturing and stringering of $\mathrm{UO}_{2}$. The pressed elemental stainless $-\mathrm{UO}_{2}$ compacts also have much better green strength. However, there is some question as to whether the elemental stainless becomes fully austenitized. Also, there is evidence that some $\mathrm{Cr}_{2} \mathrm{O}_{3}$ forms under normal sintering conditions for elemental stainless.

In order to choose the matrix powder, a series of specimens was prepared with both elemental and prealloyed powders, and a comparison of cores using the two matrix materials may be made by examination of Figure 8 . The two compacts were prepared and roll clad in an identical manner. Note the fracturing and stringering which occurs to a much greater extent in the prealloyed stainless matrix. Also, in this series specimens were run with both minus 100 plus 200-mesh natural $\mathrm{UO}_{2}$ and minus 200 plus $270-$ mesh natural $\mathrm{UO}_{2}$. The $\mathrm{UO}_{2}$ stringering was more severe when the small mesh size (minus 200 plus 270) was used.

Due to the improved appearance of the $\mathrm{UO}_{2}$ dispersion, an $18 \mathrm{w} / 0$ chromium$9 \mathrm{w} / 0$ nickel- $73 \mathrm{w} / 0$ iron elemental mixture was selected as the reference core matrix. The powders used are minus 325 mesh electrolytic iron, minus 325 mesh electrolytic chromium, and minus 325 mesh carbonyl nickel.

The occurrence of $\mathrm{Cr}_{2} \mathrm{O}_{3}$ and the degree of austenitization which takes place during the sintering operation are related due to the fact that presence of $\mathrm{Cr}_{2} \mathrm{O}_{3}$ greatly reduces the rate of chromium diffusion into the iron and nickel. Therefore, an investigation is currently in progress to improve sintering techniques.

In addition to work on the hydrogen-purification system to improve the dewpoint, three series of specimens, in which particle size of $\mathrm{UO}_{2}$ and compacting pressure have been varied, have been sintered. Examinations of compacts cold pressed at 15 to 50 tsi and sintered $4 \mathrm{hr}$ at $2300 \mathrm{~F}$ in hydrogen indicate that, whereas the compact pressed at 50 tsi contained approximately 10 volume per cent $\mathrm{Cr}_{2} \mathrm{O}_{3}$, the compact pressed at 15 tsi contained only a trace of $\mathrm{Cr}_{2} \mathrm{O}_{3}$, and after recoining had a density above 90 per cent 


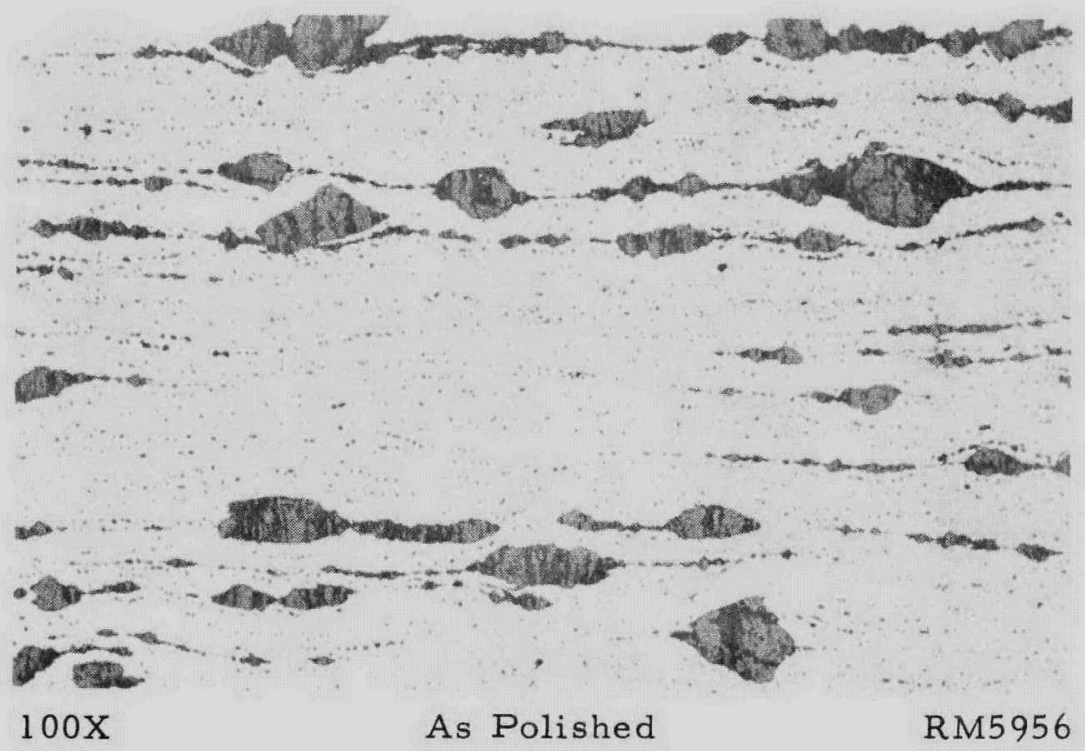

Minus 100 Plus 200-Mesh $\mathrm{UO}_{2}$ Dispersed in Type 347 Prealloyed Stainless Powder

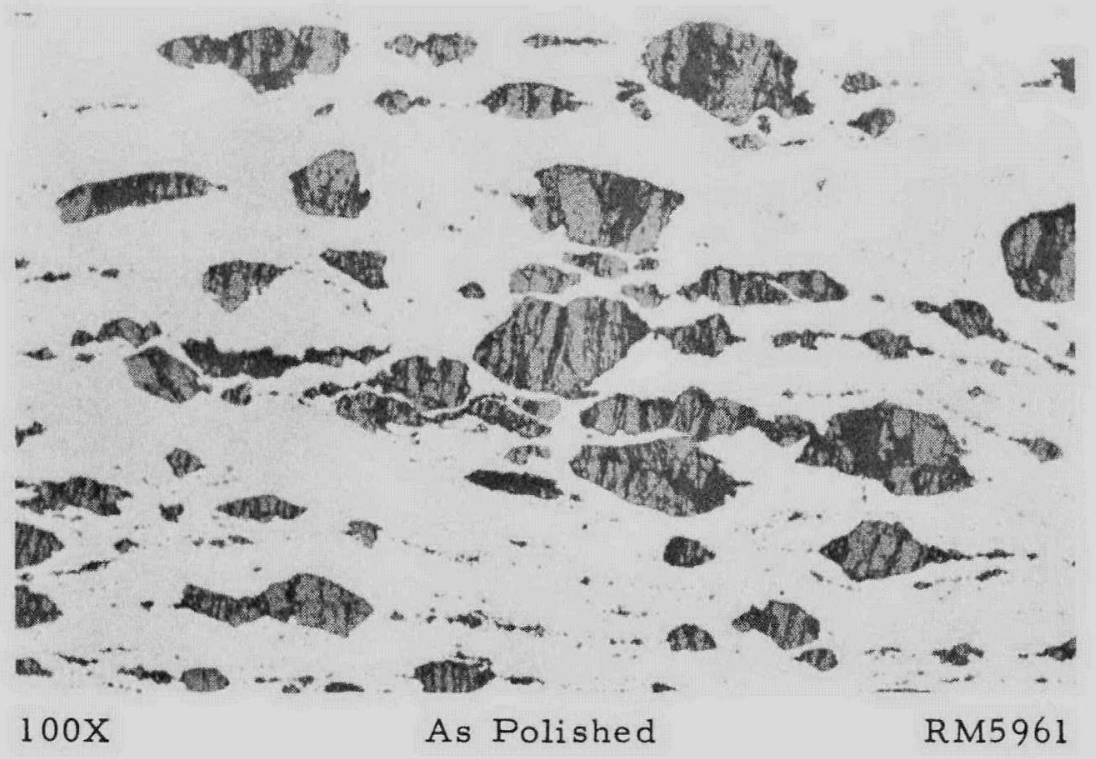

Minus 100 Plus 200-Mesh $\mathrm{UO}_{2}$ Dispersed in an $18 \mathrm{w} / 0$ Chromium-, $9 \mathrm{w} / 0$ Nicke1-73 w/o Iron Mixture

FIGURE 8. $25 \mathrm{w} / 0 \mathrm{UO}_{2}$ DISPERSED IN STAINLESS STEEL

Cores were sintered $4 \mathrm{hr}$ in hydrogen at $2200 \mathrm{~F}$. Cores were roll clad by rolling three passes at $2200 \mathrm{~F}$ and seven passes at $2200 \mathrm{~F}$ for a total reduction of 6 to 1 in thickness. 
theoretical. A series of specimens containing $\mathrm{UO}_{2}$ of minus 80 plus $100-$, minus 100 plus $150-$, minus 150 plus $200-$, or minus 200 plus 270 -mesh size were cold pressed at $15 \mathrm{tsi}$ and sintered $4 \mathrm{hr}$ at $2300 \mathrm{~F}$ in hydrogen. A second series with the same variation in $\mathrm{UO}_{2}$ particle size but with specimens cold pressed at $40 \mathrm{tsi}$ was also sintered $4 \mathrm{hr}$ at $2300 \mathrm{~F}$ in hydrogen. In the series pressed at $15 \mathrm{tsi}$, there was no $\mathrm{Cr}_{2} \mathrm{O}_{3}$ near the surface of any of the specimens, and there was much less oxide in the center of the specimens which contained either minus 150 plus 200-mesh $\mathrm{UO}_{2}$ or minus 200 plus $270-$ mesh $\mathrm{UO}_{2}$. All specimens in the series pressed at 40 tsi contained more $\mathrm{Cr}_{2} \mathrm{O}_{3}$ than those pressed at 15 tsi; however, those specimens containing minus 150 plus $200-$ and minus 200 plus 270-mesh $\mathrm{UO}_{2}$ did show evidence of $\mathrm{Cr}_{2} \mathrm{O}_{3}$ being reduced at the surface, since oxide was visible only in the center of the compact.

From these tests it appears beneficial to press the powder compacts at 15 tsi and use $\mathrm{UO}_{2}$ of minus 150 plus 270-mesh size. Additional experiments are being conducted to verify these results.

Fabrication of the cores into full-size clad fuel is accomplished by placing the sintered cores in a stainless steel picture-frame pack, welding the pack, evacuating and sealing the pack, hot and cold rolling to final size, and machining to the correct dimensions.

Rolling temperatures and furnace atmospheres greatly affect the surface finish obtained on the completed blades. If an argon atmosphere is used there is heavy scaling at temperatures above $1900 \mathrm{~F}$; consequently, when argon is used the rolling procedure consists of making three passes at $2200 \mathrm{~F}$ and then lowering the temperature to $1900 \mathrm{~F}$ before completion of the hot rolling. Also the surface is improved if the plate is vapor blasted after the $2200 \mathrm{~F}$ passes and before rolling at $1900 \mathrm{~F}$.

The entire rolling procedure is not conducted at $1900 \mathrm{~F}$ because it has been found that a better core-to-cladding bond is obtained and less fracturing of $\mathrm{UO}_{2}$ occurs if the first passes are made at a higher temperature such as $2200 \mathrm{~F}$. On the other hand, if the plates are rolled from a hydrogen muffle, the entire hot-rolling operation may be carried out at $2200 \mathrm{~F}$.

After hot rolling, plates are annealed $2 \mathrm{hr}$ at $2150 \mathrm{~F}$ in a hydrogen atmosphere, pickled, cold rolled to final size, flat annealed $2 \mathrm{hr}$ at $2150 \mathrm{~F}$ in hydrogen, radiographed, machined to final size, radiographed again, and stress-relief annealed $2 \mathrm{hr}$ at $2150 \mathrm{~F}$. Although the time at temperature may not be necessary for full anneals or complete stress relief, it is beneficial in the promotion of austenitization in the core matrix.

The exact method being used at the present time for the preparation of cores and the fabrication of fuel elements is given in Table 9. Nevertheless, a development program is continuing and minor changes in the procedure and improvements in technique will continue to be made.

Specimens are also being prepared by this method for determination of hot tensile strength and creep strength at $1500 \mathrm{~F}$. 
TABLE 9. METHOD OF FABRICATING STAINLESS-UO 2 FUEL ELEMENTS

1. Screen hydrothermal process $\mathrm{UO}_{2}$ to minus 100 plus 270 -mesh size

2. Blend minus 325-mesh chromium, nickel, and iron powders to form an 18-9 stainless composition with less than $1 / 2$ of $1 \mathrm{w} / \mathrm{o}$ lauryl alcohol; add a $25 \mathrm{w} / \mathrm{o}$ camphorin-methanol solution as a dispersant; blend $4 \mathrm{hr}$ in a Kelly $\mathrm{V}$-mixer

3. Blend $25 \mathrm{w} / 0 \mathrm{UO}_{2}$ with $75 \mathrm{w} / \mathrm{o}$ elemental stainless mixture for $4 \mathrm{hr}$ in a Kelly $\mathrm{V}-\mathrm{mixer}$

4. Cold press compacts at 15 tsi

5. Sinter $4 \mathrm{hr}$ at $2250 \mathrm{~F}$ and recoin at $50 \mathrm{tsi}$

6. Place core in thoroughly degreased and cleaned Type 347 stainless pack

7. Weld covers and stem on pack in argon atmosphere

8. Evacuate packs, heat to $600 \mathrm{~F}$, and forge the stem 'closed

9. Hot roll from a hydrogen muffle at $2200 \mathrm{~F} ; 30$ per cent total reduction on first pass, 20 per cent total reduction on all remaining passes; plate is reduced by a 6.0 -to1 ratio to $0.070 \mathrm{in}$. thick

10. Pickle in 15 volume per cent $\mathrm{HNO}_{3}-5$ volume per cent $\mathrm{Hf}-80$ volume per cent water

11. Anneal $2 \mathrm{hr}$ at $2150 \mathrm{~F}$ in hydrogen furnace

12. Cold roll, light passes, to a final size of 0.060 in. \pm 0.001

13. Flat anneal in alumina-coated jig $2 \mathrm{hr}$ at $2150 \mathrm{~F}$ in hydrogen

14. Radiograph

15. Machine to final size

16. Radiograph

17. Stress-relief anneal $2 \mathrm{hr}$ at $2150 \mathrm{~F}$ in hydrogen 
The most important factor concerned with the fabrication of subassemblies is the selection and application of the braze material. For the selection of the braze alloy the following properties are considered: tensile strength of the brazed joint at $1500 \mathrm{~F}$, creep-rupture properties of the brazed joint at $1500 \mathrm{~F}$, ease of application, nitriding resistance, undercutting properties of the braze alloy, and behavior of the joint during thermal-cycling tests. The most favorable method of application (use of powder or wire, brazing temperature, heating and cooling rates, etc.) must be determined for all braze alloys considered.

Test joints brazed with various alloys have been pulled in tension at $1500 \mathrm{~F}$. Tensile bars were designed so that a tongue-and-groove joint of the same design used in the subassembly would be located at the center of the gage length. Table 10 gives the results of the tensile tests. Similar specimens were used to obtain creep-rupture data at $1500 \mathrm{~F}$. Comparison of creep-rupture data, which are shown in Table 11, with tensile data indicates that alloying occurs between copper brazes and Nichrome V. Using the same size joint, Nichrome $V$ has a higher tensile strength in the joint when brazed with copper than stainless brazed with copper. In the creep-rupture tests, a higher stress for a given period of time is required in all cases to rupture Nichrome V brazed with copper than is required to rupture stainless brazed with copper. From data given in Tables 10 and 11 , it appears that, while copper brazes are satisfactory for brazing high-nickel alloys, 18-8 stainless brazed with copper does not have sufficient creep strength for GCRE applications. Although creep-rupture data are not available at this time, it should be noted that stainless specimens brazed with Coast Metal NP, GE-81, or GE-75 have hot tensile strengths comparable to Nichrome V specimens brazed with copper.

In order to determine the resistance to nitrogen, small tongue-and-groove joints of Type 347 stainless steel are brazed with the various alloys and submitted for $100-\mathrm{hr}$ tests in a 100 volume per cent ammonia atmosphere at $1500 \mathrm{~F}$. After the test, metallographic specimens are prepared and the depth of attack determined. Nitrogen resistance for joints brazed with the following materials has been determined: copper $-20 \mathrm{w} / \mathrm{o}$ nickel, copper-6 w/o nickel, copper wire, copper powder, Coast Metal NP, GE-75, and GE-81. Metallographic examination indicated that GE-81 was attacked to a depth of $0.1 \mathrm{mil}$, copper was attacked to a depth of $0.3 \mathrm{mil}$, and all others were attacked to a depth of 2 to 3 mils.

Since copper will not be satisfactory for GCRE applications, particularly if the atmosphere is changed to include small amounts of water vapor; brazing studies are now being conducted with GE-75, GE-81, and Nicrobraze 60. All of these materials are used in the powder form; however, the GE-81 is extruded in polyethylene to form a wire. The following procedure is being used for brazing small-scale subassemblies: (1) the powder, using Acryloid as a binder and green Stopblock as a stopoff, is placed on the joint; (2) the subassembly, which has been assembled in an alumina-coated stainless steel jig, is slowly heated in a hydrogen furnace to $100 \mathrm{~F}$ below the brazing temperature; (3) the subassembly is raised to the brazing temperature for $15 \mathrm{~min}$; and (4) the subassembly is furnace cooled. Brazing temperatures are as follows: Nicrobraze $60,2050 \mathrm{~F}$; GE-75, $2250 \mathrm{~F}$; and GE-81, $2200 \mathrm{~F}$. 
TABLE 10. RESULTS OF HOT TENSILE TESTS ON BRAZED GROOVE JOINTS

\begin{tabular}{|c|c|c|c|}
\hline Metal Brazed & Brazing Alloy & $\begin{array}{c}\text { Test Temperature, } \\
\text { F }\end{array}$ & $\begin{array}{l}\text { Fuel-Element } \\
\text { Stress at Failure, psi }\end{array}$ \\
\hline Nichrome V & Copper & 1500 & 18,400 \\
\hline Nichrome V & Copper & 1865 & 7,310 \\
\hline Type 304 stainless & Copper & 1500 & 14,800 \\
\hline Type 304 stainless & Copper & 1500 & 13,400 \\
\hline Type 304 stainless & Copper & 1865 & 4,400 \\
\hline Type 304 stainless & Coast Metal NP & $1500(a)$ & 17,800 \\
\hline Type 304 stainless & $G E-81$ & $1500(\mathrm{a})$ & 17,160 \\
\hline Type 304 stainless & $\mathrm{Cu}-6 \mathrm{w} / 0 \mathrm{Ni}$ & 1500 & 12,630 \\
\hline Type 304 stainless & $G E-75$ & 1500 & 17,740 \\
\hline Type 304 stainless & $\mathrm{Cu}-20 \mathrm{w} / 0 \mathrm{Ni}$ & 1500 & 14,600 \\
\hline
\end{tabular}

(a) Failure occurred in base metal.

TABLE 11. CREEP-RUPTURE DATA OBTAINED (AT $1500 \mathrm{~F}$ ) ON COPPER-BRAZED NICHROME V AND COPPER-BRAZED STAINLESS STEEL SPECIMENS

\begin{tabular}{|c|c|c|c|c|}
\hline & Stress, & $\begin{array}{l}\text { Rupture } \\
\text { Time, }\end{array}$ & $\begin{array}{c}\text { Final } \\
\text { Elongation, }\end{array}$ & $\begin{array}{l}\text { Time, hr, for Indicated Percentage } \\
\text { Deformation }\end{array}$ \\
\hline Specimen & psi & $\mathrm{hr}$ & per cent & $\begin{array}{lll}0.5 & 1.0 & 5.0\end{array}$ \\
\hline
\end{tabular}

\section{Nichrome V Specimens}

$\begin{array}{lrrrrrrr}\mathrm{N}-8 & 4,000 & 622.6^{(a)} & 26.0 & 10.0 & 30.0 & 75.0 & 276.0 \\ \mathrm{~N}-5(\mathrm{~b}) & 5,000 & 472.5^{(\mathrm{a})} & 43.0 & 8.0 & 13.0 & 22.0 & 76.0 \\ \mathrm{~N}-4^{(\mathrm{b})} & 6,000 & 40.9^{(a)} & 23.0 & 2.2 & 5.3 & 9.2 & -- \\ \mathrm{N}-6(\mathrm{~b}) & 7,000 & 45.3^{(a)} & 37.0 & 0.7 & 1.8 & 3.6 & 18.2 \\ \mathrm{~N}-1 & 8,000 & 2.0 & 4.0 & 0.12 & 0.74 & -- & -- \\ \mathrm{N}-3 & 12,000 & 1.1 & 12.0 & 0.04 & 0.21 & 0.383 & --\end{array}$

Stainless Steel Specimens

\begin{tabular}{lrrrrrrr} 
SS-7(b) & 1,000 & 197.3 & Nil & -- & -- & -- & -- \\
SS-6 & 2,000 & 54.8 & 2.0 & -- & -- & -- & -- \\
SS-4 & 4,000 & 1.3 & Nil & 0.54 & -- & -- & -- \\
SS-5(b) & 4,000 & 1.1 & 1.0 & -- & -- & -- & -- \\
SS-2(b) & 5,000 & 60.6 & 7.0 & 4.5 & 9.3 & 17.0 & -- \\
SS-3 & 6,000 & 1.0 & 1.0 & -- & -- & -- & -- \\
SS-1 & 8,000 & 0.3 & Nil & -- & -- & -- & -- \\
\hline
\end{tabular}

(a) These specimens failed in the base metal; all other specimens failed in the brazed joint.

(b) These specimens showed a contraction on loading. 
Due to the thin cladding used ( 5 mils), little or no undercutting by the braze alloy can be tolerated. Metallographic examination of specimens brazed with alloys listed in this section showed heavy undercutting on joints brazed with Coast Metal NP. There is also indication of slight undercutting on joints brazed with GE-75.

Before final selection of the braze alloy can be made, some additional information on GE-75, GE-81, Nicrobraze 60, and Nicrobraze 30 will be required. Creep and tensile data will be obtained at $1500 \mathrm{~F}$. In addition, full-scale subassemblies will be brazed and sectioned to determine the integrity of the braze.

\section{Preparation of Irradiation Specimens}

One phase of the GCRE program is an investigation of the irradiation damage of cermets composed of $\mathrm{UO}_{2}$ and stainless steel. For the first capsule loading, it was decided to make two specimens each of 20 and $25 \mathrm{w} / 0 \mathrm{UO}_{2}$ in a Type 18-9 elementalpowder stainless steel matrix.

Calculations determined that the specimen core must be 1 by 0.5 by 0.05 in., with the over-all clad specimen measuring 1.47 by 0.69 by $0.06 \mathrm{in}$. It was decided to fabricate the compacts by fitting pressed-powder specimens alternately with stainless steel spacers into a Type 347 stainless steel picture frame and rolling to a $6.5-$ to-1 reduction.

A compact of natural $\mathrm{UO}_{2}$ specimens was prepared and fabricated to experimentally verify the dimensional calculations and establish the proper fabrication techniques to successfully roll a specimen $0.325 \mathrm{in}$. high by $0.15 \mathrm{in}$. thick by $0.49 \mathrm{in}$. wide to a 6. 5-to-1 reduction without producing severe end effects. The spacer and specimen matrix material were prepared by blending powder of iron, chromium, and nickel in proportions of 73,18 , and $9 \mathrm{w} / \mathrm{o}$, respectively, with a menthol alcohol-camphor dispersing agent. The spacer bar was pressed directly from this blend using a pressure of $50 \mathrm{tsi}$. The core was blended by mixing 20 or $25 \mathrm{w} / 0 \mathrm{UO}_{2}$ with the stainless steel mixture. The cores were also pressed with a pressure of $50 \mathrm{tsi}$, and, with the spacer bar, were sintered in a hydrogen atmosphere at $2150 \mathrm{~F}$ for $4 \mathrm{hr}$ and recoined at the original pressure. The specimens and spacers were then machined to size and fit alternately into a picture frame, 35-mil-thick cover plates were welded on in an argon atmosphere, and the compact was evacuated to a pressure of $1 \times 10^{-3} \mathrm{~mm}$ of mercury. The compact was rolled from a helium-atmosphere furnace. Three passes, the first at a 30 per cent reduction, the other two each at a 20 per cent reduction, were made at $2200 \mathrm{~F}$. Then the pack was vapor blasted and rolled to a thickness of $71 \mathrm{mils}$ at $1900 \mathrm{~F}$, using a 20 per cent reduction per pass. The compact was again vapor blasted and cold rolled to a final thickness of 60 mils.

The cold-rolled compact was sectioned into specimens and examined. All specimens were satisfactory in regard to surface, dimension, bonding, and $\mathrm{UO}_{2}$ distribution; however, some contamination was noted in the stainless steel matrix and spacer material. The type and origin of the contamination was unknown but it was suspected to have been introduced with the iron powder. It was therefore decided to proceed with the enriched specimen but use a Type 18-8 prealloyed powder for the spacers. It was necessary to continue the use of the elemental powders for the specimen matrix, however, to obtain the desired core structure. 
Two 20 and two $25 \mathrm{w} / 0 \mathrm{UO}_{2}$-stainless specimens were planned for the irradiation capsule plus one $25 \mathrm{w} / 0 \mathrm{UO}_{2}$-stainless specimen for a preirradiation metallographic examination. The $\mathrm{UO}_{2}$ used had a particle-size range of 74 to $149 \mu$ (minus 100 plus $200 \mathrm{mesh})$, a uranium content of $87.3 \mathrm{w} / \mathrm{o}$, and an enrichment of 93.13 per cent. The specimens and spacers were prepared and fitted into the frame by the same procedure used with the natural $\mathrm{UO}_{2}$ compacts.

It was decided to prepare a similar compact of five enriched $\mathrm{UO}_{2}$ specimens at this time using an elemental-powder blend of Type 18-9 stainless steel for both specimens and spacers. A new batch of iron powder was used in this blend in an effort to eliminate the contamination. The specimens and spacers were fabricated as previously described, and both compacts were degassed to $1 \times 10^{-3} \mathrm{~mm}$ of mercury pressure and sealed and rolled using the same rolling procedure used on the natural $\mathrm{UO}_{2}$ experimental compact. The compacts were then radiographed to locate the exact position of the cores and the specimens cut to size, leaving the core centered within the bonded Type 347 stainless steel cladding.

All specimens were leak tested by boiling for three $1 / 2-\mathrm{hr}$ periods in 50 volume per cent solutions of nitric acid and water. The three solutions from each specimen were then analyzed for uranium content. No defects were found in any of the ten specimens so one $25 \mathrm{w} / \circ \mathrm{UO}_{2}$ specimen was selected from each of the compacts for metallographic examination.

Contamination still was found to be prevalent in the elemental-powder stainless steel, so the four specimens fabricated with prealloyed spacers were chosen to be encapsulated and irradiated. Figure 9 is a cross section of the metallographic specimen, and Figure 10 shows the microstructure of the core.

It was concluded from a study made of the contamination that it was $\mathrm{Cr}_{2} \mathrm{O}_{3}$. Petrographic and X-ray data indicated that the oxide was not present in the elementalpowder blend but was formed during the sintering operation in the hydrogen furnace.

Study of the green pressing pressures indicated that the high pressure resulted in a dense surface which prevented the penetration of the hydrogen into the inner material and trapped any contaminating gases within the specimens. To prevent this it was decided to decrease the green pressing pressure, increase the sintering temperature to $2300 \mathrm{~F}$, and recoin the sintered specimens as before at 50 tsi to increase the density. It was also decided to use $\mathrm{UO}_{2}$ with a higher uranium conient, thus leaving less oxygen to be released from the decomposition of oxides of a higher oxygen content than $\mathrm{UO}_{2}$ during the sintering procedure.

A new compact of irradiation specimens containing two 25 and three $30 \mathrm{w} / \mathrm{O} \mathrm{UO}_{2}$ specimens is presently being fabricated using the revised pressing and sintering techniques. The specimen matrix and spacer material is elemental-powder Type 18-9 stainless steel and the $\mathrm{UO}_{2}$ contains $87.60 \mathrm{w} / \mathrm{o}$ uranium with an enrichment of 88.13 per cent and a particle-size range of 53 to $149 \mu$ (minus 100 plus $270 \mathrm{mesh}$ ). The rolling procedure is identical to the previously fabricated compacts. Specimens are being machined and prepared for encapsulation.

In addition to small-scale irradiation specimens, a full-size subassembly is being fabricated for in-pile-loop studies. The fuel-element plates have been fabricated 


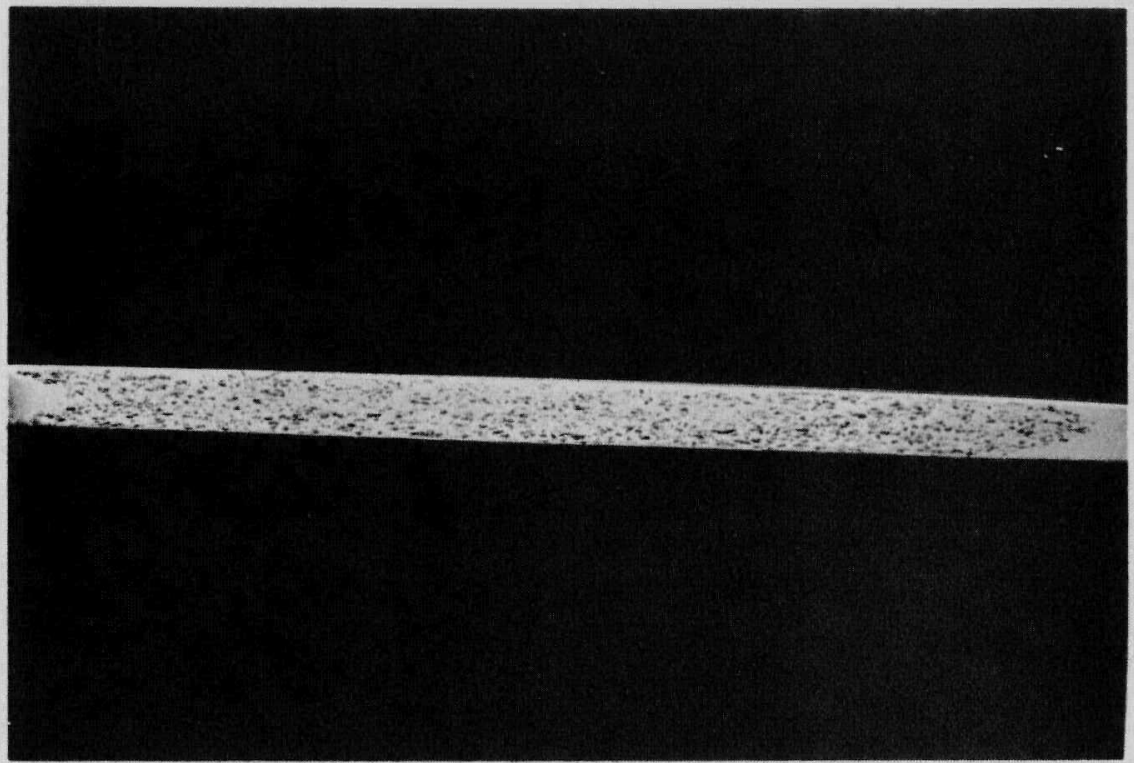

$4-1 / 2 X$

RM6607

FIGURE 9. CROSS SECTION OF AN IRRADIATION SPECIMEN COMPOSED OF $25 \mathrm{w} / 0 \mathrm{UO}_{2}$ IN TYPE 18-9 ELEMENTAL POWDER STAINLESS STEEL

End-cladding material is prealloyed Type 18-8 stainless steel.

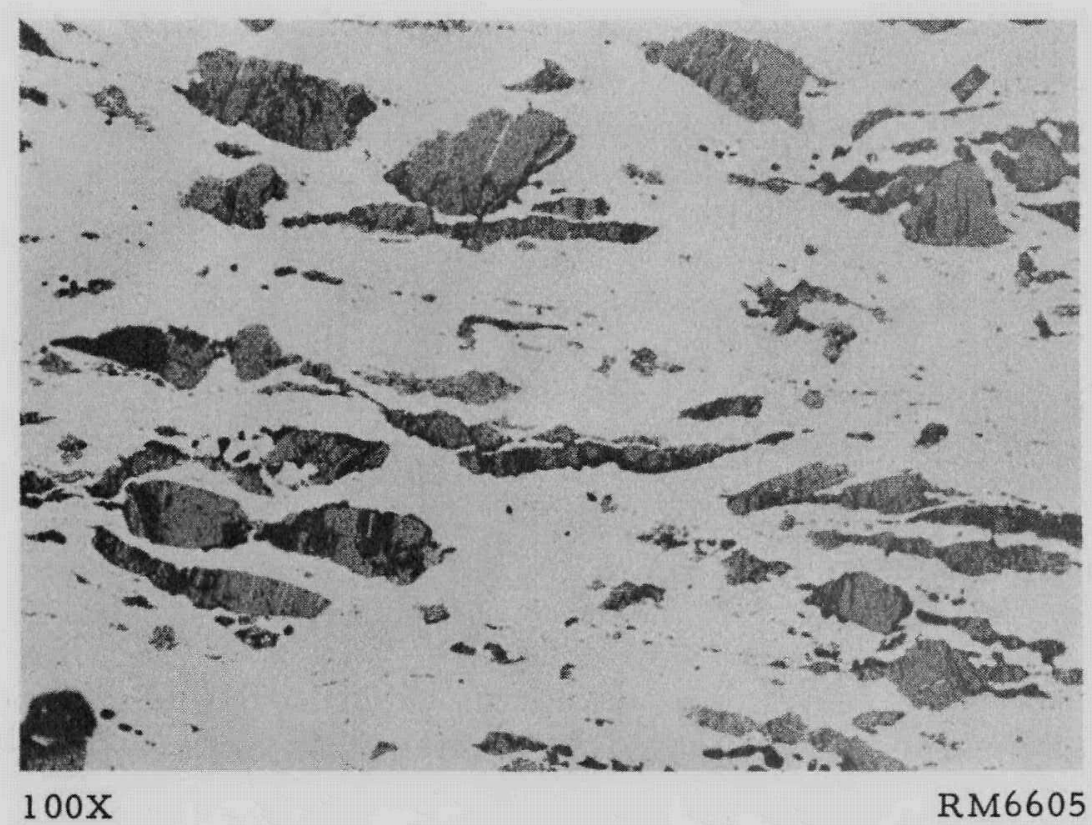

FIGURE 10. PHOTOMICROGRAPH OF IRRADIATION SPECIMEN COMPOSED OF $25 \mathrm{w} / 0 \mathrm{UO}_{2}$ IN TYPE 18-9 ELEMENTAL POW DER STAINLESS STEEL 
according to the procedure outlined in the section on fuel-element fabrication. The plates are being machined and, after a stress-relief anneal, will be brazed into a subassembly. The $\mathrm{UO}_{2}$ used contains $87.3 \mathrm{w} / \mathrm{o}$ uranium, of which $93.13 \mathrm{w} / \mathrm{o}$ is uranium-235.

\section{Preparation of Enriched Uranium-Niobium and Uranium-Molybdenum Irradiation Samples}

A. A. Bauer, J. A. DeMastry, and R. F. Dickerson

Since some consideration has been given to alloys as an alternate fuel material for the GCRE, there was interest in a cursory study of those alloys which might be useful under the operating conditions of the reactor. Uranium alloys containing 75 and $80 \mathrm{w} / \mathrm{o}$ niobium and 75 and $80 \mathrm{w} / 0$ molybdenum, having relatively good properties at the operating temperatures, were chosen as possible materials, and a program designed to determine the effect of irradiation damage on this material was initiated. Since no alloy-development program was to be undertaken, it was necessary to obtain some feel for the fabricability of the alloys.

Experience with both alloy systems indicated that the niobium alloys would probably fabricate more easily than the high-molybdenum alloys. With this in mind, it was decided to first produce the 75 and $80 \mathrm{w} / 0$ niobium specimens and then follow up with the high-molybdenum alloys. The procedures used for the preparation of the niobiumalloy specimens are discussed in the following paragraphs.

Several 200-g charges of biscuit uranium and commercial-grade niobium were made up containing $80 \mathrm{w} / 0$ niobium. The charges were arc melted under a helium atmosphere, finally being cast into bars 4 by 1 by 0.25 in. The bars were melted a total of 14 times in order to achieve maximum homogeneity. The bars were then given a 24-hr homogenization treatment at $900 \mathrm{C}$ and water quenched.

After quenching, sections from the ends, top, bottom, and the center of the bars were removed. Chips were removed from the above pieces and submitted for chemical analysis. The sections were then examined metallographically. Both the metallographic examinations and chemical analyses indicated that a high degree of homogeneity had been obtained.

On the basis of these results, and since the fabrication characteristics of the uranium-80 w/o niobium alloy were already known, no further studies were made and enriched-uranium specimens were prepared. The uranium used was of 93.22 per cent enrichment, the niobium was triple-sintered high-purity stock. Complete chemical analyses were available for these materials.

Two 200-g charges were prepared, one containing $75 \mathrm{w} / 0$ niobium, the other $80 \mathrm{w} / \mathrm{o}$ niobium. These were arc melted employing the same techniques used in the preparation of the natural uranium samples. The castings were then sealed in evacuated Vycor tubes, homogenized for $24 \mathrm{hr}$ at $900 \mathrm{C}$, and water quenched. 
The specimens were hot rolled at $1850 \mathrm{~F}$ from a helium atmosphere. After a 5 per cent reduction, cracks started to appear at the edges of the specimens and no further reduction was attempted.

The bars were then sectioned and pieces removed from the ends for metallographic studies. These pieces showed what appeared to be good homogeneity. After this examination the bars were machined to 1.5 by 0.375 by 0.50 -in. plates. Samples were removed from the ends and surface of the bars as they were being machined for chemical analysis. No results have been obtained as of this date.

Preirradiation photomacrographs were taken and dimensions and densities were measured. Encapsulation has been initiated.

Some difficulty has been encountered in the casting of uranium-molybdenum alloys. Tungsten-electrode arc-melting techniques have not been found satisfactory and consumable-electrode methods are now being investigated. When satisfactory castings are prepared, fabrication procedures will be studied.

\section{Calrod Fabrication}

S. J. Paprocki and E. S. Hodge

One of the alternate fuel-element systems considered for use in the Gas-Cooled Reactor Experiment was a Calrod-type element consisting of a uranium oxide core clad with stainless steel. The main advantage to this type of fuel element is the savings in cost in fuel-element fabrication. If uranium oxide could be sufficiently densified and clad with stainless steel by fabrication of a stainless steel tube containing packed uranium oxide, a significant savings could be achieved. A cursory investigation was made of the feasibility of using this type of element for this application.

Irradiations carried out at various sites have shown that the release of gaseous fission products by irradiated uranium dioxide is a function of the surface area of the oxide material. Material of high density exhibits greatly enhanced retention of gaseous fission products, with densities of 90 per cent being highly desirable. A Calrod-type element prepared with packed oxide would be a very economical approach to the production of a high-density clad uranium dioxide core.

A few exploratory specimens were prepared and examined in an attempt to establish a method of producing a Calrod-type unit. The number of specimens prepared was limited; consequently, the conclusions made are based on trends observed rather than sufficient data to outline a process.

After reviewing the literature available on the preparation of this type of element and studying the fabrication problems involved, it was decided to attempt to prepare several exploratory specimens by three different methods. Essentially, these methods included hot swaging of uranium oxide powder packed in a stainless steel tube, pressure bonding of specimens previously subjected to the first treatment, and direct pressure bonding of stainless steel tubing on packed uranium oxide powder. 
Preparation of Specimens for Bonding

In this investigation, uranium oxide received from Mallinckrodt was used as the core material. Type 304 stainless steel tubing with wall thicknesses of 32 and 68 mils was used as cladding material. In order to facilitate easy uniform packing of the oxide in the tube, it was necessary to use a lubricant. Additions of $0.2 \mathrm{w} / 0$ and $2 \mathrm{w} / \mathrm{o}$, respectively, of aluminum stearate and Carbowax $20 \mathrm{M}$ were used. To protect the surface of the stainless steel from oxidation during hot swaging, the specimens were inserted in an outer protective tube of Ti-Namel or 1020 steel.

Lubricant and oxide were hand mixed in the desired proportions and poured into a capsule. Packing of the oxide was achieved by using a plunger mounted in a 50-ton press. Pressures of 30 to 35,000 psi were used in an attempt to pack the oxide in the tubes with a minimum amount of pressing operations and still obtain a relatively good starting density of 40 to 45 per cent.

After the tube was packed, the lubricants were removed by heating at an elevated temperature while evacuating the tube. The specimens were sealed off and inserted in protection tubes for hot swaging or in the case of direct pressure bonding, the stainless steel tube was pressure bonded immediately after sealing off.

\section{Fabrication of the Calrod-Type Specimens}

Temperatures of 2000 to $2200 \mathrm{~F}$ were used during hot swaging and pressures of 8 to 10,000 psi at temperatures of 1500 to $1650 \mathrm{~F}$ for times of 4 to 8 hr were used during pressure bonding. Densities of 65 to 75 per cent of theoretical were achieved by hot swaging to a 95 per cent reduction. Similar densities were achieved for pressurebonded specimens prepared by direct pressure bonding. Specimens subjected to hot swaging prior to pressure bonding were the most satisfactory, based on density measurements. Densities of 70 to 85 per cent were obtained by this procedure.

In this investigation, the control of dimensional tolerances was a problem. Swaging at elevated temperatures produced specimens exhibiting variable densities and variable cladding thickness along the length of the specimens. The combination of a thickwalled stainless steel tube and a Ti-Namel outer protective tube produced the best specimen prepared by hot swaging. Although relatively good densities were obtained, the core exhibited cracks and dimensional control was poor.

Specimens hot swaged and then pressure bonded produced good densification of the core; however, some cracks and variable cladding thickness produced during hot swaging were still evident after pressure bonding. Less swaging prior to pressure bonding would probably have produced better core properties.

Only one specimen was pressure bonded with no previous densification by hot swaging; however, the temperature used was not high enough to produce satisfactory densification of the core. 


\section{Conclusions}

Preparation of a Calrod-type element by pressure bonding with the oxide studied appears somewhat promising. It is doubtful if hot swaging would yield a satisfactory product. A sufficient number of specimens were not pressure bonded to determine how much if any densification by hot swaging is necessary prior to pressure bonding. Additional development of the pressure-bonding method appears the most promising process for preparing this type of element. By this technique, a large number of elements would be prepared simultaneously.

Recent advances made in the field of pressure bonding strongly indicate that the higher temperature now being employed would produce better specimens than those obtained by pressure bonding at the lower temperature used in this cursory study. 
RADIATION-EFFECTS PROGRAM

J. H. Saling, E. M. Chandler, J. E. Whitney, W. S. Diethorn, P. Schall, Jr., R. H. Barnes, and G. D. Calkins

The radiation-effects program on fuel materials includes the evaluation of UO2stainless steel fuel and possible alternate fuels. Most of the effort in this program has been directed to obtaining radiation-effects data on the $\mathrm{UO}_{2}$-stainless steel fuel specimens. Fabrication of alternate fuel specimens for irradiation is under way.

The program includes the following phases:

(1) A survey of pertinent available information on radiation effects from all sources.

(2) The continuation of a cooperative program with KAPL to study the effects of postirradiation heat treatments at 1200 to $1650 \mathrm{~F}$ on $\mathrm{UO}_{2}-$ cermet specimens irradiated by KAPL at temperatures below $1200 \mathrm{~F}$.

(3) The irradiation and evaluation of $\mathrm{UO}_{2}$-cermet specimens under GCRE conditions of temperature and burnup.

(4) The estimation of the release of fission products from the reference fuel element.

(5) The irradiation and evaluation of promising alternate fuel materials.

Survey of Radiation Stability of Fuel Elements of Interest to GCRE

As a part of the GCRE program on reference and alternate fuels, the survey of available literature on the effect of radiation on $\mathrm{UO}_{2}$ cermets and other potential fuelelement materials was continued.

\section{$\mathrm{UO}_{2}$ Dispersions}

The effects of burnup, temperature, and time at temperature on $\mathrm{UO}_{2}$ dispersions in stainless steel, the GCRE reference fuel element, were reviewed in a general way in BMI-1133. There is very little new information to report on this type of fuel element.

KAPL has irradiated flat-plate and pin specimens of $\mathrm{UO}_{2}$ dispersed in stainless steel. Fully clad (4 mil) flat-plate specimens containing 5, 10, 20, and $30 \mathrm{w} / \mathrm{o}$ enriched $\mathrm{UO}_{2}$ were irradiated at temperatures as high as $1300 \mathrm{~F}$ to uranium-235 burnups of 19 per cent. The $5 \mathrm{w} / 0$ specimens showed no dimensional changes. All the other flat-plate specimens exhibited blister formation on both sides.

Fully clad pin specimens containing less than $25 \mathrm{w} / 0$ enriched $\mathrm{UO}_{2}$ have been irradiated to uranium-235 burnups as high as 27 per cent at temperatures of $800 \mathrm{~F}$. 
Diameter increases of 0.002 in. have been observed. Fission-gas retention was excellent for these pins.

Postirradiation tensile properties of $25 \mathrm{w} / \mathrm{o} \mathrm{UO}_{2}$ in stainless steel have been reported by KAPL (see Table 12). The data show that the tensile and yield strength of 25 w/o UO2-stainless steel core material decreased with increasing burnup at 1200 to $1400 \mathrm{~F}$.

Bend-test data for $25 \mathrm{w} / \mathrm{o} \mathrm{UO}_{2}$ in stainless steel are presented in Table 13.

Specimens 1 and 2 contained fine particle-size, 10 to $44 \mu, \mathrm{UO}_{2}$. Their ductility was much less than the preirradiation values. The strength of these two specimens increased, however. Specimens 3 and 4 contained coarse-particle-size, 105 to $210 \mu$, $\mathrm{UO}_{2}$. These specimens were embrittled, but they retained their preirradiation strength. Specimen 5 was fabricated by the cold-binder extrusion method. This specimen decreased very little in ductility. Specimens 1 and 2 were hot swaged; Specimens 3 and 4 were hot drawn.

Other sites have reported irradiation tests of flat-plate and ribbon-type $\mathrm{UO}_{2-}$ dispersion specimens. These tests were conducted at temperatures of 1500 to $1800 \mathrm{~F}$. Fully clad ( 4 mil) flat-plate specimens, for example, containing 30 to $40 \mathrm{w} / \mathrm{o} \mathrm{UO}_{2}$ in stainless steel, have been irradiated to burnups of 0.65 to 2 a/o total. Dimensional stability and fission-gas retention were excellent for many of these specimens. The performance of ribbon-type specimens was similar.

\section{Alternate Fuels}

Sintered $\mathrm{UO}_{2}$ slugs, annularly loaded $\mathrm{UO}_{2}$ pins, swaged $\mathrm{UO}_{2}$ pins, high-niobiumuranium alloys, and zirconium-uranium hydride alloys are being considered in the alternate-fuel program for GCRE. Radiation-effects data on only the first two fuel materials are reported below. No information on the other systems was available.

Sintered UO2 Slugs. Successful use of high-density $\mathrm{UO}_{2}$ slugs clad in Zircaloy 2 has been demonstrated in the WAPD-PWR program. The low resistance of $\mathrm{UO}_{2}$ slugs to thermal shock is a major disadvantage of this fuel, however. ANL reports that highdensity $\mathrm{UO}_{2}$ slugs, $0.050 \mathrm{in}$. long by $0.187 \mathrm{in}$. in $\mathrm{OD}$, irradiated to a uranium burnup of 0.16 per cent, fracture when the radial temperature gradient is as low as $200 \mathrm{~F}$. WAPD reports that, at much higher temperatures, $\mathrm{UO}_{2}$ slugs, $0.354 \mathrm{in}$. long by $0.354 \mathrm{in}$. in $O D$, were irradiated to uranium burnups of less than 1 per cent with radial temperature gradients of $1000 \mathrm{~F}$ and higher. Fracturing also occurs.

The poor stability of sintered $\mathrm{UO}_{2}$ slugs in a radiation field is also shown by recent Hanford results. A 1.285 in. in OD by 4-in.-long specimen having a theoretical density of 85 per cent fractured axially after a uranium burnup of less than 0.1 per cent. The irradiation temperature was less than $1000 \mathrm{~F}$.

Dimensional changes occur when $\mathrm{UO}_{2}$ slugs are irradiated. The following data are representative of $\mathrm{UO}_{2}$ slugs having a theoretical density of 92 per cent. 
TABLE 12. TENSILE PROPERTIES OF $25 \mathrm{w} / 0$ UO2-STAINLESS STEEL DISPERSIONS OBTAINED AT KAPL

\begin{tabular}{ccccccc}
\hline \hline $\begin{array}{c}\text { Uranium-235 } \\
\text { Burnup, } \\
\text { per cent }\end{array}$ & $\begin{array}{c}\text { Total } \\
\text { Burnup, } \\
\text { a/o }\end{array}$ & $\begin{array}{c}\text { Test } \\
\text { Temperature }\end{array}$ & $\begin{array}{c}\text { Tensile } \\
\text { Strength, } \\
\text { psi }\end{array}$ & $\begin{array}{c}\text { O.2 Per Cent } \\
\text { Offet Yield } \\
\text { Strength, } \\
\text { psi }\end{array}$ & $\begin{array}{c}\text { Elongation, } \\
\text { per cent }\end{array}$ & $\begin{array}{c}\text { Reduction } \\
\text { in Area, } \\
\text { per cent }\end{array}$ \\
\hline 3.2 & 0.175 & RT & 48,000 & 44,700 & 8.0 & 4.8 \\
15.3 & 0.84 & RT & 46,700 & 42,700 & 4.2 & 8.2 \\
21.3 & 1.17 & RT & 49,500 & 46,500 & 1.8 & 2.3 \\
6.7 & 0.37 & 1000 & 32,300 & 28,200 & 4.3 & 4.6 \\
10.5 & 0.58 & 1000 & 33,200 & 31,300 & 3.1 & 5.0 \\
19.4 & 1.07 & 1000 & 33,700 & 31,200 & 2.4 & 3.7 \\
6.6 & 0.36 & 1200 & 21,800 & 19,200 & 3.4 & 3.1 \\
12.0 & 0.66 & 1200 & 20,900 & 19,100 & 2.8 & 4.8 \\
18.5 & 1.02 & 1200 & 18,500 & 18,500 & 2.2 & 1.5 \\
6.6 & 0.36 & 1400 & 15,000 & 15,000 & 2.2 & 2.0 \\
12.0 & 0.66 & 1400 & 9,900 & 8,700 & 3.8 & 6.1 \\
\hline \hline
\end{tabular}

TABLE 13. BEND TESTS ON $25 \mathrm{w} / 0 \mathrm{UO}_{2}$-STAINLESS STEEL DISPERSIONS

\begin{tabular}{lcccc}
\hline \hline & $\begin{array}{c}\text { Uranium-235 } \\
\text { Burnup, } \\
\text { per cent }\end{array}$ & $\begin{array}{c}\text { Total } \\
\text { Burnup, } \\
\text { a/o }\end{array}$ & $\begin{array}{c}\text { Maximum } \\
\text { Load, } \\
\text { lb }\end{array}$ & $\begin{array}{c}\text { Deflection } \\
\text { at Fracture, } \\
\text { in. }\end{array}$ \\
\hline $1(18-35 \mathrm{E})$ & 28 & 1.54 & 163 & 0.05 \\
$2(18-35 \mathrm{C})$ & 24 & 1.32 & 158 & 0.05 \\
$3(18-44 \mathrm{~J})$ & 20 & 1.10 & 113 & 0.28 \\
$4(18-44 \mathrm{~L})$ & 20 & 1.10 & 116 & 0.29 \\
$5(16-41)$ & 17 & 0.93 & 92 & -- \\
\hline \hline
\end{tabular}




\begin{tabular}{c}
$\begin{array}{c}\text { Uranium Burnup, } \\
\text { per cent }\end{array}$ \\
\hline 0.043 \\
0.14 \\
0.23 \\
0.12
\end{tabular}

\begin{tabular}{c}
$\begin{array}{c}\text { Volume Change, } \\
\text { per cent }\end{array}$ \\
\hline 0.4 \\
13.9 \\
8.8 \\
0.2
\end{tabular}

WAPD and Chalk River have studied the release of fission gas from $\mathrm{UO}_{2}$ slugs as a function of $\mathrm{UO}_{2}$ density and temperature. Typical results of WAPD experiments are listed in Table 14, and show a large decrease in the release of fission gas at $\mathrm{UO}_{2}$ densities above 90 per cent.

\section{TABLE 14. UO2 FISSION-GAS RELEASE EXPERIMENTS}

\begin{tabular}{|c|c|c|c|}
\hline $\begin{array}{l}\mathrm{UO}_{2} \\
\text { Density, } \\
\text { per cent }\end{array}$ & $\begin{array}{l}\text { Uranium } \\
\text { Burnup, } \\
\text { per cent }\end{array}$ & $\begin{array}{c}\text { Heat-T reatment } \\
\text { Temperature, } \\
\text { F }\end{array}$ & $\begin{array}{l}\text { Krypton }-85 \text { Released During } \\
\text { Postirradiation Heat Treatment } \\
\text { for } 2 \mathrm{Hr} \text {, per cent }\end{array}$ \\
\hline \multirow[t]{4}{*}{80} & 0.17 & No heat treatment & $10.1(\mathrm{a})$ \\
\hline & & 482 & 0.02 \\
\hline & & $480-1100$ & 0.02 \\
\hline & & $1100-1800$ & 0.07 \\
\hline \multirow[t]{4}{*}{90} & 0.59 & No heat treatment & $0.82^{(a)}$ \\
\hline & & 482 & 0.002 \\
\hline & & $480-1100$ & 0.04 \\
\hline & & $1100-1800$ & 0.04 \\
\hline 93 & 0.14 & No heat treatment & $0.43(a)$ \\
\hline 95 & 0.14 & No heat treatment & $0.11^{(a)}$ \\
\hline
\end{tabular}

(a) Collected after irradiation prior to a postirradiation heat treatment.

Chalk River has also reported a marked decrease in the amount of fission gas released for $\mathrm{UO}_{2}$ theoretical densities greater than about 90 per cent. In their postirradiation heat treatments of $\mathrm{UO}_{2}$ slugs, 6 per cent of the total fission gas was released after $4 \mathrm{hr}$ at $2600 \mathrm{~F}$. The results of these and other fission-gas experiments show that release increases with burnup for a given $\mathrm{UO}_{2}$-slug density but decreases rapidly with increasing $\mathrm{UO}_{2}$-slug densities greater than 90 per cent. In addition, the amount of fission gas released during high-temperature irradiations is much larger than that found during postirradiation heat treatments at high temperature following lowtemperature irradiations.

Annularly Loaded UO2 Pins. Pins, $0.080 \mathrm{in.}$ and $0.160 \mathrm{in}$. in $\mathrm{OD}$, having a cen-

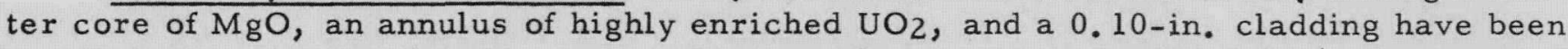
irradiated to uranium-235 burnups as high as 46 per cent, 4 and 7 total a/o, respectively, for the $0.160 \mathrm{in}$. and $0.080 \mathrm{in}$. pins, at temperatures as high as $1500 \mathrm{~F}$. The $\mathrm{UO}_{2}$ density in these pins was 65 per cent of theoretical. In general, fission-gas retention 


\section{CONFIDENTIAL}

and dimensional stability of these pins at irradiation temperatures of $1200 \mathrm{~F}$ or below has been excellent.

On a total-atom basis a uranium-235 burnup of 40 per cent in the large pin is equivalent to a 63 per cent uranium-235 burnup in a $25 \mathrm{w} / \mathrm{o} \mathrm{UO}_{2}$ dispersion. For the smaller pin, the equivalent uranium-235 burnup in a $25 \mathrm{w} / 0 \mathrm{UO}_{2}$ dispersion would be 100 per cent. When the performance of the $\mathrm{UO}_{2}$ dispersions and pins are compared in this manner, the superiority of the pins is readily apparent.

\section{Postirradiation Heat-Treatment Study of KAPL UO2 Cermets}

In view of the lack of data on the radiation stability of the $\mathrm{UO}_{2}$ cermet at temperatures of pertinence to the GCRE and the great importance of this information in making an early decision concerning the suitability of the $\mathrm{UO}_{2}$ cermet, a cooperative program with KAPL was organized. The purpose of this program was to study the temperature

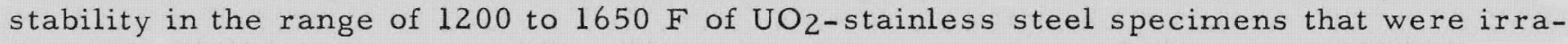
diated by KAPL to burnups of 8 to 20 per cent at temperatures below about $1200 \mathrm{~F}$.

\section{Description of Specimens}

KAPL has irradiated a series of pin-type specimens ( $1 L-40$ series) containing 25 w/o 93 per cent enriched UO2 dispersed in and fully clad with Type 347 stainless steel. They are $0.160 \mathrm{in}$. in OD, have a 0.140 -in. core, and were fabricated by the coldbinder technique. The $\mathrm{UO}_{2}$ consists of particles of 105 to $210 \mu$ in diameter. They are 2 in. long. These specimens received burnups of 8,21 , and 26 per cent of the uranium235 at a maximum estimated surface temperature of 1200,1020 , and $840 \mathrm{~F}$, respectively.

KAPL in connection with the same program has irradiated some 28-in,-long pins of material of the same composition with a varying burnup along the length of the pin of from 8 to 22 per cent of the uranium-235. These pins were fabricated by the hotextrusion technique.

At the time the program was organized the capsules containing the fully clad specimens had not as yet been opened and their condition was not known. For this reason, it was thought advisable to incorporate an alternate plan to cover the possibility that all or part of these specimens had suffered radiation damage, making them unfit for postirradiation heat treatments. The alternate plan consisted of postirradiation heat treatment of five specimens cut from the $28-\mathrm{in}$. fuel pin. These specimens were to be $1-1 / 2$ in. long and would have burnups of 12,14,16, 18, and 21 per cent of uranium-235. These specimens, of course, would not be end clad. Any of the fully clad specimens not receiving radiation damage would also be included in the alternate plan.

After opening the capsules, KAPL determined that the fully clad specimens receiving burnups of 21 and 26 per cent of the uranium-235 had suffered cladding cracks to such an extent as to make them unsuitable for postirradiation heat treatments. The reas on for the failure of these specimens is not certain. The specimens grew as much as $0.006 \mathrm{in}$. in diameter and the cracks penetrated into the core material. There is 


\section{CONFIDENTIAL}

52

some feeling that, since the over-all density of the compact was approximately 98 per cent of theoretical, fission-product release caused the swelling and cracking.

Following the alternate plan, KAPL shipped to Battelle the fully clad specimen from the $1 L-40$ series having 8 per cent burnup of the uranium-235 and sections from the 18-44 fuel pin having the burnups specified above.

\section{Experimental Work}

The specimens were weighed, physical dimensions and densities measured, and stereomacrographs taken prior to heat treatment. The specimens were loaded in Vycor tubes having a thin break-off section at one end. The other end of the capsule below the seal consisted of a Vycor to Pyrex seal and the male portion of a Pyrex ball joint. After loading five specimens in these capsules, the capsules were attached to a manifold for evacuation and flushing with argon. Argon was used as a flushing gas to remove oxygen from the capsule in order to prevent chemical reactions. The pressure was reduced to approximately $100 \mu$ and the individual capsules sealed with a gas-oxygen torch using the master-slave manipulators.

The heat treatments were conducted for $100 \mathrm{hr}$ each at the following temperatures: $1200,1350,1500$, and $1650 \mathrm{~F}$. Each specimen was encapsulated in a Vycor capsule and the entire system was flushed with argon. The pressure was then reduced to approximately $100 \mu$ and the capsules were sealed off. After heat treating at each temperature for $100 \mathrm{hr}$, the capsules were punctured and the amount of fission gas released during the heat treatment was determined. Physical dimensions, densities, and stereomacrographs were taken after each heat treatment.

\section{Results and Conclusions}

The information obtained from this study is summarized in Table 15 and the data do not show any general correlation with temperature or burnup. In the open-ended specimens, the only significant change was the release of fission gas. The specimen at 16 per cent burnup appeared to be the best specimen. However, there is no obvious explanation for its superiority. The variation of the gas released may have resulted from small differences in porosity or stringering of the core of the specimens.

The fully clad specimen with 8 per cent burnup showed signs of incipient failure after the first $1650 \mathrm{~F}$ heat treatment. It had cracked at the braze area between the end plugs and the body of the specimen. This specimen released 9.5 per cent of the theoretical amount of fission gas in it during this heat treatment. Since the brazing alloy had a melting point of $1832 \mathrm{~F}$, it was known that this was a weak point in the cladding. The amount of fission gas released during this heat treatment indicates that the failure resulted from gas pressure. No significant changes occurred in the second heat treatment at $1650 \mathrm{~F}$.

It is interesting to note that none of these specimens failed by blistering. This type of failure has been reported for flat-plate $\mathrm{UO}_{2}$-cermet specimens at $1400 \mathrm{~F}$ and 14 per cent burnup of the uranium-235. Of course, the KAPL specimens had a cladding 
TABLE 15. EFFECT OF POSTIRRADIATION HEAT TREATMENTS ON FISSION-GAS RELEASE, DENSITY, AND PHYSICAL DIMENSIONS OF KAPL, UO 2 -CERMET SPECIMENS

\begin{tabular}{|c|c|c|c|c|c|c|c|c|c|c|}
\hline \multirow[b]{2}{*}{ Specimen } & \multirow{2}{*}{$\begin{array}{c}100-\mathrm{Hr} \\
\text { Heat } \\
\text { Treatment, } \\
\mathrm{F} \\
\end{array}$} & \multirow{2}{*}{$\begin{array}{c}\text { Uranium-235 } \\
\text { Burnup, } \\
\text { per cent } \\
\end{array}$} & \multicolumn{2}{|c|}{$\begin{array}{l}\text { Amount of Gas Evolved, } \\
\text { per cent of theoretical }\end{array}$} & \multicolumn{2}{|c|}{$\begin{array}{c}\text { Change in Density, } \\
\text { per cent }\end{array}$} & \multicolumn{2}{|c|}{$\begin{array}{c}\text { Change in Diameter, } \\
\text { per cent } \\
\end{array}$} & \multicolumn{2}{|c|}{$\begin{array}{c}\text { Change in Length, } \\
\text { per cent }\end{array}$} \\
\hline & & & Per Run & Cumulative & Per Run & Cumulative & Per Run & Cumulative & Per Run & Cumulative \\
\hline \multirow{5}{*}{$1-B M I-B$} & 1200 & 12 & 1.5 & 1.5 & -0.3 & -0.3 & $<0.1$ & $<0.1$ & +0.06 & +0.06 \\
\hline & 1350 & 12 & $<0.1$ & 1.5 & -0.1 & -0.4 & $<0.1$ & $<0.1$ & 0.00 & +0.06 \\
\hline & 1500 & 12 & $<0.1$ & 1.5 & -0.4 & -0.8 & $<0.1$ & $<0.1$ & +0.04 & +0.10 \\
\hline & 1650 & 12 & $<0.1$ & 1.6 & +0.3 & -0.5 & $<0.1$ & $<0.1$ & +0.01 & +0.11 \\
\hline & 1650 & 12 & 0.1 & 1.7 & $<0.1$ & -0.5 & $<0.1$ & $<0.1$ & 0.00 & +0.11 \\
\hline \multirow[t]{3}{*}{ 2-BMI-D } & 1500 & 14 & 1.9 & 1.9 & -0.1 & -0.1 & +0.1 & +0.1 & +0.12 & +0.12 \\
\hline & 1650 & 14 & 1.4 & 3.3 & $<0.1$ & -0.1 & +0.2 & +0.3 & -0.11 & +0.01 \\
\hline & 1650 & 14 & \multicolumn{2}{|c|}{ Gas sample lost } & -0.1 & -0.2 & -0.2 & +0.1 & +0.05 & +0.06 \\
\hline \multirow[t]{5}{*}{ 3-BMI-F } & 1200 & 16 & $<0.1$ & $<0.1$ & -0.4 & -0.4 & +0.1 & +0.1 & +0.06 & +0.06 \\
\hline & 1350 & 16 & $<0.1$ & $<0.1$ & $<0.1$ & -0.4 & $<0.1$ & +0.1 & +0.05 & +0.11 \\
\hline & 1500 & 16 & $<0.1$ & $<0.1$ & -0.2 & -0.6 & $<0.1$ & +0.1 & +0.01 & +0.12 \\
\hline & 1650 & 16 & 0.4 & 0.4 & $<0.1$ & -0.6 & +0.1 & +0.2 & -0.03 & +0.09 \\
\hline & 1650 & 16 & 1.0 & 1.5 & +0.1 & -0.5 & $<0.1$ & +0.2 & +0.10 & +0.20 \\
\hline \multirow[t]{2}{*}{ 4-BMI-I } & 1200 & 18 & $<0.1$ & $<0.1$ & $<0.1$ & $<0.1$ & $<0.1$ & $<0.1$ & $<0.01$ & $<0.01$ \\
\hline & 1350 & 18 & \multicolumn{2}{|c|}{ Specimen oxidized } & -1.3 & -1.3 & +2.1 & +2.1 & +1.48 & +1.48 \\
\hline \multirow[t]{5}{*}{ 5-BMI-M } & 1200 & 20 & 10.1 & 10.1 & -0.4 & -0.4 & +0.1 & +0.1 & +0.10 & +0.10 \\
\hline & 1350 & 20 & 0.7 & 10.8 & -0.3 & -0.7 & -0.2 & -0.1 & $<0.01$ & +0.10 \\
\hline & 1500 & 20 & 0.7 & 11.5 & -0.1 & -0.8 & +0.1 & $<0.1$ & +0.10 & +0.19 \\
\hline & 1650 & 20 & $<0.1$ & 11.5 & -0.1 & -0.8 & +0.4 & +0.4 & +0.05 & +0.25 \\
\hline & 1650 & 20 & 0.2 & 11.7 & -0.2 & -1.0 & +0.1 & +0.5 & -0.03 & +0.21 \\
\hline \multirow[t]{5}{*}{ C-24 No. 7} & 1200 & 8 & \multicolumn{2}{|c|}{ Sample lost } & $<0.1$ & $<0.1$ & $<0.1$ & $<0.1$ & +0.04 & +0.04 \\
\hline & 1350 & 8 & $<0.1$ & $<0.1$ & +0.3 & +0.3 & +0.1 & +0.1 & +0.02 & +0.06 \\
\hline & 1500 & 8 & $<0.1$ & $<0.1$ & -0.2 & +0.1 & +0.2 & +0.3 & -0.03 & +0.04 \\
\hline & 1650 & 8 & 9.5 & 9.5 & -0.5 & -0.4 & +0.7 & +1.0 & +0.15 & +0.18 \\
\hline & 1650 & 8 & 1.3 & 10.7 & -0.1 & -0.6 & $<0.1$ & +1.0 & +0.03 & +0.20 \\
\hline
\end{tabular}




\section{CONFIDENTIAL}

2. 5 times heavier than the blistered specimens. Apparently, there was not enough resistance to the movement of gases toward the ends of the specimens to cause swelling or deformation.

These specimens have been returned to KAPL where metallographic examination of each specimen will be conducted. Results of the metallographic examination will be reported as soon as they are available.

The cooperative program with KAPL is continuing. KAPL has recently irradiated some annularly loaded pins to estimated burnups of 15 to 34 per cent of the uranium235. Two of these pins, each $9-3 / 4$ in. long with a maximum pin burnup of 22 per cent and 34 per cent, have been made available to Battelle for postirradiation heat-treatment studies. These specimens are fully clad and are approximately 0,160 in. in diameter. They were irradiated at a temperature of $525 \mathrm{C}$. It is proposed to run a $100-\mathrm{hr}$ heat treatment on each of these specimens at $1500 \mathrm{~F}$ and, possibly, $1650 \mathrm{~F}$. The specimens have been received and the postirradiation heat-treatment studies will be started as soon as possible.

\section{Preliminary Irradiation and Evaluation of Reference-Type}

Fuel-Element Specimens

As a part of the program to obtain data for evaluating the suitability of the $\mathrm{UO}_{2}$ cermet for the GCRE at the earliest possible date, it was decided to irradiate a set of specimens that was already available at Battelle.

\section{Description of Specimens}

The material available at Battelle consisted of flat-plate specimens having 10 and $30 \mathrm{w} / \mathrm{o}$ of 93 per cent enriched $\mathrm{UO}_{2}$ dispersed in an 18-8 stainless steel compounded from the elemental powders. The majority of these specimens, as shown in Table 16 , contained $0.012 \mathrm{in}$. of core and were clad with $0.004 \mathrm{in}$. of Type 347 stainless steel. Two edges of the specimens had exposed core material, and these were closed by brazing on a strip of Type 347 stainless steel at $2200 \mathrm{~F}$. Different UO2 particle sizes were included.

The specimens were fabricated by the picture-frame technique under a helium atmosphere. During the edge brazing operation at $2200 \mathrm{~F}$, a few of the specimens blistered, evidently from helium gas entrained in the material. Only those specimens that withstood the heat treatment at $2200 \mathrm{~F}$ without blistering were used in this program.

The arrangement of the specimens in the irradiation capsule is shown in Figure 11 , and the amount of uranium-235 in each specimen is also shown. The capsule was intentionally loaded heavier at the bottom to offset the tendency for the bottom portion of irradiation capsules to operate at a lower temperature when the loading is uniform. This tendency has been evident in previous capsules on other programs. In addition, assuming an unequal vertical-flux distribution, the four specimens at the top of the capsule that are in close proximity, $2 \mathrm{in}$, , to each other should be in a comparatively uniform flux. The same reasoning applied to the bottom-six specimens. Therefore, 
TABLE 16. DESCRIPTION FOR SPECIMEN CAPSULE BMI-11-1(a)

\begin{tabular}{ccccccc}
\hline \hline Specimen & $\begin{array}{c}\text { UO } 2 \\
\text { Loading, } \\
\text { w/o }\end{array}$ & $\begin{array}{c}\text { Cladding } \\
\text { Thickness, } \\
\text { mils }\end{array}$ & $\begin{array}{c}\text { Core } \\
\text { Thickness, } \\
\text { mils }\end{array}$ & $\begin{array}{c}\text { Particle } \\
\text { Size, } \\
\mu\end{array}$ & $\begin{array}{c}\text { Length, } \\
\text { in. }\end{array}$ & $\begin{array}{c}\text { Width, } \\
\text { in. }\end{array}$ \\
\hline $15-1$ & 10 & 4 & 12 & $15-44$ & 0.50 & 0.45 \\
$15-2$ & 10 & 4 & 12 & $15-44$ & 0.50 & 0.44 \\
$15-3$ & 10 & 4 & 12 & $15-44$ & 0.50 & 0.44 \\
$15-4$ & 10 & 4 & 12 & $15-44$ & 0.50 & 0.45 \\
$10-5$ & 30 & 6 & 12 & $15-44$ & 0.50 & 0.45 \\
$30-1$ & 30 & 4 & 12 & $44-105$ & 0.50 & 0.46 \\
$30-2$ & 30 & 4 & 12 & $15-44$ & 0.52 & 0.18 \\
$24-1$ & 30 & 4 & 12 & $15-44$ & 0.52 & 0.18 \\
$24-2$ & 30 & 4 & $15-44$ & 0.52 & 0.18 \\
$24-3$ & 30 & & & & & \\
\hline
\end{tabular}

(a) All specimens are $0.020 \mathrm{in}$. thick. 


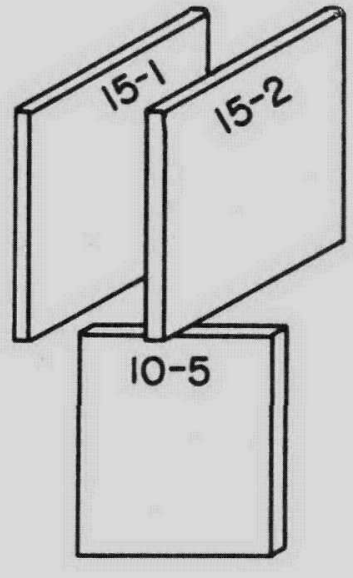

Specimen

$$
\begin{array}{ll}
15-1,15-2 & =0.051 \mathrm{~g}(a) \\
10-5 & =0.053 \mathrm{~g} \\
30-1 & =0.076 \mathrm{~g} \\
15-3,15-4 & =0.050 \mathrm{~g}(a) \\
30-2 & =0.076 \mathrm{~g} \\
24-1,24-2, & \\
24-3 & =0.096 \mathrm{~g}
\end{array}
$$

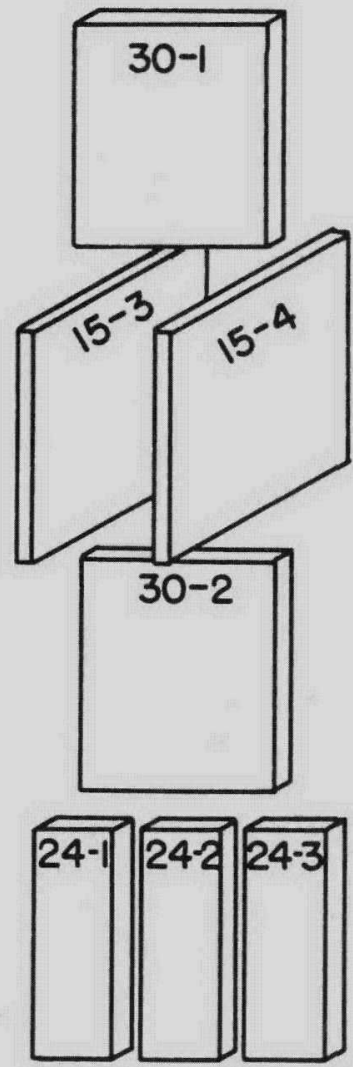

(a) Weight of uranium-235 in both specimens.

\section{$A-23913$}

FIGURE 11. THE ARRANGEMENT OF SPECIMENS IN THE IRRADIATION CAPSULE BMI-11-1 
both the top and the bottom of the capsule should furnish valid data for a comparison of $30 \mathrm{w} / 0$ and $10 \mathrm{w} / 0 \mathrm{UO}_{2}$ specimens even though the capsule experienced a nonuniform flux.

\section{Capsule Design}

Details of the capsule are shown in Figure 12. It consisted of a double capsule, the two sections of which were separated by a helium annulus as a heat barrier. The inner capsule material was Type 347 stainless steel. Type 304 stainless steel was used for the outer capsule, which operated at a lower temperature. The capsule was designed to have the specimens operate at about $1500 \mathrm{~F}$ from fission heat alone. The specimens were held in place in the inner capsule by a specimen basket fabricated from Type 347 stainless steel ribbon, as shown in Figure 13. The specimens occupied 4 in. of the capsule length adjacent to the gas-seal ball at the bottom of the capsule. This included a 0.25-in. clearance between the bottom specimens and the end of the capsule.

One dosimeter extending from the top to the bottom of the fueled section of the capsule provided information on the integrated flux distribution.

Assembly of the capsule began with the attachment of the loaded specimen basket to four thermocouples that were inserted through the holes shown in the capsule top. The inner capsule was then welded to the capsule top and the excess weld material was machined off. Thirty-two $\mathrm{cm}^{3}$ of $\mathrm{NaK}$ was injected through the gas-seal opening under an argon atmosphere, after which the stainless steel ball and the threaded gas-seal plug were placed in the position shown. The gas-seal plug was tightened and welded to the assembly, and the interior of the capsule and the gas annulus were evacuated through the fill tubes shown on each end of the capsule. After evacuation, helium was introduced at the pressures shown, and the fill tubes were crimped at red heat and welded. A protective cover for the bottom fill tube is shown welded in position.

\section{$\underline{\text { Irradiation }}$}

Irradiation of BMI-11-1 was initiated at the beginning of Cycle 71 at the MTR. The temperatures in the capsule during irradiation were determined by two thermocouples, one located beside Specimen 30-1 and the other adjacent to Specimen 24-2.

Irradiation was purposely started at the 37 -in. line in the reactor, well below the estimated design flux, $2 \times 1014 \mathrm{nv}$, for the capsule, where the specimens operated at about $600 \mathrm{~F}$. It was then moved to the 32 -in. line at the midcycle refueling shutdown after about 1 week of irradiation, and operated at $1100 \mathrm{~F}$ in a flux of about $1.7 \times 1014 \mathrm{nv}$. During subsequent cycles the specimens operated at temperatures between 1450 and $1550 \mathrm{~F}$. Analysis of the average dosimeter flux for the capsule showed a burnup of 10 per cent of the uranium-235.

\section{Results of Postirradiation Evaluation}

The $30 \mathrm{w} / 0$ specimens failed by the formation of blisters while the $10 \mathrm{w} / \mathrm{o}$ specimens appeared to be in good condition, as indicated in Table 17. In general, the 


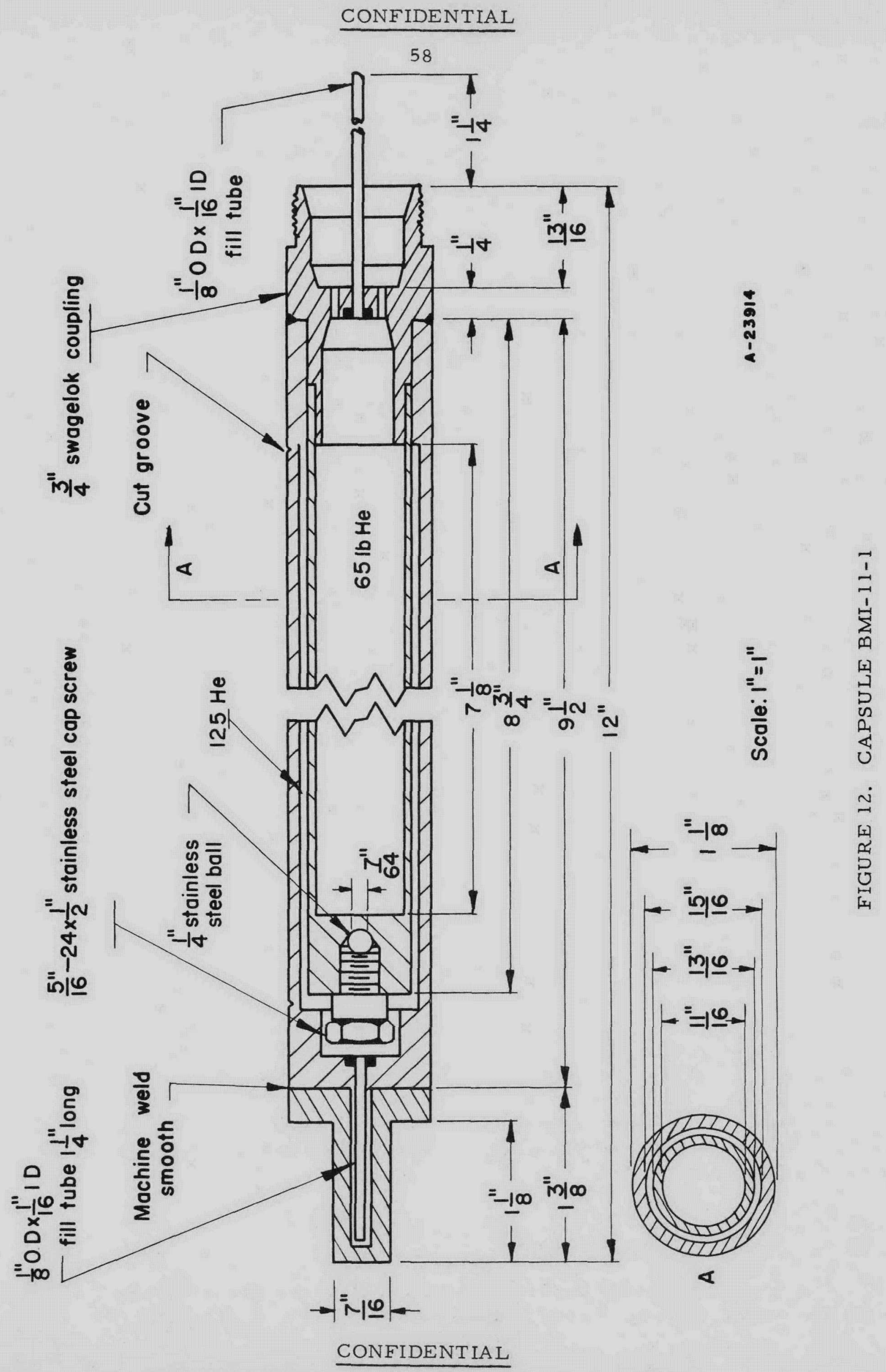

1. 
59
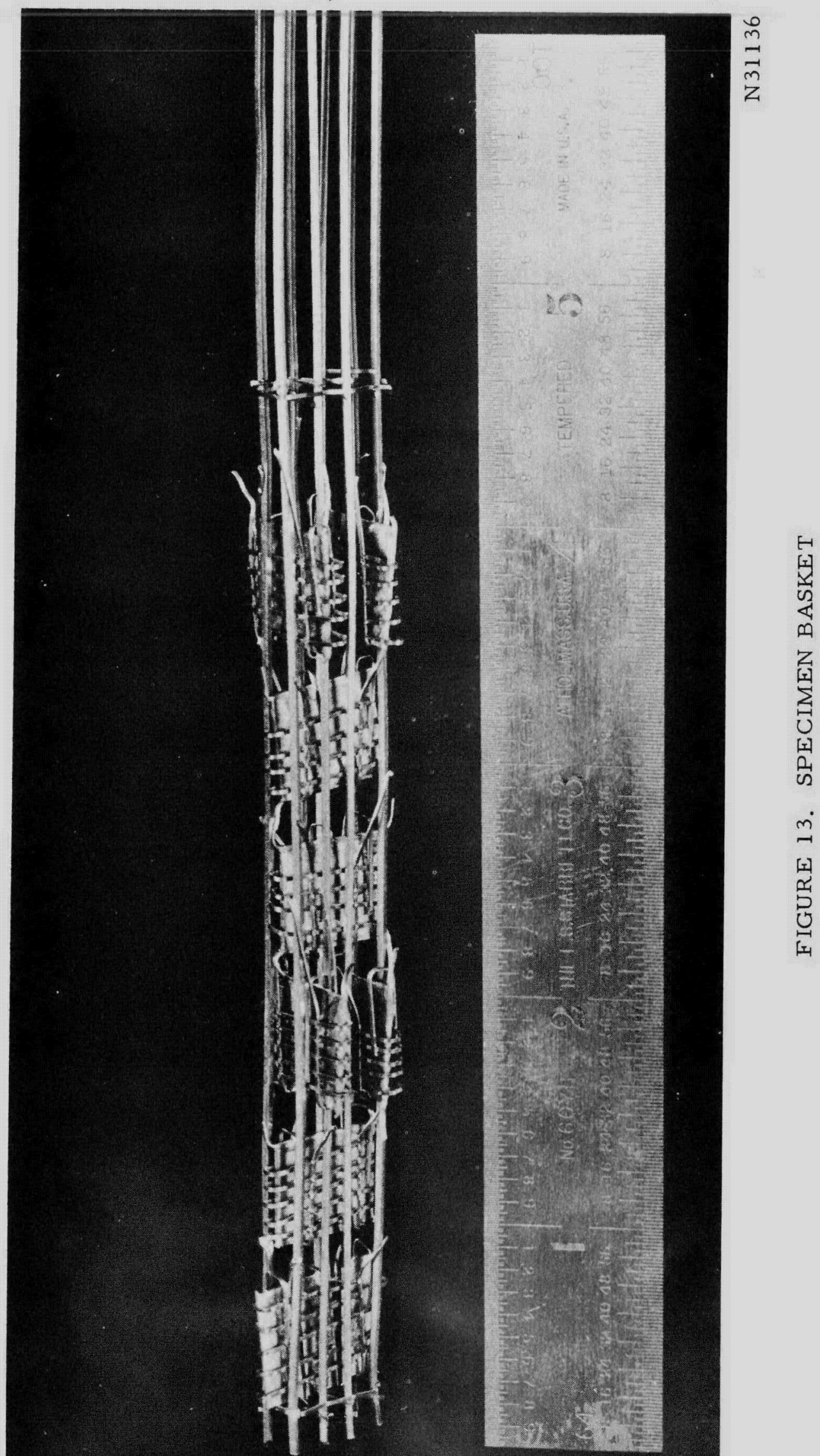

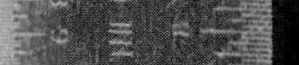

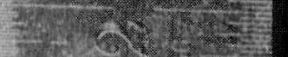

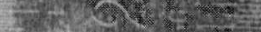

the vis:

1

CONFIDENTIAL

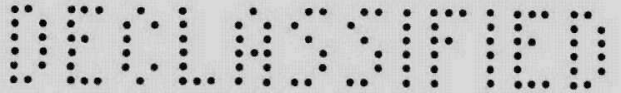


TABLE 17. EFFECT OF RADIATION ON UO2-CERMET SPECIMENS IN CAPSULE BMI-11-1

\begin{tabular}{|c|c|c|c|}
\hline Specimen & $\begin{array}{l}\quad \mathrm{UO}_{2} \\
\text { Concentration } \\
\text { in Core, w/o }\end{array}$ & $\begin{array}{l}\text { Density } \\
\text { Change(a), } \\
\text { per cent }\end{array}$ & Remarks \\
\hline $15-1(b)$ & 10 & $<0.3$ & $\begin{array}{l}\text { Both sides of specimen in very good shape; } \\
\text { no blisters or cracks }\end{array}$ \\
\hline $15-2(b)$ & 10 & $<0.3$ & $\begin{array}{l}\text { Both sides of specimen in very good shape; } \\
\text { no blisters or cracks }\end{array}$ \\
\hline $15-3(b)$ & 10 & -0.6 & $\begin{array}{l}\text { Both sides of specimen in very good shape; } \\
\text { no blisters or cracks }\end{array}$ \\
\hline $15-4(b)$ & 10 & $<0.3$ & $\begin{array}{l}\text { Both sides of specimen in very good shape; } \\
\text { no blisters or cracks }\end{array}$ \\
\hline $30-1^{(c)}$ & 30 & -7.1 & $\begin{array}{l}\text { Blisters on both sides opposite each other; } \\
\text { one blister showed signs of rupture }\end{array}$ \\
\hline $30-2(c)$ & 30 & -3.5 & $\begin{array}{l}\text { Prominent bulge on one side of specimen } \\
\text { only; slight swelling apparent on braze- } \\
\text { free area on both sides of specimen }\end{array}$ \\
\hline $10-5(b)$ & 30 & -4.8 & $\begin{array}{l}\text { Blister on both sides and opposite each } \\
\text { other; no evidence of rupture or cracks }\end{array}$ \\
\hline $24-1^{(b)}$ & 30 & -3.9 & $\begin{array}{l}\text { Blisters on both sides opposite each other; } \\
\text { one side had fine cracks at peak of blister; } \\
\text { no cracks on other side }\end{array}$ \\
\hline $24-2(b)$ & 30 & -9.0 & $\begin{array}{l}\text { Blisters on both sides opposite each other; } \\
\text { three radial cracks from one blister; no } \\
\text { cracks on other side }\end{array}$ \\
\hline $24-3(b)$ & 30 & -5.4 & $\begin{array}{l}\text { Blisters on both sides opposite each other; } \\
\text { four large radial cracks from one blister; } \\
\text { several fine cracks from blister on } \\
\text { opposite side }\end{array}$ \\
\hline
\end{tabular}

\footnotetext{
(a) Precision of density change, \pm 0.3 per cent.

(b) $\mathrm{UO}_{2}$ particle size, 15 to $44 \mu$.

(c) $\mathrm{UO}_{2}$ particle size, 53 to $105 \mu$.
} 
damage was not as severe as that observed in some similar Pratt \& Whitney specimens containing $30 \mathrm{w} / \mathrm{O} \mathrm{UO}_{2}$ that were irradiated at 1200 and $1400 \mathrm{~F}$ at burnups of 16 and 14 per cent of the uranium-235.

The central small specimen (Figure 13) at the bottom of the capsule showed the greatest density change, 9 per cent. The temperature of this specimen was higher by about $100 \mathrm{~F}$ than those in the middle of the capsule because of the higher fuel loading in this region. The $\mathrm{UO}_{2}$ particle size was also in the lower range for this specimen.

It is interesting to compare Specimens 30-2 and 10-5. Specimen 30-2 had the larger size of $\mathrm{UO}_{2}$ particles, a higher fuel loading, and probably operated at a slightly higher temperature than Specimen 10-5, which showed the greater density change. This indicates some advantage for the larger particle size.

The large change in density of Specimen 30-1 is difficult to explain when compared with Specimen 30-2. These specimens were identical with the exception that Specimen 30-2 probably operated at a slightly higher temperature and received a slightly lower burnup than Specimen 30-1. Specimen 30-1 showed twice the density change of Specimen 30-2.

These data confirm that $\mathrm{UO}_{2}$ cermets of the type used in these tests are not satisfactory at GCRE conditions if they contain $30 \mathrm{w} / \mathrm{O} \mathrm{UO}_{2}$ and receive a burnup of about 10 per cent. With these specimens it will be necessary to lower the burnup or the fuel loading to achieve GCRE conditions.

A continuing evaluation of $\mathrm{UO}_{2}$ cermets is under way in which lower loadings of $\mathrm{UO}_{2}, 20$ and $25 \mathrm{w} / \mathrm{o}$, and different fabrication techniques will be checked.

\section{Irradiation of GCRE Reference-Fuel Specimens}

Irradiation of fuel-element specimens fabricated from reference materials for the GCRE has been initiated. The specimens supplied for Capsule BMI-11-2 consist of clad flat plates having fuel cores, $0.060 \mathrm{in}$. thick, containing 20 and $25 \mathrm{w} / \mathrm{o}$ of 93 per cent enriched $\mathrm{UO}_{2}$ dispersed in an 18-8 stainless steel matrix compounded from the elemental powders. The specimens were clad with 0.005 in. of Type 347 stainless steel.

Capsule BMI-11-2 was designed to be placed in a flux of about $1.8 \times 10^{14} \mathrm{nv}$ for a period of four MTR cycles, or about 60 days, to achieve the desired temperatures, and a burnup of approximately 10 per cent of uranium-235 in the $25 \mathrm{w} / \mathrm{O}_{2} \mathrm{UO}_{2} \mathrm{specimens}$ desired.

This capsule was shipped to the MTR for charging in Cycle 80, starting December 17,1956 . As yet, the irradiation has not been completed. 
Evaluation of Alternate Fuels

Since there is a real possibility that the UO2-cermet fuel element may not be satisfactory for GCRE conditions, an irradiation-evaluation program for alternate fuels has been initiated. Capsules BMI-11-4, BMI-11-5, and BMI-11-6 are in the preliminary design stage, and each will contain two specimens composed of alternate fuel materials. Capsule BMI-11-4 will contain one molybdenum-20 w/o uranium and one molybdenum-25 w/o uranium specimen. Capsule BMI-11-5 will contain one niobium-20 w/o uranium and one niobium $-25 \mathrm{w} / \mathrm{o}$ uranium specimen, and Capsule BMI-11-6 will contain two $\mathrm{Zr}$ (0.75 to $1.00 \mathrm{w} / \mathrm{o}$ uranium) $\mathrm{H}_{1.6}$ specimens. The temperature and burnup for these three capsules have not yet been selected.

\section{Release of Fission Products From the Reference Fuel Element}

An important criterion for a satisfactory fuel element for the GCRE is fissionproduct containment during the service lifetime of the fuel element. Although no sound basis exists for a reliable estimate of fission-product release from the reference fuel element, a paper-and-pencil estimate of the accumulated fission-product radioactivity released to the coolant by thermal diffusion was made for 2-megawatt operation of the GCRE for 1 year. Thermal diffusion of fission products through the 5 -mil cladding of the reference fuel element at $1500 \mathrm{~F}$ was the only release mechanism assumed. Fission products other than bromine, iodine, krypton, and xenon were assumed to diffuse too slowly to make any significant contribution to the coolant activity. A diffusion constant of $10-10 \mathrm{~cm}^{2}$ per sec was assumed for all these species.

Steady-state diffusion of these fission products was estimated to release an accumulated amount of 6000 curies to the coolant. Of this amount, about 500 curies is gamma activity with an average energy less than $0.5 \mathrm{mev}$. Thus gamma activity is 500 times the estimated equilibrium argon-4l gamma activity produced by neutron capture in the nitrogen coolant. It is estimated that $48 \mathrm{hr}$ after reactor shutdown, and after a purge of the coolant gas, the total beta and gamma activity of the fission products deposited inside the coolant system will be 300 curies.

Long-term fission-product retention in nuclear fuels cannot be reliably evaluated at present in view of the very limited information available on the the rmal diffusion of fission products through fuel and cladding materials. A direct experimental program is needed to determine the rates of fission-product diffusion in these materials. 


\title{
NITROGEN-COOLANT STUDIES
}

\author{
D. L. Keller
}

In BMI-1133, the reasons for the choice of nitrogen as the GCRE gas coolant in preference to $\mathrm{CO}_{2}$ or air are discussed in some detail. It was explained that the choice of a solid hydride material as the reference moderator ultimately led to the choice of nitrogen as the coolant. Hydrogen would be present in the gas coolant either from diffusion or leaks through the walls of the moderator cladding or because it is deliberately added to prevent such losses. With hydrogen present in the coolant, the corrosion problem on the various component materials appeared easier to solve with nitrogen than either $\mathrm{CO}_{2}$ or air.

Hydrogen additions of about 7.5 volume per cent are equivalent to a hydrogen partial pressure of $1 \mathrm{~atm}$ at a total gas pressure of $200 \mathrm{psi}$. This is sufficient hydrogen to counterbalance the dissociation pressure of the moderator at estimated maximum temperatures. However, this leads to $\mathrm{NH}_{3}$ being present in the coolant gas, calculated to be approximately 1 volume per cent. Cracking of this $\mathrm{NH}_{3}$ on the metal surfaces would supply nascent nitrogen, accelerating nitriding. Also, radiation effects might create additional active nitrogen species.

Therefore, initial nitriding studies were carried out in 100 per cent $\mathrm{NH}_{3}$. When the se conditions proved to be too severe, nitrogen plus 1 volume per cent $\mathrm{NH}_{3}$ was tested. This condition also proved to be too severe for protecting 5 -mil fuel-element claddings. In most recent tests, small amounts of water vapor have been added to the diluted ammonia mixture and nitriding has been retarded. These studies are reported in the section "Resistance of Materials to Nitriding".

The effects of irradiation on nitriding and the thermodynamic considerations leading to the additions of water vapor to the reference gas mixture are treated in the final sections of this part of the report.

\section{Resistance of Materials to Nitriding}

H. J. Wagner, C. J. Slunder, and A. M. Hall

The purpose of this research is to determine the effect which the coolant gas will have on materials considered for use in the Gas Cooled Reactor Experiment. At present, the proposed coolant is a mixture containing 12.5 atm nitrogen and 1 atm hydrogen. However, it is possible that this mixture will be modified by additions of water vapor.

The probability of the presence of active species of nitrogen due to irradiation in the reactor made it necessary to determine the resistance of materials to atmospheres more aggressive than molecular nitrogen. Ammonia has been used commercially to nitride certain metals, and is known to react with metals at a much higher rate than does molecular nitrogen. This behavior has been attributed to the formation of nascent nitrogen on the metal surfaces. Consequently, ammonia was tentatively chosen as a 
suitable environment for screening a large number of materials. It was recognized, in making this choice, that the amount of nascent nitrogen reacting with the metal in an ammonia environment would be far greater than the amount of active species expected in the reactor. On the other hand, materials found to be completely resistant to this atmosphere would be expected to be resistant, as well, to molecular nitrogen containing active species. The metal temperature in the reactor is expected to be $1500 \mathrm{~F}$. Accordingly, 100-hr screening tests were conducted on selected materials at $1500 \mathrm{~F}$ in 100 per cent ammonia.

Calculations have been made to determine the concentration of ammonia formed under equilibrium conditions wherein the partial pressures of nitrogen and hydrogen are 12.5 and $1.0 \mathrm{~atm}$, respectively. An estimate of the concentration of active nitrogen species due to irradiation was also made. Based on the se calculations, an environment consisting of 1 volume per cent ammonia in nitrogen at atmospheric pressure was considered to be suitable for evaluating the resistance of materials to nitriding under conditions expected in the reactor. Consequently, supplementary tests were conducted in this environment on certain materials selected by screening tests in 100 per cent ammonia.

In previous work, which is described in BMI-1133, no materials were found which were completely resistant to 100 per cent ammonia at $1500 \mathrm{~F}$. A class of alloys containing 65 to $80 \mathrm{w} / 0$ nickel, namely Inconel, Nichrome V, and Nichrome, were found to be the most resistant of the alloys tested. In general, it was observed that the resistance to nitriding increased as the nickel content increased, up to about $80 \mathrm{w} / 0$ nickel. Alloys containing 80 to $100 \mathrm{w} / 0$ nickel were attacked at increasing rates as the nickel content increased.

Work during this period has been primarily directed toward (1) determining the rates at which the more promising materials nitride when exposed to 100 per cent ammonia for periods up to $500 \mathrm{hr}$, (2) determining the relative resistance of materials to nitriding in nitrogen plus 1 volume per cent ammonia, and (3) determining the relative resistance of additional materials to nitriding in 100 per cent ammonia in $100-\mathrm{hr}$ screening tests. Thermodynamic calculations, reported in a subsequent section, and experimental evidence from the Engineer Research and Development Laboratories, Fort Belvoir, Virginia, indicated that the presence of an oxidizing agent would retard or entirely prevent reactions of metals with nitrogen. Therefore, exploratory tests were made at Battelle to determine whether the addition of water vapor to nitrogen plus 1 per cent ammonia would prevent nitriding of certain materials.

\section{Tests in 100 Per Cent Ammonia}

Screening Tests. Various materials of interest were exposed to 100 per cent ammonia for $100 \mathrm{hr}$ at $1500 \mathrm{~F}$. These tests were used as a basis for determining the relative resistance of a wide variety of materials considered for use as structural components. The results of the tests are summarized in Tables 18 and 19 .

Table 18 shows the depths of observable nitrogen penetration for a number of metallic materials in which nitrides appeared after exposure to ammonia. The depths 
of penetration were determined by metallographic examination of the specimens after exposure. In general, "depth of penetration" is defined as a maximum depth below the surface of the exposed specimen at which nitrides, or perhaps carbonitrides, are visible at $500 x$ magnification. Since these tests were primarily for screening purposes, no correction was made for an increase in specimen thickness resulting from nitriding of the surface. Many of the data shown in Tables 18 and 19 were reported previously in BMI-1133, but are repeated here for completeness.

Most of the materials in Table 18 have been described in detail in BMI-1133. Generally, they formed hard cases consisting of complex mixtures of nitrides. Of the better materials, molybdenum and Alnicro were introduced into the investigation since the preparation of BMI-1133.

A number of metallic materials did not form visible nitrides when exposed to 100 per cent ammonia in the 100-hr screening tests. Two of these metals, namely silver and tungsten, showed no apparent changes resulting from these tests, although tungsten is reported in the literature as capable of forming stable nitrides. It is apparent from consideration of the neutron-capture cross-section of silver and tungsten that their usefulness as structural or fuel-element cladding materials is limited to either alloy additions or extremely thin protective coatings. The other materials in this group deteriorated through the formation of voids.

TABLE 18. DEPTH OF VISIBLE NITROGEN PENETRATION IN METALS IN WHICH NITRIDES APPEARED AFTER A 100-HR EXPOSURE TO AMMONIA AT $1500 \mathrm{~F}(\mathrm{a})$

\begin{tabular}{|c|c|c|c|c|c|c|}
\hline \multirow[b]{2}{*}{ Material } & \multicolumn{5}{|c|}{ Nominal Composition, w/o } & \multirow{2}{*}{$\begin{array}{c}\text { Depth of } \\
\text { Penetration, } \\
\text { mils }\end{array}$} \\
\hline & $\mathrm{Ni}$ & $\mathrm{Fe}$ & $\mathrm{Cr}$ & $\mathrm{Al}$ & Other & \\
\hline Molybdenum, hydrogen sintered & -- & -- & -- & -- & $100 \mathrm{Mo}$ & 0.3 \\
\hline Alnicro & Bal & -- & 20 & 4 & -- & 1.1 \\
\hline Driver-Harris 242 & Bal & -- & 20 & -- & $1 \mathrm{Si}, 1 \mathrm{Nb}$ & 1.5 \\
\hline Inconel $\mathrm{X}$, aged & $\mathrm{Bal}$ & 6 & 15 & 0.5 & $2.5 \mathrm{Ti}, 0.5 \mathrm{Nb}$ & 1.8 \\
\hline Nichrome V & $\mathrm{Bal}$ & -- & 20 & -- & -- & 2.0 \\
\hline Alumel & Bal & -- & -- & 2 & $1 \mathrm{Si}, 2.5 \mathrm{Mn}$ & 2.0 \\
\hline Inconel & Bal & 6 & 15 & -- & -- & 2.1 \\
\hline Inconel X, solution annealed & Bal & 6 & 15 & 0.5 & $2.5 \mathrm{Ti}, 0.5 \mathrm{Nb}$ & 2.5 \\
\hline Nichrome & 65 & Bal & 15 & -- & -- & 2.6 \\
\hline AISI 330 & 35 & Bal & 15 & -- & -- & 6.1 \\
\hline Incoloy & 35 & $\mathrm{Bal}$ & 20 & -- & -- & 6.9 \\
\hline AISI $310 \mathrm{~S}$ & 20 & Bal & 25 & -- & -- & 7. 7 \\
\hline Chromel P & $\mathrm{Bal}$ & -- & 10 & - & -- & 7.7 \\
\hline AISI 314 & 20 & $\mathrm{Bal}$ & 24 & -- & $\mathrm{Mn}, \mathrm{Si}$ & 8.5 \\
\hline AISI 347 & 8 & $\mathrm{Bal}$ & 18 & -- & $\mathrm{Nb}$ & 12.9 \\
\hline AISI 446 & -- & Bal & 25 & -- & -- & 14.9 \\
\hline $\mathrm{Fe}-\mathrm{Cr}-10 \mathrm{Al}$ & -- & $\mathrm{Bal}$ & 26 & 10 & -- & 16.0 \\
\hline $\mathrm{Fe}-\mathrm{Cr}-5 \mathrm{Al}$ & -- & Bal & 26 & 5 & -- & 19.2 \\
\hline
\end{tabular}

(a) Further data on molybdenum, Alnicro, Nichrome, Inconel, Incoloy, and AISI 347 are shown in Table 20. 
Table 19 summarizes the results of tests on structural and fuel-element-cladding material in which no nitrides were visible after exposure to ammonia for $100 \mathrm{hr}$ at $1500 \mathrm{~F}$.

TABLE 19. RESULTS OF EXPOSURE OF VARIOUS METALS IN WHICH NO NITRIDES WERE VISIBLE AFTER A 100-HR EXPOSURE TO 100 PER CENT AMMONLA AT $1500 \mathrm{~F}$

\begin{tabular}{|c|c|c|}
\hline Material & $\begin{array}{c}\text { Depth of } \\
\text { Attack, mils }\end{array}$ & Remarks \\
\hline Silver & $\mathrm{Nil}$ & -- \\
\hline Tung sten & $\mathrm{Nil}$ & -- \\
\hline OFHC copper & 0.7 & Subsurface voids \\
\hline Nickel, commercial, wrought & 7. 7 & Many voids \\
\hline Nickel, Watts electroplated & -- & $\begin{array}{l}\text { Entire plate ( } 4-5 \text { mils thick) deteri- } \\
\text { orated by void deformation }\end{array}$ \\
\hline $\begin{array}{l}\text { Nickel, sulfamate, electro- } \\
\text { plated }\end{array}$ & -- & $\begin{array}{l}\text { Entire plate ( } 2 \text { mils thick) deteri- } \\
\text { orated by void deformation }\end{array}$ \\
\hline $\begin{array}{l}\text { Driver-Harris } 33 \\
(97 \mathrm{w} / 0 \mathrm{Ni}-3 \mathrm{w} / 0 \mathrm{Si})\end{array}$ & 12.5 & Void formation \\
\hline Monel & -- & $\begin{array}{l}\text { Entire specimen ( } 50 \text { mils thick) } \\
\text { deteriorated by void formation }\end{array}$ \\
\hline
\end{tabular}

Rates of Nitriding. In addition to the 100-hr tests on materials described in Tables 18 and 19, further work was done to determine the rate of nitriding of a number of materials of interest. These materials were AISI 347, Alnicro, Incoloy, molybdenum, Nichrome, and Nichrome V. The depths of observable nitrogen penetration were recorded for individual specimens of these materials which had been exposed to 100 per cent ammonia at $1500 \mathrm{~F}$ for various lengths of time up to $500 \mathrm{hr}$. The results of these tests are shown graphically in Figure 14. With very few exceptions, the points on these curves are the averages of at least two separate determinations on specimens run in individual tests.

Figure 14 shows that the depth of visible nitrogen penetration may be expressed by a parabolic rate law as follows:

$$
\mathrm{P}=\mathrm{kt} \mathrm{t}^{1 / 2}+\mathrm{C}
$$

where $P$ is the depth of visible nitrogen penetration in mils, $t$ is the time in hours, and $\mathrm{k}$ and $\mathrm{C}$ are constants for a particular material. Values of $\mathrm{k}$ and $\mathrm{C}$ for various materials are tabulated in Table 20. These constants apply within the range 15 to $500 \mathrm{hr}$. The points on the curve show some downward trend, but the experimental variation was too large to justify drawing curved lines through the points. Since there is a downward trend, however, the constants can probably be used to give conservative estimates of the depth of penetration at longer times of exposure to 100 per cent ammonia. 


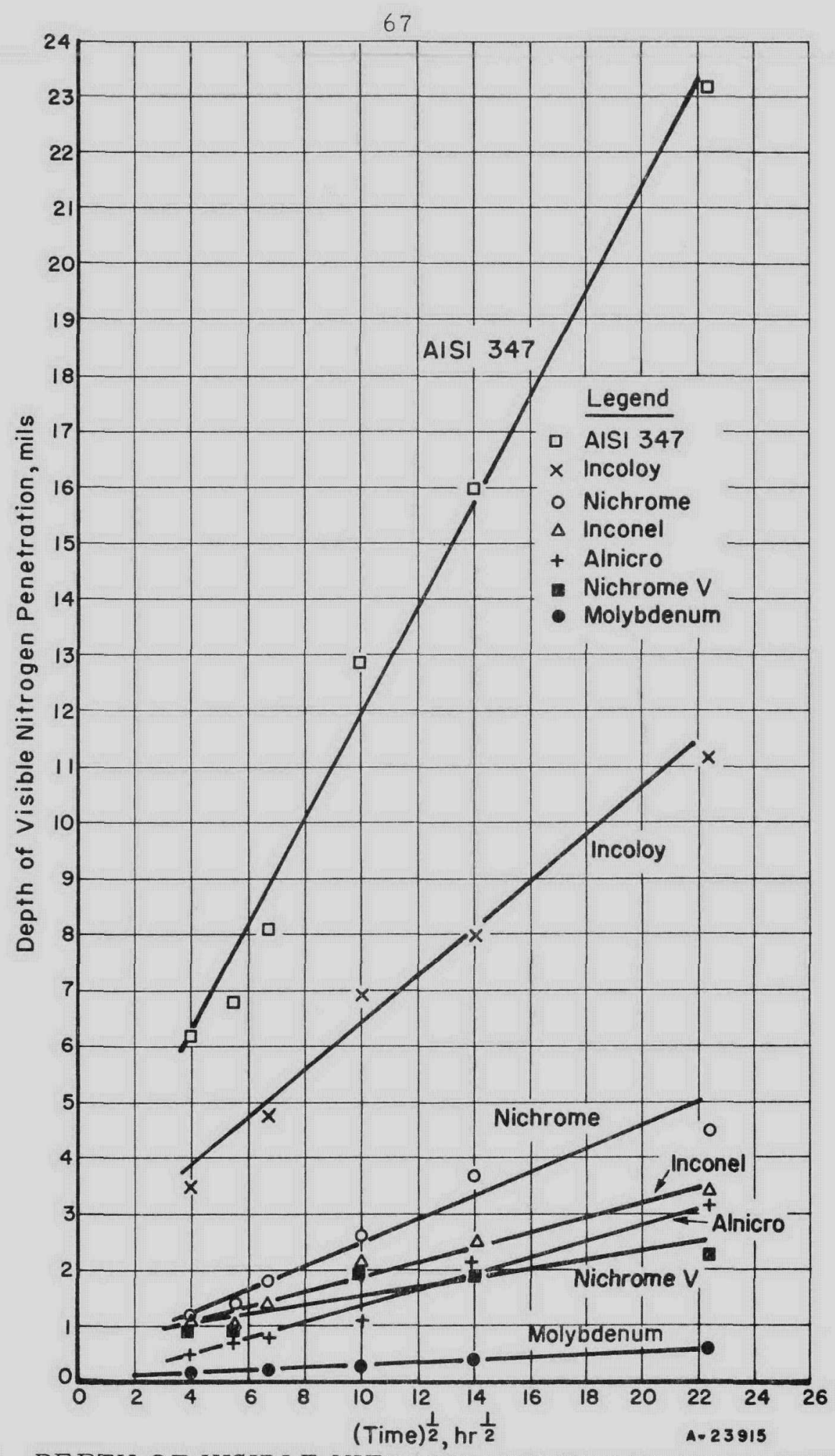

FIGURE 14. DEPTH OF VISIBLE NITROGEN PENETRATION AS A FUNCTION OF (TIME) $1 / 2$ FOR VARIOUS MATERIALS EXPOSED TO 100 PER CENT AMMONIA AT $1500 \mathrm{~F}$ 
TABLE 20. RATE-LAW CONSTANTS FOR VARIOUS MATERIALS EXPOSED TO 100 PER CENT AMMONIA FOR 15 TO 500 HR AT $1500 \mathrm{~F}$

\begin{tabular}{lcc}
\hline \multicolumn{1}{c}{ Material } & $\mathrm{k}$, mils per $\mathrm{hr}^{1 / 2}$ & $\mathrm{C}, \mathrm{mils}$ \\
\hline AISI 347 & 0.95 & 2.5 \\
Incoloy & 0.42 & 2.2 \\
Nichrome & 0.21 & 0.4 \\
Inconel & 0.13 & 0.5 \\
Alnicro & 0.14 & -0.2 \\
Nichrome V & 0.081 & 0.7 \\
Molybdenum & 0.025 & 0.05 \\
\hline \hline
\end{tabular}

Adherence to a parabolic rate law indicates that nitrogen penetration in the materials is a diffusion-controlled phenomenon. Within the limits of experimental error, only molybdenum and Alnicro have intercepts through the origin. This would indicate that the rate-controlling factor was not fully established in the other materials for a measurable length of time, while in Alnicro and molybdenum the rate-controlling factor was rapidly established.

Metallographic examination of the specimens wherein one component of the alloy nitrided to form particles embedded in a matrix indicated that the rate-controlling factor after the initial period was probably diffusion through the metal nitride, whereas during the initial period diffusion through the alloy matrix itself was most important. This was deduced from the observation that the nitrides became larger, and occupied a larger proportion of the immediate subsurface layers with increasing time exposure. Possibly, the continual changes in the nature and amount of nitride in the surface layer contributed to the apparent downward trend of the points on the curves.

In Alnicro it was observed that the chromium nitride formed in a more continuous layer than in the other alloys, thereby limiting the diffusion rate at an earlier stage in the nitriding than if discreet particles had formed. Likewise, in molybdenum, the nitride which formed was smooth and even. It appears that diffusion through this nitride was very slow compared to the other materials.

It was observed, however, that although molybdenum was not deeply penetrated by nitrides it showed low bend ductility. This may have resulted from either notch sensitivity or absorption of nitrogen not visible by metallographic examination. In the bending of nitrided molybdenum the hard nitride cracks and results in an extremely sharp notch at the boundary between the nitride and the base metal. This would have an important influence on the ductility. To determine the influence of notch sensitivity on the ductility of the nitrided molybdenum, a specimen which had previously shown negligible ductility was ground to remove the nitride layer. The ground specimen was then bent, and showed as good ductility as the original molybdenum. 
It appears that further work should be done to determine the feasibility of using molybdenum in the GCRE. It would be necessary to know, for instance, how mechanical properties are affected by the coolant gas. It would also be necessary to know whether high ammonia concentration is required for the establishment of a protective nitride layer.

$\underline{\text { Tests in Nitrogen + One Volume Per Cent Ammonia }}$

After it became apparent that only silver and tungsten were completely resistant to the action of 100 per cent ammonia at $1500 \mathrm{~F}$, an atmosphere containing a lower percentage of active nitrogen was considered. Thermodynamic calculations and estimates of the amount of active species of nitrogen expected in the reactor resulted in the choice of a testing environment containing one volume per cent ammonia in nitrogen. First tests in this environment showed a marked decrease in both the depth and severity of nitriding. For instance, $\mathrm{Fe}-\mathrm{Cr}-5 \mathrm{Al}$, which had been nitrided in 100 per cent ammonia to a depth of about 19 mils was nitrided in the dilute ammonia atmosphere to. a depth of only 5 mils. Furthermore, the "case" consisted of aluminum nitride needles only after nitriding in dilute ammonia, whereas the "case" had consisted of complex mixed aluminum and chromium nitrides after nitriding in 100 per cent ammonia. Other materials, namely, Nichrome V, Nichrome, Incoloy, and AISI Types 347, 314, $310 \mathrm{~S}$, and 330 stainless steels, showed no apparent attack in the dilute ammonia atmosphere.

Inconel, however, showed a 1.9-mil depth of case in one of the tests. Possible reasons for the apparently anomolous behavior of Inconel are differences in surface condition, impurities in the gas mixture which protected certain specimens, and ammonia concentration differences.

It was observed in a separate experiment, that, when ammonia concentrations were lower than 1 volume per cent, nitriding was dependent upon the ammonia concentration. Specifically, Inconel nitrided to a depth of $3.2 \mathrm{mils}$ in $500 \mathrm{hr}$ at $1500 \mathrm{~F}$ when the ammonia concentration was 0.3 to 1.0 volume per cent. At lower concentrations, however, the nitriding became spotty and occurred in only random areas. At the points where nitriding had occurred, the depth was the same as it was in Inconel nitrided in atmospheres containing 0.3 to 1.0 volume per cent ammonia concentrations. In addition, the depths of penetration were similar to those observed in Inconel which had been exposed to 100 per cent ammonia for the same periods of time.

Although AISI 347 had shown no attack in the first tests, subsequent tests showed that up to 8 mils of a complex case could result after $500-\mathrm{hr}$ exposure to atmospheres containing 0.3 to 1.0 volume per cent ammonia. This depth of penetration was about 30 per cent of the depth observed in this alloy exposed to 100 per cent ammonia for the same period of time. At ammonia concentrations lower than 0.3 volume per cent, the only manifestation of nitrogen in the surface layers was a fine second phase visible to a depth of 3 mils.

The reasons for the difference in behavior between Inconel and AISI 347 in dilute ammonia as compared with their behavior in 100 per cent ammonia may be related to the impurity content of the gaseous environment. For instance, if the oxygen content were such as to form a film on AISI 347 which was protective against nitriding, the more oxidation-resistant Inconel may not have been sufficiently oxidized to influence nitriding characteristics. 
Tests in Nitrogen Plus 1 Volume Per Cent Ammonia Plus Water Vapor

Recent work at the Engineer Research and Development Laboratories (ERDL) indicated that $1 / 2$ volume per cent oxygen in nitrogen might prevent AISI Type 347 stainless from absorbing nitrogen at $1600 \mathrm{~F}$. Inconel, on the other hand, showed little difference in behavior in nitrogen and in nitrogen containing $1 / 2$ volume per cent oxygen.

The addition of oxygen to the proposed coolant gas was therefore considered as a means of preventing nitriding. However, since hydrogen was to be present, water vapor was chosen as a possible oxidizing agent. Thermodynamic calculations we re made which showed the feasibility of preventing nitride formation through preferential oxide formation by the addition of small water-vapor concentrations to the nitrogen-1 volume per cent ammonia mixtures. Tests were then commenced at Battelle to study the effect which the addition of water vapor to the gas mixture would have on the nitriding characteristics of certain alloys, particularly Type 347 stainless and Inconel.

In the first experiment, the water-vapor concentration was approximately 0.05 per cent by volume. It was observed that after a 500-hr exposure at $1500 \mathrm{~F}$, Inconel was nitrided when the concentration of ammonia was 1 volume per cent, but that, at lower concentrations, no nitriding had occurred. In specimens of Type 347 stainless, however, the depth and quantity of nitriding in the water-containing atmosphere was much less than had been observed in the dry atmosphere, even at the 1 volume per cent ammonia concentration. It was observed that nitrides had formed to a depth of $3 \mathrm{mils}$ in some areas, but that generally the quantity of this phase was lower than in dry ammonia-containing atmospheres.

In a second test, specimens of Type 347 stainless, Incoloy, Inconel, Alnicro, Nichrome, and Nichrome $\mathrm{V}$ were exposed to a mixture of nitrogen-1 volume per cent ammonia-0.3 volume per cent water vapor for $500 \mathrm{hr}$ at $1500 \mathrm{~F}$. Metallographic examination showed that Type 347 stainless, Nichrome, and Nichrome V were not generally nitrided, but were covered with an oxide layer about $0.03 \mathrm{mil}$ in thickness. In certain areas of the specimen, however, spotty nitriding had occurred where the surface had not been thoroughly cleaned at the start of the test.

Incoloy, although not visibly nitrided, had been intergranularly oxidized to a depth of about $0.3 \mathrm{mil}$ below the surface, and had an oxide layer approximately $0.1 \mathrm{mil}$ in thickness. The Alnicro specimen showed voids which penetrated to 0.3 mil below the surface. Some aluminum nitride was visible among the voids.

The Inconel specimen was seriously attacked to a depth of 2 to 3 mils. The surface layers showed the presence of both nitrides and oxides. Their appearance suggested that depletion of chromium by nitriding had made the nickel-rich component susceptible to oxidation. It is not known why this had not occurred in the metallurgically similar Nichrome or Nichrome V. It appears from these results that Inconel is not amenable to protection from nitriding by the presence of an oxidizing ing redient in the gas. This may explain the apparently anomalous behavior of Inconel in the earlier tests in dry atmospheres containing 1 volume per cent ammonia. Since Inconel, at that time, showed attack, while most of the other alloys did not show any nitriding, it appears that the atmosphere in the first test was slightly contaminated with an agent, which formed a protective film on the other alloys.

CONFIDENTIAL 
In a third test, specimens of both Inconel and Type 347 stainless were exposed to nitrogen-1 volume per cent ammonia-0.3 volume per cent water vapor for $250 \mathrm{hr}$ at $1500 \mathrm{~F}$. These specimens, which measured $1 / 2$ by 6 by $0.110 \mathrm{in}$. were bent $180 \mathrm{deg}$ around a radius less than the thickness of the metal. Both the Inconel and the Type 347 stainless showed good ductility in this test.

As a result of these tests, it appears that the addition of small amounts of water vapor to the nitrogenous atmospheres can prevent nitriding of some alloys without causing excessive oxidation.

$\underline{\text { Prevention of Nitriding by Electroplating }}$

With regard to the prevention of nitriding, it has been suggested that electroplated or other coatings might be effective in preventing access of nitrogen to the specimen surface. To be effective in this regard, it would be necessary for the coating to be not only immune to nitriding, but also to be impermeable to nitrogen.

Since it had been observed previously that silver and copper were not nitrided in 100 per cent ammonia, these metals were electroplated on Inconel and Types 347 and 403 alloys. The plated specimens were then exposed to 100 per cent ammonia for $100 \mathrm{hr}$ at $1500 \mathrm{~F}$. The results of this test indicated that nitriding could be prevented by coating with a material which does not form a stable nitride. It appears also that materials which do not form stable nitrides are likewise impermeable to nitrogen. Some caution must be exercised, however, in the application of these coatings, as it was found that, where the coating was not adherent, nitriding had occurred. Furthermore, where the coating was particularly compatible with the base metal, as copper on Inconel, some diffusion had occurred. It is questionable when diffusion occurs between the base metal and the coating whether continued protection would result after long exposures at $1500 \mathrm{~F}$.

\section{Control Materials}

Several materials of interest as control rods were subjected to 100 -hr screening tests in 100 per cent ammonia at $1500 \mathrm{~F}$. These materials were either cobalt and cobalt-base alloys or cermets containing samarium and gadolinium oxides dispersed in cobalt and cobalt-alloy binders.

It was found that cobalt deteriorated through the formation of voids, in a manner similar to the deterioration of nickel. Various grades of cobalt were used, and these showed voids penetrating below the surface of the specimen to a depth of as much as 9 mils.

Haynes 25, a cobalt-base alloy containing chromium, nickel, and tungsten, developed a nitride case to a depth of 2.1 mils.

In the cermets, the type of attack of the binder component was either by formation of voids or formation of a nitride case, depending on whether the binder was cobalt, or a cobalt alloy containing a nitridable component. The cobalt used in the cermets 
showed better resistance to the ammonia atmosphere than any of the other commercial cobalt samples previously tested. In addition, all the cermets showed better resistance to the ammonia than did the pure binder component. The results of $100-\mathrm{hr}$ tests in 100 per cent ammonia at $1500 \mathrm{~F}$ are summarized in Table 21.

TABLE 21. DEPTH OF ATTACK OF VARIOUS CERMETS EXPOSED IN 100 PER CENT AMMONIA FOR 100 HR AT 1500 F

\begin{tabular}{|c|c|c|c|c|}
\hline \multicolumn{2}{|c|}{ Composition, w/o } & \multicolumn{2}{|c|}{ Particle Size, mesh } & \multirow{2}{*}{$\begin{array}{c}\text { Depth } \\
\text { of Attack, } \\
\text { mils }\end{array}$} \\
\hline Binder & $\begin{array}{l}\text { Sm and Gd } \\
\text { Oxides }\end{array}$ & Binder & $\begin{array}{l}\mathrm{Sm} \text { and } \mathrm{Gd} \\
\text { Oxides }\end{array}$ & \\
\hline $100 \mathrm{Co}$ & 0 & -325 & -- & 2.9 \\
\hline $90 \mathrm{Co}$ & 10 & -325 & -325 & 1.0 \\
\hline $90 \mathrm{Co}$ & 10 & -325 & -100 to +140 & 2.7 \\
\hline $80 \mathrm{Co}$ & 20 & -325 & -325 & 0 to 0.5 \\
\hline $70 \mathrm{Co}$ & 30 & -325 & -100 to +270 & 3.9 \\
\hline $\begin{array}{l}90 \text { Stellite } 31 \text { ( } 25 \mathrm{Cr} \text {, } \\
10 \mathrm{Ni}, 8 \mathrm{~W} \text {, bal Co) }\end{array}$ & 10 & -100 & -100 to +270 & 0.9 \\
\hline 90 Haynes 25 & 10 & -325 & -100 to +270 & 1.2 \\
\hline $\begin{array}{l}(25 \mathrm{Cr}, 10 \mathrm{Ni}, 10 \mathrm{~W} \\
\text { bal Co) }\end{array}$ & & & -100 to +140 & 1.5 \\
\hline
\end{tabular}

The data on cermets with a cobalt binder are shown graphically in Figure 15 . Increased percentages of fine-particle-size oxides resulted in increased resistance to attack by ammonia. This was not the case with coarse-particle-size oxides. Metallographically, it was observed that the coarse-oxide particles were very porous, leading to high depths of penetration when the particle was at the specimen surface. Furthermore, the particles were spaced farther apart, so their influence on the cobalt binder would be expected to be less than if they were finely dispersed throughout the cobalt.

Further work would be required to determine the optimum percentage of oxides and their particle size from both a nitriding as well as a mechanical-strength point of view.

\section{Conclusions}

On the basis of the investigations on the resistance of materials to nitriding at $1500 \mathrm{~F}$, the following conclusions have been reached:

(1) The most promising materials for use in nonoxidizing ammonia-containing atmospheres as structural or fuel-element components are Alnicro, Nichrome V, Inconel, and molybdenum. 


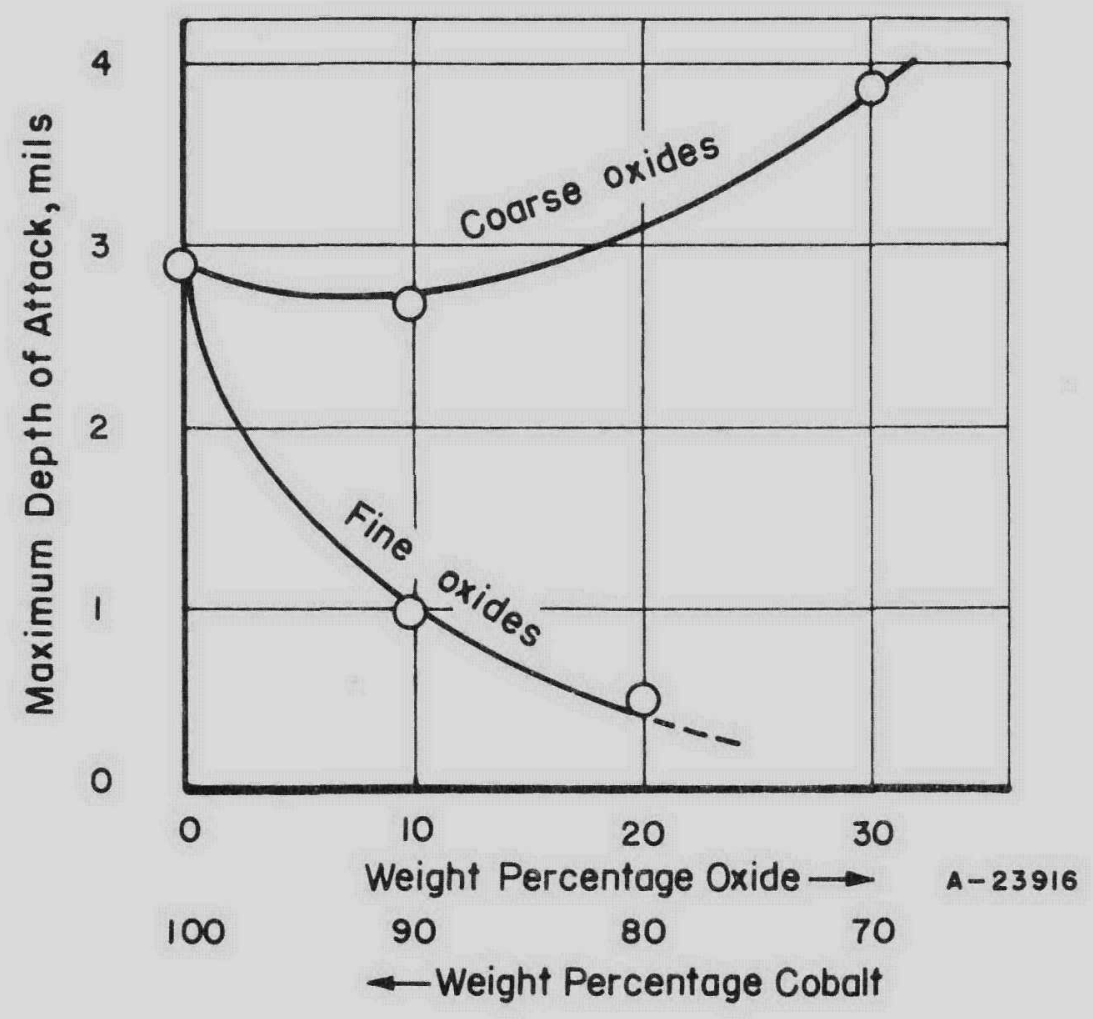

FIGURE 15. DEPTH OF ATTACK AS A FUNCTION OF CERMET COMPOSITION FOR VARIOUS COBALT + GADOLINIUM AND SAMARIUM OXIDE CERMETS WHICH WERE EXPOSED TO 100 PER CENT AMMONIA FOR 100 HR AT $1500 \mathrm{~F}$ 


\section{CONFIDENTIAL}

(2) The severity of nitriding appears to be reduced in Type 347 stainless steel, and not greatly changed in Inconel, when small amounts of water vapor are added to the nitrogenous atmosphere.

(3) Materials which do not form stable nitrides, such as silver and copper, are capable of protecting materials which nitride readily.

(4) The most promising control material was found to be cermet containing $80 \mathrm{w} / 0$ cobalt and $20 \mathrm{w} / 0$ samarium and gadolinium oxides. The highest resistance to nitriding was observed in this material when the particle size of the oxides was below 325 mesh.

\section{Radiation-Induced Nitriding}

W. S. Diethorn, P. Schall, and G. D. Calkins

As a part of the program to determine the effect of radiation on the nitriding behavior of GCRE metals in a radiation field, nitriding tests in the MTR Gamma Facility were conducted in nitrogen and an ammonia-nitrogen mixture. Prior to the radiation tests, duplicate tests in the absence of radiation were run at Battelle. All nitriding tests have been completed. The test conditions and results are presented below.

Initially an operating gas pressure of 200 psi was proposed for the nitriding tests. Preliminary experiments showed, however, that a high flow rate of dilute ammonia would be required to prevent 100 per cent the rmal cracking of the ammonia at 200 psi under the temperature conditions of the test. Accordingly, the gas pressure in the dilute-ammonia test was reduced to $100 \mathrm{psi}$, so that the available supply of dilute ammonia would be adequate for a 100-hr test. The pure nitrogen test was run at this lower pressure also.

The proposed length of the irradiation and nonirradiation tests and the method of measuring the thickness of the nitride layers were also changed in view of the high rate of nitriding observed in other experiments on GCRE metals. One hundred-hour tests were considered adequate for all the proposed tests in the radiation-effects program. Standard methods of microscopy were used to examine the test specimens in all the tests. These two changes in experimental procedure reduced both the time and cost of the irradiation-effects program.

\section{Nitriding Tests in the Absence of Radiation}

Nitriding tests in the absence of radiation were conducted in a flow system at 100 psia. Each test consisted of a 100-hr exposure of three specimens of six different metals. Three specimen temperatures in the range of 1000 to $1500 \mathrm{~F}$ were selected for both tests. Continuous monitoring of each of the three the rmocouples located at the three specimen positions indicated that the temperature of each of the three specimen positions did not vary more than $20 \mathrm{~F}$ during the tests. 
Matheson prepurified nitrogen and a prepurified nitrogen-1 volume per cent $\mathrm{NH}_{3}$ mixture were used for the nitriding tests. These gases were not purified further before use. Since no oxide layers were observed on the nitrided specimens, oxygen impurity in these gases was not believed to interfere with the interpretation of the test results.

In the dilute-ammonia tests, the specimens were actually exposed to a concentration of ammonia considerably less than 1 volume per cent because ammonia partially dissociated at the high-temperature conditions of the tests. Periodic sampling of the exit-gas stream during the 100-hr tests showed that the minimum ammonia concentration of the gas in contact with the specimens was 0.2 volume per cent.

Metal specimens $1 / 2$ by $1 / 16$ in. were exposed to the gases in the nitriding tests. These specimens were cut from as-received fabricated sheet stock and were not heat treated or pickled prior to surface grinding. One side of each specimen was rough ground and finished with 600-mesh grinding paper (ground). The same surface treatment was repeated on the other side, but in addition, this surface was polished on a wheel with alumina to a good mirror finish (polished). These surface preparations did not remove more than 1 to 2 mils from the specimen surface. Both sides of each specimen were exposed to flowing gas during the nitriding tests.

Test specimens exposed to dilute ammonia and pure nitrogen had the same general appearance. All specimen surfaces exhibited a black to gray coloration. The most uniform surface colorations were observed on the highest temperature specimens.

The specimens were examined by optical microscopy only. Two different types of microstructure, presumably nitrides, were observed. Type A was characterized by a dense region of complex nature below the specimen surface. Two distinct phases were often present. Type $B$ was characterized by a loosely packed layer in the specimen subsurface. Definite spatial orientation of these precipitates was evident.

The results of the nitriding tests in pure nitrogen and in nitrogen-1 volume per cent $\mathrm{NH}_{3}$ are presented in Tables 22 and 23 . A single value for the depth of the visible nitride layer is quoted when the layer was nearly uniform over the specimen. When the depth of the nitride layer varied on a single specimen, a range of values is reported.

\section{Nitriding Tests in the Presence of Radiation}

Specimen preparation, gas pressure, and flow rate were the same in the $100-\mathrm{hr}$ radiation tests. Within the temperature uncertainty quoted in the nonirradiation tests, the thermocouple temperatures in the dilute-ammonia test were identical to those in the nonirradiation test. The lowest and intermediate temperatures were about $70 \mathrm{~F}$ higher in the radiation test than in the nonirradiation test with pure nitrogen.

Dose-rate measurements conducted by MTR personnel indicated that all specimens in any test received the same radiation dose within \pm 10 per cent. The average $100-\mathrm{hr}$ air dose at the specimen positions in the dilute ammonia test was estimated to be $3 \times 10^{8} \mathrm{rep}$. In the pure-nitrogen test, the average $100-\mathrm{hr}$ air dose was 26 per cent lower. 
The nature and amount of nitriding observed in the radiation tests were similar to those reported in Tables 22 and 23 for the nonirradiation tests. There is, therefore, no need to tabulate the test results here. A difference in the behavior of Inconel and a single Type 347 stainless specimen was observed, however. The Inconel nitrided more heavily in the radiation tests than in the nonirradiation tests. In the pure nitrogen test the Type 347 specimen at the intermediate temperature did not nitride.

In view of the qualitative agreement between the result of the irradiation and nonirradiation tests, the differences in behavior between Inconel and the Type 347 stainless steel are not considered significant. Furthermore, it is now apparent that radiationinduced nitriding of the specimens is much smaller than the the rmally induced nitriding which occurs at the temperature conditions of the tests. Any specific effects of radiation on the nitriding of GCRE metals in the se tests were, therefore, masked by the the rmally induced nitriding.

\section{Conclusions}

The experimental results show that the radiation-induced nitriding of GCRE metals in a $100-\mathrm{hr}$ test at temperatures of 1000 to $1500 \mathrm{~F}$ is much less than the thermally induced nitriding which occurs at these temperatures. Specific radiation effects are either absent or masked by thermally induced nitride formation.

In the dilute-ammonia tests, all GCRE metals nitrided appreciably in $100 \mathrm{hr}$ at 1000 to $1500 \mathrm{~F}$. All GCRE metals nitrided to some extent at $1140 \mathrm{~F}$ in pure nitrogen. The qualitative temperature-nitride relationships were the same in both the diluteammonia and pure-nitrogen tests. In all the tests, surface conditions on a given specimen influence nitriding. For this reason, the unusual nitriding-temperature relationship observed for Inconel and Type 347 stainless in the dilute-ammonia test, and the differences in the pure-nitrogen tests, previously discussed, are probably not significant.

Battelle nitriding tests reported in previous monthly reports indicated that all the se GCRE metals, except Inconel and Type 347 stainless, did not nitride in nitrogen-1 volume per cent $\mathrm{NH}_{3}$ at a 1 -atm pressure at $1500 \mathrm{~F}$. The higher total gas pressure used in the tests reported here is not believed to account for the observed difference in nitriding behavior in this and the previous Battelle tests. The inconsistency may be the result of subtle experimental factors which are difficult to control and reproduce. Additional nitriding tests are needed to define these factors.

All the specimens tested in both gas atmospheres showed edge effects not specifically reported in Tables 22 and 23 or discussed in previous paragraphs. Nitride layers on the edges of the specimens often differed in depth and microstructure from the nitride found below the specimen surfaces. These edge effects may be the results of specific surface conditions characteristic of the cutting operation used during specimen fabrication.

Completion of these tests concludes the current program of study on the nitriding of GCRE metals in a radiation field. If the presence or absence of a real radiation effect is to be clearly defined in future irradiation tests, it is apparent that irradiation 

TABLE 22. VISIBLE PENETRATION OF NITROGEN IN GCRE METALS EXPOSED TO NITROGEN-1 VOLUME PER CENT $\mathrm{NH}_{3}$ FOR $100 \mathrm{HR}(\mathrm{a})$

\begin{tabular}{|c|c|c|c|c|}
\hline & & $\begin{array}{r}\text { Thicknes } \\
\text { After Exp }\end{array}$ & $\begin{array}{l}\text { nils, and Microst } \\
\text { re at Indicated Te }\end{array}$ & $\begin{array}{l}\text { ture Type } \\
\text { erature }(b)\end{array}$ \\
\hline Material & Surface & $1030 \mathrm{~F}$ & $1370 \mathrm{~F}$ & $1510 \mathrm{~F}$ \\
\hline Nichrome V & Ground & $1, \mathrm{~A}$ & 0.3 to $1.2, \mathrm{~A}$ & 0.3 to $1.2, \mathrm{~A}$ \\
\hline & Polished & $1, \mathrm{~A}$ & 0.3 to $1.2, \mathrm{~A}$ & 0.3 to $1.5, \mathrm{~A}$ \\
\hline Inconel & Ground & $1.3, \mathrm{~A}$ & $\mathrm{Nil}$ & $\mathrm{Nil}$ \\
\hline & Polished & 1. 3, spotty & 1. 5, very spotty & $\mathrm{Nil}$ \\
\hline Type 347 stainless & Ground & $\mathrm{Nil}$ & $0.3, \mathrm{~A}$ & 1.5 to $2.5, \mathrm{~A}$ \\
\hline & Polished & $10, \mathrm{~A}$ & $11, \mathrm{~A}$ & 5 to $12.5, A$ \\
\hline Type 330 stainless & Ground & 2.7 to $3.3, \mathrm{~A}$ & 4.5 , spotty, A & 4 to $6, \mathrm{~A}$ \\
\hline & Polished & 2.7 to $3.3, \mathrm{~A}$ & $4.5, \mathrm{~A}$ & $6, \mathrm{~A}$ \\
\hline Type 310 stainless & Ground & $2, \mathrm{~A}$ & $1.2, \mathrm{~A}$ & $3.5, \mathrm{~A}$ \\
\hline & Polished & 1.5 to $2.5, \mathrm{~A}$ & $6, A$ & $9, \mathrm{~A}$ \\
\hline Type 446 stainless & Ground & 7 to $10, A$ & $13, \mathrm{~B}$ & $30, \mathrm{~B}$ \\
\hline & Polished & $15, \mathrm{~A}$ & $10, \mathrm{~B}$ & $30, \mathrm{~B}$ \\
\hline
\end{tabular}

(a) Effective ammonia concentration in contact with specimens was estimated to be greater than 0.2 volume per cent.

(b) Type A was characterized by a dense region of complex nature below the specimen surface. Type B was characterized by a loosely packed layer in the specimen subsurface, 
TABLE 23. VISIBLE PENETRATION OF NITROGEN IN GCRE METALS EXPOSED TO PURE NITROGEN FOR $100 \mathrm{HR}$

\begin{tabular}{|c|c|c|c|c|c|}
\hline \multirow[b]{2}{*}{ Material } & \multirow[b]{2}{*}{ Surface } & \multicolumn{4}{|c|}{$\begin{array}{l}\text { Thickness, mils, and Microstructure Type } \\
\text { After Exposure at Indicated Temperature(a) }\end{array}$} \\
\hline & & $1140 \mathrm{~F}$ & & $1370 \mathrm{~F}$ & $1500 \mathrm{~F}$ \\
\hline \multirow[t]{2}{*}{ Nichrome V } & Ground & $\mathrm{Nil}$ & & 0.3 to $1, \mathrm{~A}$ & 0.6 to $1.5, \mathrm{~A}$ \\
\hline & Polished & $\mathrm{Nil}$ & & 0.1 to $1, \mathrm{~A}$ & 0.6 to $1.5, \mathrm{~A}$ \\
\hline Inconel & $\begin{array}{l}\text { Ground } \\
\text { Polished }\end{array}$ & $<0.1^{\text {(b) }}$ & & $<0.1^{(b)}$ & 0.6 \\
\hline \multirow[t]{2}{*}{ Type 347 stainless } & Ground & $\mathrm{Nil}$ & & 1.2 to $3, \mathrm{~A}$ & $\mathrm{Nil}$ \\
\hline & Polished & Nil & & 1 to $1.8, A$ & $5, A$ \\
\hline \multirow[t]{2}{*}{ Type 330 stainless } & Ground & Nil & - & $2, B$ & $2, \mathrm{~B}$ \\
\hline & Polished & $\mathrm{Nil}$ & & $1.2, \mathrm{~B}$ & $4, \mathrm{~B}$ \\
\hline \multirow[t]{2}{*}{ Type 310 stainless } & Ground & $<0.2, \mathrm{~B}$ & & $2.5, \mathrm{~B}$ & $5, \mathrm{~B}$ \\
\hline & Polished & $\mathrm{Nil}$ & & $2.5, \mathrm{~B}$ & $5, B$ \\
\hline \multirow[t]{2}{*}{ Type 446 stainless } & Ground & 0.3 , spotty, & A & $10, \mathrm{~A}$ & $23, \mathrm{~A}$ \\
\hline & Polished & $\mathrm{Nil}$ & & $10.5, \mathrm{~A}$ & $45, \mathrm{~A}$ \\
\hline
\end{tabular}

(a) Type A was characterized by a dense region of complex nature below the specimen surface. Type B was characterized by a loosely packed layer in the specimen subsurface.

(b) Subsurface-void formation on all specimens; nitride layer was not readily identified nor measured accurately. 
tests should not be conducted until it has been shown that thermally induced nitriding is small. The entire problem of nitriding in a radiation field is now being reviewed. Further irradiation tests will not be scheduled until thermally induced nitriding has been minimized in the gas-metal systems of interest.

\section{The rmodynamic Conside rations}

J. J. Ward

The nitriding of GCRE candidate metals might be substantially reduced by the formation of an oxide film on the metal surfaces functioning as a barrier to nitrogen diffusion. More encouraging would be the realization that nitriding could be completely prevented by the addition of a small amount of oxidizing agent to the gas coolant, creating an environment in which the metal nitrides were not thermodynamically stable. In such an event, an improvement would be realized only if the resulting oxidation were substantially less than the nitriding which has occurred in previous tests.

Therefore, the question arose as to the equilibrium partial pressure of water vapor required to stabilize an oxide layer against nitride formation, and whether this partial pressure of water would be oxidizing to the metal. The required equilibrium partial pressure of $\mathrm{H}_{2} \mathrm{O}(\mathrm{g})$ was computed by means of the rmodynamic considerations. The method of computation and a discussion of its limitations and assumptions are given below. The results of the equilibrium calculations are tabulated in Tables 24 and 25. A compilation of fundamental data are given in Table 26.

In Table 24, the action of steam on a metal nitride at $1500 \mathrm{~F}$ is compared with that of steam on the metal according to the reactions:

$$
\begin{aligned}
& \mathrm{MN}(\mathrm{c})+3 / 2 \mathrm{H}_{2} \mathrm{O}(\mathrm{g}) \rightarrow 1 / 2 \mathrm{M}_{2} \mathrm{O}_{3}(\mathrm{c})+1 / 2 \mathrm{~N}_{2}(\mathrm{~g})+3 / 2 \mathrm{H}_{2}(\mathrm{~g}) \\
& \mathrm{M}(\mathrm{c})+3 / 2 \mathrm{H}_{2} \mathrm{O}(\mathrm{g}) \rightarrow 1 / 2 \mathrm{M}_{2} \mathrm{O}_{3}(\mathrm{c})+3 / 2 \mathrm{H}_{2}(\mathrm{~g}) .
\end{aligned}
$$

The oxide, nitride, and metal were taken in their standard states, and the equilibrium partial pressure of water was calculated for three sets of equilibrium conditions of nitrogen and hydrogen. These equilibrium conditions were:

\begin{tabular}{ccc} 
Set & $\begin{array}{c}\text { Partial Pressure of } \\
\text { Nitrogen, } \\
\text { PN }_{2} \text {, atm }\end{array}$ & $\begin{array}{c}\text { Partial Pressure of } \\
\text { Hydrogen, } \\
\text { PN }_{2} \text { atm }\end{array}$ \\
\cline { 2 - 2 } 1 & 0.985 & 0.015 \\
3 & 0.250 & 0.75 \\
3 & 13.0 & 1.0
\end{tabular}

The first two sets compare to experimental conditions. The third set was chosen because it is similar to proposed operating pressures in the reference design. 
TABLE 24. EQUILIBRIUM PARTIAL PRESSURE OF $\mathrm{H}_{2} \mathrm{O}(\mathrm{g})$ REQUIRED TO STABILIZE A METALLIC OXIDE FILM AGAINST METAL-NITRIDE FORMATION

\begin{tabular}{|c|c|c|c|c|c|c|c|c|c|c|}
\hline \multirow{3}{*}{\multicolumn{2}{|c|}{ 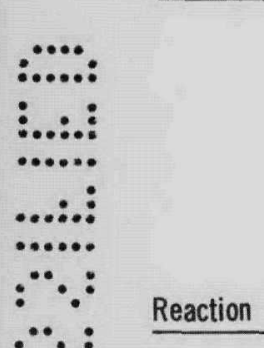 }} & & \multirow{3}{*}{$\begin{array}{c}\text { Standard } \\
\text { Free-Energy } \\
\text { Change, } \\
\Delta \mathrm{F}^{\circ} \text {, at } \\
1500 \mathrm{~F} \text {, cal }\end{array}$} & \multirow{3}{*}{$\begin{array}{l}\text { Equilibrium } \\
\text { Constant } \\
\text { at } 1500 \mathrm{~F} \\
\end{array}$} & \multicolumn{6}{|c|}{$\begin{array}{l}\text { Equilibrium Partial Pressure of } \mathrm{H}_{2} \mathrm{O}(\mathrm{g}) \text { at } 1500 \mathrm{~F} \text { in Equilibrium with the } \\
\text { Indicated Partial Pressures of } \mathrm{N}_{2}(\mathrm{~g}) \text { and } \mathrm{H}_{2}(\mathrm{~g})\end{array}$} \\
\hline & & & & & \multicolumn{2}{|c|}{$\begin{array}{l}\mathrm{P}_{\mathrm{H}_{2}}=0.015 \mathrm{~atm} \\
\mathrm{P}_{\mathrm{N}_{2}}=0.985 \mathrm{~atm}\end{array}$} & \multicolumn{2}{|c|}{$\begin{array}{r}\mathrm{P}_{\mathrm{H}_{2}}=0.75 \mathrm{~atm} \\
\mathrm{P}_{\mathrm{N}_{2}}=0.25 \mathrm{~atm} \\
\end{array}$} & \multicolumn{2}{|c|}{$\begin{array}{l}\mathrm{P}_{\mathrm{H}_{2}}=1.0 \mathrm{~atm} \\
\mathrm{P}_{\mathrm{N}_{2}}=13.0 \mathrm{~atm}\end{array}$} \\
\hline & & 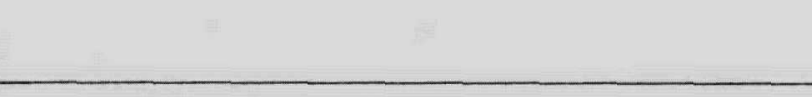 & & & Atm & $\begin{array}{c}\mathrm{Mm} \mathrm{Hg} \\
\text { Pressure } \\
\end{array}$ & Atm & $\begin{array}{c}\mathrm{Mm} \mathrm{Hg} \\
\text { Pressure } \\
\end{array}$ & Atm & $\begin{array}{c}\mathrm{Mm} \mathrm{Hg} \\
\text { Pressure } \\
\end{array}$ \\
\hline & 1 & $\mathrm{Fe}_{4} \mathrm{~N}(\mathrm{c})+4 \mathrm{H}_{2} \mathrm{O}(\mathrm{g}) \longrightarrow 4 \mathrm{FeO}(\mathrm{c})+4 \mathrm{H}_{2}(\mathrm{~g})+\mathrm{V} / 2 \mathrm{~N}_{2}(\mathrm{~g})$ & $-17,115$ & 2727.8 & $1.50 \times 10^{-2}$ & 11.4 & 0.087 & 66.3 & 0.191 & 144.9 \\
\hline & 2 & $4 \mathrm{Fe}(\mathrm{c})+4 \mathrm{H}_{2} \mathrm{O}(\mathrm{g}) \longrightarrow 4 \mathrm{FeO}(\mathrm{c})+4 \mathrm{H}_{2}(\mathrm{~g})$ & $-6,680$ & 21.43 & $7.0 \times 10^{-3}$ & 5.3 & 0.349 & 265.1 & 0.465 & 353.4 \\
\hline & 3 & $\mathrm{CrN}(\mathrm{c})+3 / 2 \mathrm{H}_{2} \mathrm{O}(\mathrm{g}) \longrightarrow 1 / 2 \mathrm{Cr}_{2} \mathrm{O}_{3}(\mathrm{c})+1 / 2 \mathrm{~N}_{2}(\mathrm{~g})+3 / 2 \mathrm{H}_{2}(\mathrm{~g})$ & $-27,255$ & $2.96 \times 10^{5}$ & $3.36 \times 10^{-6}$ & $2.55 \times 10^{-3}$ & $11.0 \times 10^{-5}$ & $8.0 \times 10^{-2}$ & $53.0 \times 10^{-5}$ & 0.402 \\
\hline & 4 & $\mathrm{Cr}(\mathrm{c})+3 / 2 \mathrm{H}_{2} \mathrm{O}(\mathrm{g}) \longrightarrow 1 / 2 \mathrm{Cr}_{2} \mathrm{O}_{3}(\mathrm{c})+3 / 2 \mathrm{H}_{2}(\mathrm{~g})$ & $-34,575$ & $8.73 \times 10^{6}$ & $3.54 \times 10^{-7}$ & $2.70 \times 10^{-4}$ & $1.8 \times 10^{-5}$ & $1.35 \times 10^{-2}$ & $2.4 \times 10^{-5}$ & $1.8 \times 10^{-2}$ \\
\hline 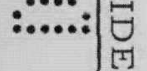 & 5 & $\mathrm{AIN}(\mathrm{c})+3 / 2 \mathrm{H}_{2} \mathrm{O}(\mathrm{g}) \longrightarrow 1 / 2 \mathrm{Al}_{2} \mathrm{O}_{3}(\mathrm{c})+1 / 2 \mathrm{~N}_{2}(\mathrm{~g})+3 / 2 \mathrm{H}_{2}(\mathrm{~g})$ & $-44,940$ & $1.05 \times 10^{9}$ & $1.45 \times 10^{-8}$ & $1.1 \times 10^{-5}$ & $4.6 \times 10^{-7}$ & $3.5 \times 10^{-4}$ & $4.9 \times 10^{-6}$ & $3.7 \times 10^{-3}$ \\
\hline & 6 & $\mathrm{Al}(\mathrm{c})+3 / 2 \mathrm{H}_{2} \mathrm{O}(\mathrm{g}) \longrightarrow \mathrm{Al}_{2} \mathrm{O}_{3}(\mathrm{c})+3 / 2 \mathrm{H}_{2}(\mathrm{~g})$ & $-91,525$ & $2.36 \times 10^{18}$ & $8.45 \times 10^{-15}$ & $6.42 \times 10^{-12}$ & $4.2 \times 10^{-13}$ & $3.2 \times 10^{-10}$ & $5.7 \times 10^{-13}$ & $4.3 \times 10^{-10}$ \\
\hline$\sqrt{5}$ & 7 & $\mathrm{Mo}_{2} \mathrm{~N}(\mathrm{c})+4 \mathrm{H}_{2} \mathrm{O}(\mathrm{g}) \longrightarrow 2 \mathrm{MoO}_{2}(\mathrm{c})+1 / 2 \mathrm{~N}_{2}(\mathrm{~g})+4 \mathrm{H}_{2}(\mathrm{~g})$ & $-14,180$ & 703.1 & 0.291 & 221.2 & 0.123 & 93.1 & 0.268 & 203.7 \\
\hline & 8 & $2 \mathrm{Mo}(\mathrm{c})+4 \mathrm{H}_{2} \mathrm{O}(\mathrm{g}) \longrightarrow 2 \mathrm{MoO}_{2}(\mathrm{c})+4 \mathrm{H}_{2}(\mathrm{~g})$ & $-9,280$ & 72.98 & 0.513 & 390.0 & 0.257 & 195.0 & 0.342 & 260.0 \\
\hline & 9 & $1 / 4 \mathrm{Si}_{3} \mathrm{~N}_{4}(\mathrm{c})+3 / 2 \mathrm{H}_{2} \mathrm{O}(\mathrm{g}) \rightarrow 3 / 2 \mathrm{SiO}_{2}(\mathrm{c})+1 / 2 \mathrm{~N}_{2}(\mathrm{~g})+3 / 2 \mathrm{H}_{2}(\mathrm{~g})$ & $-31,984$ & $2.63 \times 10^{6}$ & $7.8 \times 10^{-7}$ & $5.95 \times 10^{-4}$ & $2.48 \times 10^{-5}$ & 0.02 & $1.23 \times 10^{-4}$ & $9.4 \times 10^{-2}$ \\
\hline & 10 & $3 / 4 \mathrm{Si}(\mathrm{c})+3 / 2 \mathrm{H}_{2} \mathrm{O}(\mathrm{g}) \longrightarrow 3 / 2 \mathrm{SiO}_{2}(\mathrm{c})+1 / 2 \mathrm{~N}_{2}(\mathrm{~g})+3 / 2 \mathrm{H}_{2}(\mathrm{~g})$ & $-55,100$ & $1.15 \times 10^{11}$ & $6.34 \times 10^{-10}$ & $4.82 \times 10^{-7}$ & $3.16 \times 10^{-8}$ & $2.40 \times 10^{-5}$ & $4.22 \times 10^{-8}$ & $3.21 \times 10^{-5}$ \\
\hline & 11 & $1 / 2 \mathrm{Mn}_{5} \mathrm{~N}_{2}(\mathrm{c})+5 / 2 \mathrm{H}_{2} \mathrm{O}(\mathrm{g}) \longrightarrow 5 / 2 \mathrm{MnO}(\mathrm{c})+5 / 2 \mathrm{H}_{2}(\mathrm{~g})+1 / 2 \mathrm{~N}_{2}(\mathrm{~g})$ & $-61,190$ & $1.92 \times 10^{12}$ & $1.83 \times 10^{-7}$ & $1.39 \times 10^{-4}$ & $6.94 \times 10^{-6}$ & $5.27 \times 10^{-3}$ & $2.04 \times 10^{-5}$ & $1.55 \times 10^{-2}$ \\
\hline & 12 & $5 / 2 \mathrm{Mn}(\mathrm{c})+5 / 2 \mathrm{H}_{2} \mathrm{O}(\mathrm{g}) \longrightarrow 5 / 2 \mathrm{MnO}(\mathrm{c})+5 / 2 \mathrm{H}_{2}(\mathrm{~g})$ & $-70,260$ & $1.27 \times 10^{14}$ & $3.42 \times 10^{-8}$ & $2.6 \times 10^{-5}$ & $1.71 \times 10^{-6}$ & $1.3 \times 10^{-3}$ & $2.28 \times 10^{-6}$ & $1.73 \times 10^{-3}$ \\
\hline & 13 & $\mathrm{TiN}(\mathrm{c})+2 \mathrm{H}_{2} \mathrm{O}(\mathrm{g}) \longrightarrow \mathrm{TiO}_{2}(\mathrm{c})+2 \mathrm{H}_{2}(\mathrm{~g})+\mathrm{I} / 2 \mathrm{~N}_{2}(\mathrm{~g})$ & $-32,700$ & $3.66 \times 10^{6}$ & $7.81 \times 10^{-6}$ & $5.94 \times 10^{-3}$ & $2.77 \times 10^{-4}$ & 0.21 & $9.92 \times 10^{-4}$ & 0.75 \\
\hline & 14 & $\mathrm{Ti}(\mathrm{c})+2 \mathrm{H}_{2} \mathrm{O}(\mathrm{g}) \longrightarrow \mathrm{TiO}_{2}(\mathrm{c})+2 \mathrm{H}_{2}(\mathrm{~g})$ & $-88,780$ & $6.64 \times 10^{17}$ & $1.84 \times 10^{-11}$ & $1.40 \times 10^{-8}$ & $9.20 \times 10^{-10}$ & $7.0 \times 10^{-7}$ & $1.23 \times 10^{-9}$ & $9.32 \times 10^{-7}$ \\
\hline & 15 & $\mathrm{Ni}(\mathrm{c})+\mathrm{H}_{2} \mathrm{O}(\mathrm{g}) \rightarrow \mathrm{NiO}(\mathrm{c})+\mathrm{H}_{2}(\mathrm{~g})$ & $+11,700$ & $4.48 \times 10^{-3}$ & 33.5 & $2.55 \times 10^{4}$ & $1.67 \times 10^{3}$ & $1.27 \times 10^{6}$ & $2.23 \times 10^{3}$ & $1.69 \times 10^{6}$ \\
\hline
\end{tabular}


In Table 25, there is shown the effect of monatomic nitrogen and ammonia on the steam requirement to prevent nitriding.

In Table 26, the dissociation pressures at $1500 \mathrm{~F}$ of the nitrides are given. A tabulation of fundamental data and the literature sources of the data are shown.

\section{Conclusions} 24 to 26 .

The following conclusions may be drawn from a study of the data given in Tables

(1) Data in Table 24 indicate that the nitrides of aluminum, chromium, manganese, silicon, and titanium can be prevented from forming by less than a $1-\mathrm{mm}$ partial pressure of $\mathrm{H}_{2} \mathrm{O}(\mathrm{g})$. However, the partial pressure of $\mathrm{H}_{2} \mathrm{O}(\mathrm{g})$ that prevents nitride formation is larger than that necessary to oxidize the metal. Hence, the rate of oxidation of the metal by steam must be slow or an impervious layer of oxide must form.

As an example of interpreting the data in Table 24, Reactions 1 and 2 for the case of $\mathrm{Fe}_{4} \mathrm{~N}(\mathrm{c})$ may be considered. Under the first set of equilibrium conditions $11.4 \mathrm{~mm}$ of mercury pressure of $\mathrm{H}_{2} \mathrm{O}(\mathrm{g})$ will prevent nitride formation, while only $5 \mathrm{~mm}$ of mercury pressure of $\mathrm{H}_{2} \mathrm{O}(\mathrm{g})$ will oxidize the metal. Under the other two sets of equilibrium conditions 66 and $145 \mathrm{~mm}$ of mercury pressure of $\mathrm{H}_{2} \mathrm{O}(\mathrm{g})$ are necessary to prevent nitride formation while a larger partial pressure of $\mathrm{H}_{2} \mathrm{O}(\mathrm{g})$ would be needed to oxidize the metal.

(2) In Table 25, Reactions 1 and 2 show that if monatomic nitrogen is present in a nonequilibrium concentration $\mathrm{H}_{2} \mathrm{O}(\mathrm{g})$ will not prevent nitride formation. However, Reaction 5 indicates that monatomic nitrogen is unstable with respect to the formation of molecular nitrogen. Under these conditions it is known that the half-life of monatomic nitrogen is a very short time.

(3) Reaction 4 of Table 25 indicates that if $\mathrm{NH}_{3}(\mathrm{~g})$ exists at $1500 \mathrm{~F}$, it is in a metastable state, and that the the rmodynamic tendency is for $\mathrm{NH}_{3}(\mathrm{~g})$ to dissociate into nitrogen and hydrogen. It should be noted, though, that if $\mathrm{NH}_{3}$ occurs in a metastable state, a higher partial pressure of $\mathrm{H}_{2} \mathrm{O}$ will be necessary to prevent nitride formation than if the $\mathrm{NH}_{3}$ were dissociated into nitrogen and hydrogen gases. This observation can be generalized, but is shown specifically for chromium in Reaction 3, Table 25.

(4) In Table 26, the dissociation pressures of the nitrides are shown. These dissociation pressures were calculated by assuming that the nitride does not form a solid solution with the metal. The fact that iron nitride and iron form solid solutions explains why the calculated dissociation pressure of $\mathrm{Fe}_{4} \mathrm{~N}$ is much higher than the observed dissociation pressure. 
$\therefore: . . .:$

¿...:

.......

....::

.....

$\because \because$

$\because \because$

$\cdots$

:

......

$\therefore$

$\therefore:$ :

$\therefore . .$.

TABLE 25. STANDARD FREE-ENERGY CHANGE AND EQUILIBRIUM PRESSURES OF $\mathrm{H}_{2} \mathrm{O}(\mathrm{g})$ IN REACTIONS OF INTEREST IN NITRIDING METALS

\begin{tabular}{|c|c|c|c|c|c|c|}
\hline \multirow[b]{2}{*}{ Reaction } & & & \multirow{2}{*}{$\begin{array}{l}\text { Standard Free-Energy } \\
\text { Change, } 1 \mathrm{~F}^{\circ} \text {, } \\
\text { at } 1500 \mathrm{~F} \text {, cal }\end{array}$} & \multirow{2}{*}{$\begin{array}{l}\text { Equilibrium } \\
\text { Constant at } \\
1500 \mathrm{~F}, \mathrm{~K}\end{array}$} & \multicolumn{2}{|c|}{$\begin{array}{l}\text { Equilibrium Partial } \\
\text { Pressure of } \mathrm{H}_{2} \mathrm{O}(\mathrm{g})\end{array}$} \\
\hline & & & & & Atm & $\mathrm{Mm} \mathrm{Hg}$ \\
\hline 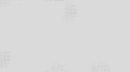 & & \multicolumn{2}{|c|}{ When $\mathrm{P}_{\mathrm{N}_{2}}=0.01$ Atm and $\mathrm{P}_{\mathrm{H}_{2}}=0.75 \mathrm{Atm}$} & & & \\
\hline 1 & $\mathrm{CrN}(\mathrm{c})+3 / 2 \mathrm{H}_{2} \mathrm{O}(\mathrm{g}) \longrightarrow 1 / 2 \mathrm{Cr}_{2} \mathrm{O}_{3}(\mathrm{c})+3 / 2$ & $2 \mathrm{H}_{2}(\mathrm{~g})$ & $+42,435$ & $3.03 \times 10^{-9}$ & $1.66 \times 10^{4}$ & $1.26 \times 10^{7}$ \\
\hline \multirow[t]{2}{*}{2} & $\mathrm{AlN}(\mathrm{c})+3 / 2 \mathrm{H}_{2} \mathrm{O}(\mathrm{g}) \rightarrow 1 / 2 \mathrm{Al}_{2} \mathrm{O}_{3}(\mathrm{c})+\mathrm{N}(\mathrm{g})$ & g) $+3 / 2 \mathrm{H}_{2}(\mathrm{~g})$ & $+24,750$ & $1.07 \times 10^{-5}$ & 71.5 & $5.43 \times 10^{4}$ \\
\hline & & \multicolumn{2}{|c|}{ When $\mathrm{PNH}_{3}=1.0 \mathrm{Atm}$ and $\mathrm{N}+\mathrm{N}_{2}=0$} & & & \\
\hline 3 & $\mathrm{CrN}(\mathrm{c})+3 / 2 \mathrm{H}_{2} \mathrm{O}(\mathrm{g}) \longrightarrow 1 / 2 \mathrm{Cr}_{2} \mathrm{O}_{3}(\mathrm{c})+\mathrm{NH}_{3}$ & $3(g)$ & $-9,995$ & 101.5 & 0.046 & 35.0 \\
\hline 4 & $1 / 2 \mathrm{~N}_{2}(\mathrm{~g})+3 / 2 \mathrm{H}_{2}(\mathrm{~g}) \longrightarrow \mathrm{NH}_{3}(\mathrm{~g})$ & & $+17,260$ & $3.43 \times 10^{-4}$ & - & - \\
\hline 5 & $1 / 2 \mathrm{~N}_{2}(\mathrm{~g}) \longrightarrow(\mathrm{N})(\mathrm{g})$ & & $+69,690$ & $1.025 \times 10^{-14}$ & -- & - \\
\hline
\end{tabular}




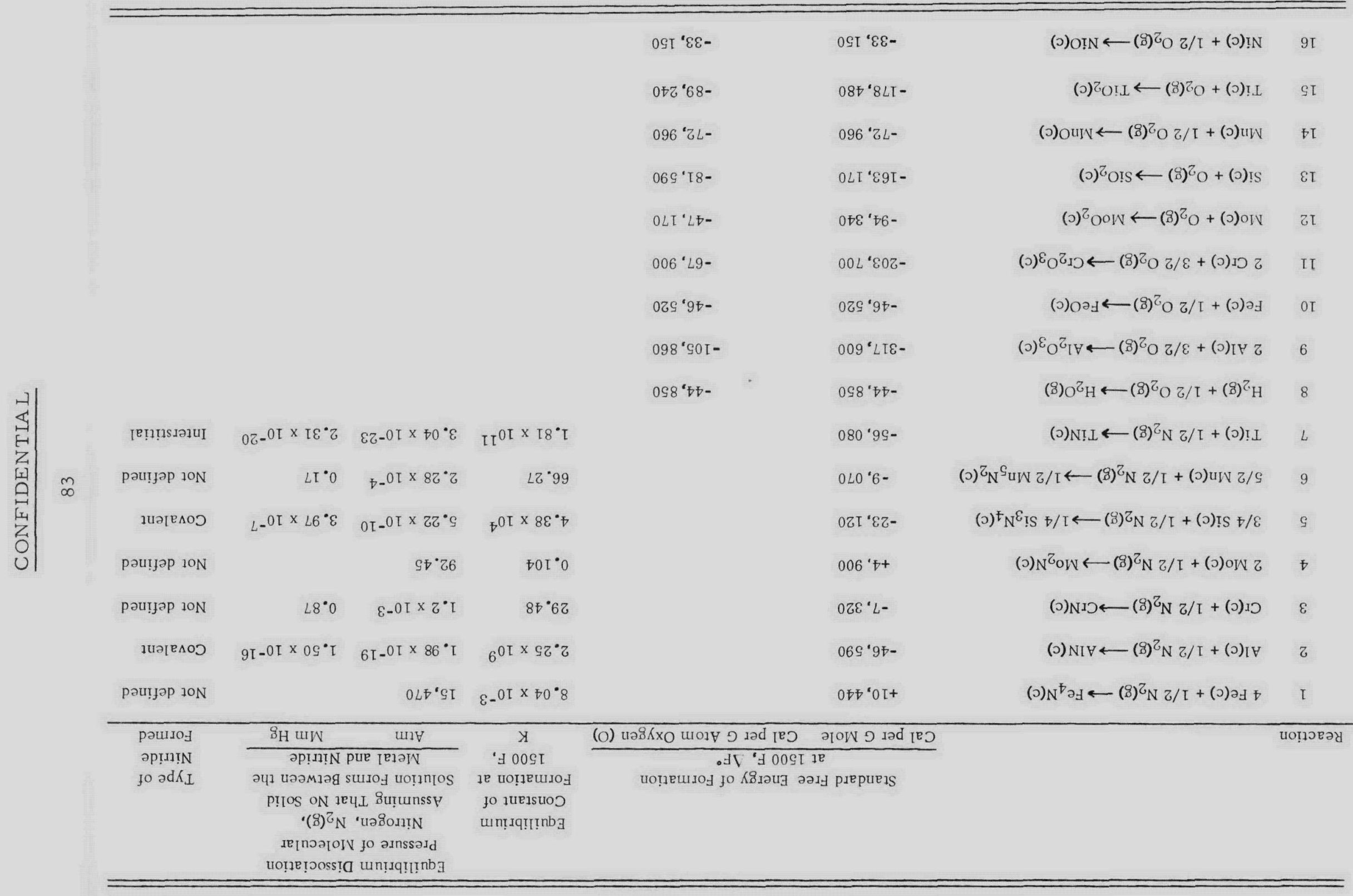

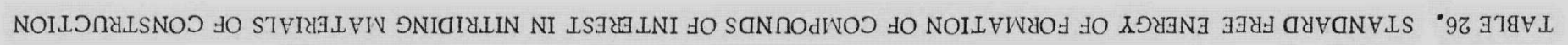




\section{CONFIDENTIAL}

84

Method of Calculation

The required equilibrium partial pressure of $\mathrm{H}_{2} \mathrm{O}(\mathrm{g})$ was computed from the rmodynamic considerations. The calculations were made for the ordinary gravitational field. No attempt was made to calculate the effect of a high-energy field on the steadystate requirement of water vapor to prevent nitride formation.

The calculational method can be outlined by considering the following reaction:

$$
\mathrm{CrN}(\mathrm{c})+3 / 2 \mathrm{H}_{2} \mathrm{O}(\mathrm{g}) \rightarrow 1 / 2 \mathrm{Cr}_{2} \mathrm{O}_{3}(\mathrm{c})+1 / 2 \mathrm{~N}_{2}(\mathrm{~g})+3 / 2 \mathrm{H}_{2}(\mathrm{~g}) \text {. }
$$

The standard free-energy change of the reaction, $\Delta F_{R}^{\circ}$, at $1500 \mathrm{~F}$ was computed from data listed in Table 26. With this value of the standard free-energy change, the equilibrium constant of the reaction was computed by the following equation:

$$
\Delta \mathrm{F}_{\mathrm{R}}^{\circ}=-\mathrm{R} T \ln \mathrm{K}
$$

where

$$
\begin{aligned}
\Delta \mathrm{F}_{\mathrm{R}}^{\circ} & =\text { Standard free energy of the reaction, cal } \\
\mathrm{T} & =\text { Temperature, } \mathrm{K} \\
\mathrm{R} & =\text { Universal gas constant, } 1.986 \mathrm{cal} /(\text { mole })(\mathrm{K}) \\
\mathrm{K} & =\text { Equilibrium constant; }
\end{aligned}
$$

or

$$
\log _{10} \mathrm{~K}=\frac{-\Delta \mathrm{F}_{\mathrm{R}}^{\circ}}{4.576 \mathrm{~T}}
$$

For the above reaction,

$$
\mathrm{K}=\frac{{ }_{\mathrm{Cr}}^{1 / 2} \mathrm{O}_{3} \cdot f_{\mathrm{N}_{2}}^{1 / 2} \cdot \mathrm{f}_{\mathrm{H}_{2}}^{3 / 2}}{{ }^{\mathrm{a}} \mathrm{CrN} \cdot \mathrm{f}_{\mathrm{H}_{2} \mathrm{O}}^{3 / 2}}
$$

whe re

and

$$
\mathrm{a}=\text { activity of the solid } \mathrm{Cr}_{2} \mathrm{O}_{3} \text { or } \mathrm{CrN}
$$

$$
f \text { = fugacity of the gas } \mathrm{N}_{2} \text { or } \mathrm{H}_{2} \text {. }
$$

Two simplifying assumptions were made. The solids $\mathrm{Cr}_{2} \mathrm{O}_{3}$ and $\mathrm{CrN}$ were considered to be immiscible. That is, they do not form solid solutions, but remain in their standard states, and hence have an activity of unity. The gases were assumed to behave ideally, or fugacities were taken equivalent to partial pressures. Both assumptions are reasonable. The expression for $\mathrm{K}$ then becomes, 


\section{CONFIDENTIA L}

85

$$
\mathrm{K}=\frac{1 / 2 \mathrm{p}_{\mathrm{N}_{2}} \cdot \begin{array}{l}
3 / 2 \\
\mathrm{p}_{\mathrm{H}_{2}}
\end{array}}{3 / 2} .
$$

The equilibrium pressure of $\mathrm{H}_{2} \mathrm{O}(\mathrm{g})$ may then be computed as below:

$$
\mathrm{p}_{\mathrm{H}_{2} \mathrm{O}}=\frac{\mathrm{p}_{\mathrm{N}_{2}} \cdot \mathrm{p}_{\mathrm{H}_{2}}}{\mathrm{~K}^{2 / 3}} \text {. }
$$




\section{CONFIDENTIAL}

IN-PILE-LOOP FACILITY AT THE BRR

S. L. Fawcett, G. T. Bodnar, G. A. Francis, and A. M. Rockwood

In July 1956, a program was initiated to design, construct and operate an in-pileloop facility at the Battelle Research Reactor for evaluating GCRE fuel-element specimens. The purpose of this loop facility is to evaluate full-scale fuel-element assemblies under conditions simulating GCRE operating conditions as closely as practicable. Thus, tests in this loop would be considered as final proof tests aimed at showing up limitations in design, fabrication techniques, or materials.

The choice of the Battelle Research Reactor for a test facility of this type was based primarily on two considerations.

(1) The Battelle reactor, being of the pool type, offered sufficient space next to the core for testing full-scale fuel assemblies.

(2) The thermal-neutron flux available was considered sufficient to produce flux levels equivalent to GCRE levels or perhaps a factor of two greater. However, flux was not available for the very high burnup rate which might be needed in tests designed for the preliminary screening of fuel material.

\section{$\underline{\text { Loop-Design Specifications }}$}

The loop was designed to be capable of operating under the following conditions:

Gas type

Gas pressure, ambient

Gas temperature, inlet to specimens

Gas temperature outlet from specimen

Gas-flow rate

Pressure drop across specimen

Specimen size

Maximum specimen power generation
Nitrogen plus additives

200 psi $\max$

$750 \mathrm{~F} \max$

$1150 \mathrm{~F} \max$

$0.415 \mathrm{lb}$ per sec $\max$

5 psi $\max$

1. $5 \mathrm{in}$. in $O D$ by $24.0 \mathrm{in.}$ long

$50 \mathrm{kw} \max$ 
The loop assembly consists primarily of the test section, a heat exchanger and a blower. The assembly is supported from a movable bridge spanning the reactor pool and is completely submerged in the pool at roughly the same depth as the reactor core.

By this arrangement the loop assembly is completely shielded by the pool water. Also the loop can be removed from the vicinity of the reactor for maintenance, loading and unloading, etc, , without limiting the reactor operations. For example, in the event of loop malfunctioning, the reactor need be shut down only long enough to move the loop assembly into the back end of the pool.

\section{General Layout and Piping}

The general layout of the loop assembly in the reactor pool is shown in Figures 16 and 17. The loop is shown assembled in Figure 18.

The materials used in the primary loop system are aluminum for the pressure walls and Inconel pipe for the areas containing hot flowing nitrogen gases. An annulus of static nitrogen is maintained between the aluminum pressure wall and the Inconel pipe. This static chamber acts as an insulator to reduce the heat losses from the loop.

The gas flows from the blower through a center tube to the diffuser section, and then passes through the orifice plate, where the flow is measured by a differentialpressure system. After leaving the orifice-plate assembly, the flow is diverted into an annulus formed by two Inconel tubes and continues to the test specimen. The coolant gas then enters the tube which houses the test specimen. After leaving the test section, the gas returns through the center tube to the heat exchanger. The gas is then returned to the blower. A view of the typical tube arrangement is shown in Figure 19.

A manually controlled pneumatic valve is located in the loop ahead of the heat exchanger. This valve is used to manually control the rate of coolant-gas flow and to purge the system during initial startup.

Seals used at all the flanges in the primary loop system consist of stainless steel self-energizing O-rings backed up by rubber O-rings made from compounds suitable for use in this application. Seals used in the blower assembly are flat aluminum gaskets.

\section{Blower}

The blower and auxiliary blower equipment are located in the blower cask. The centrifugal blower impeller is $10 \mathrm{in}$. in diameter. It is designed to operate at $10,000 \mathrm{rpm}$ and deliver $46 \mathrm{cfm}$ of nitrogen at $200 \mathrm{psia}$ and $750 \mathrm{~F}$ against a resistance equivalent to $10 \mathrm{psi}$. The impeller is mounted directly on a common shaft with the $5-\mathrm{hp}$ drive motor. The impeller, armature, and shaft assembly are supported by two sets of oil-lubricated ball bearings. The upper bearing consists of a duplex set of precision 



\section{CONFIDENTIAL}

89

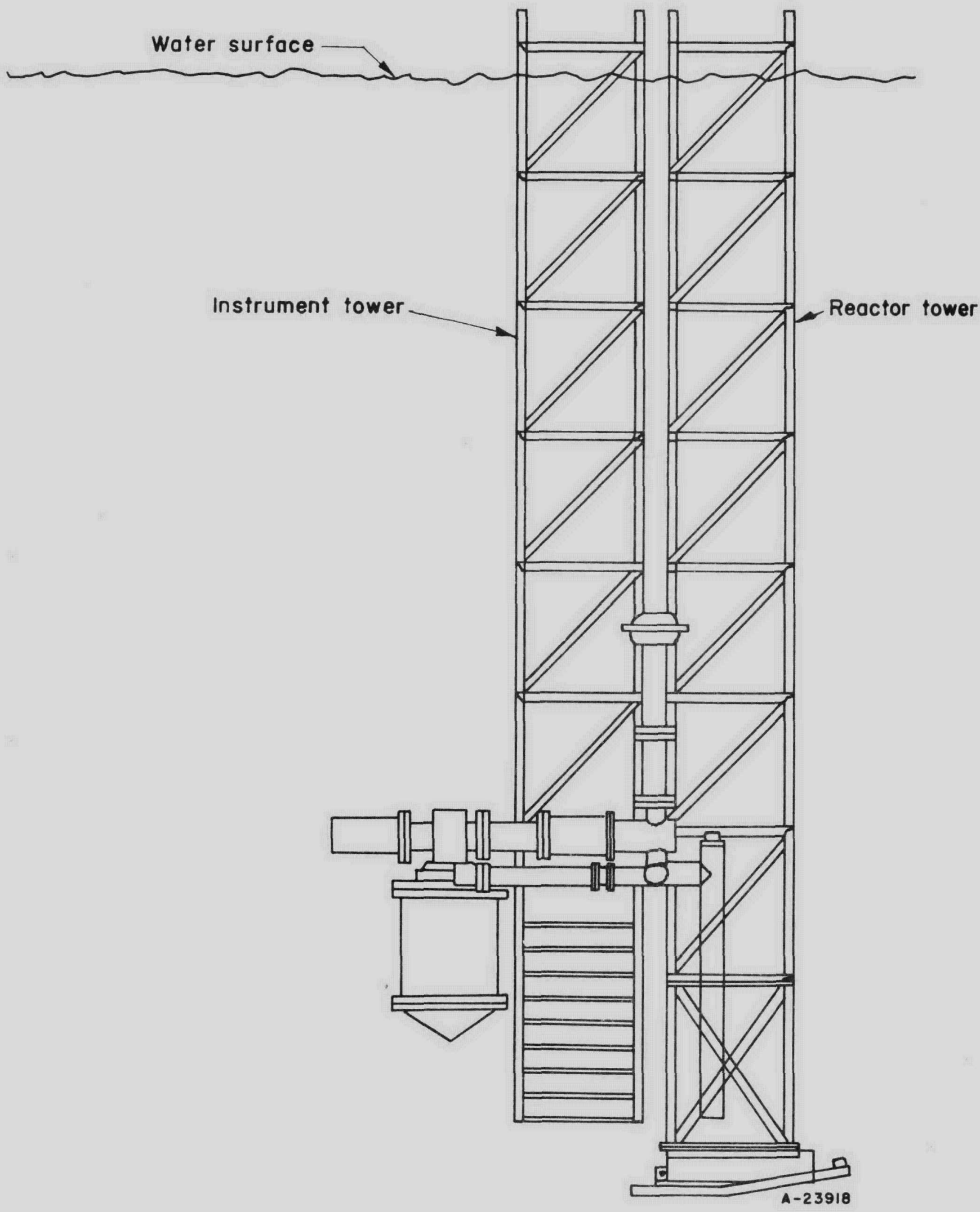

FIGURE 17. SIDE VIEW OF LOOP IN REACTOR POOL CONEIDENTIAL

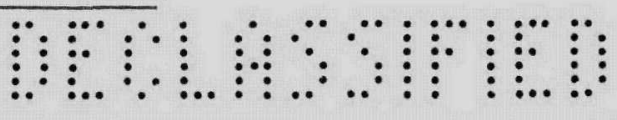




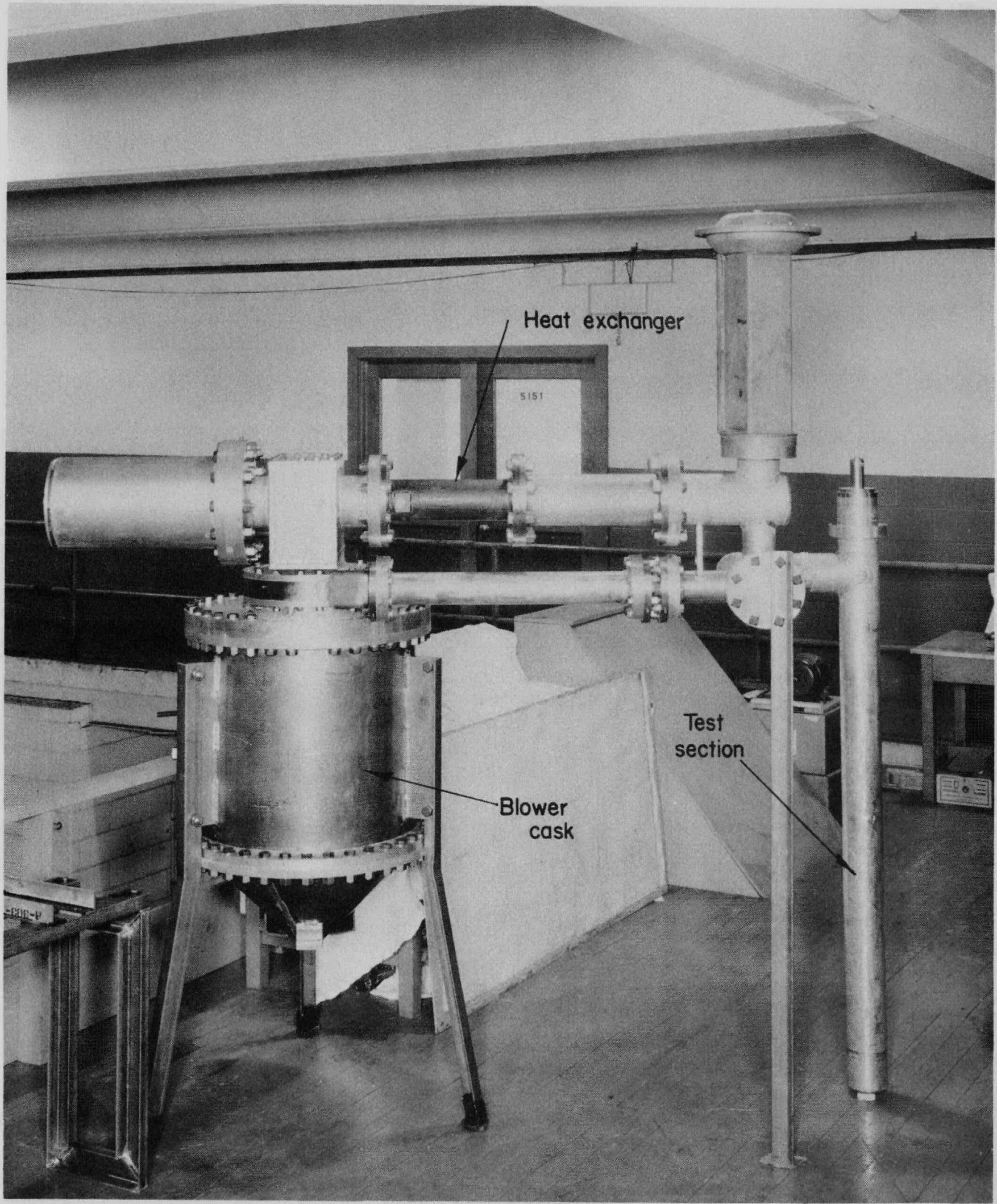

FIGURE 18. THE IN-PILE-LOOP ASSEMBLY 


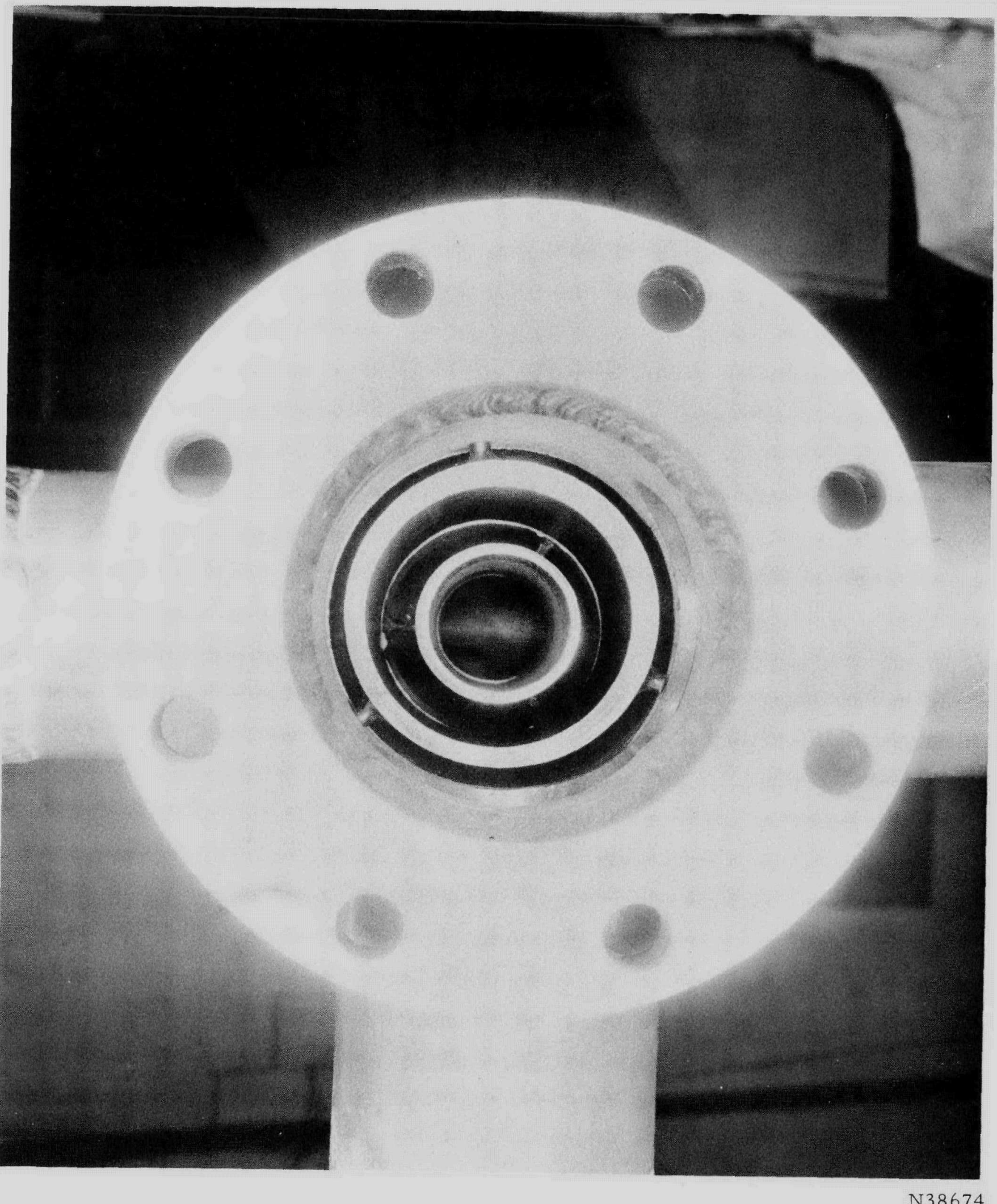

FIGURE 19. TYPICAL ARRANGEMENT OF INCONEL INNER TUBING WITHIN THE ALUMINUM PRESSURE TUBE 
angular-contact bearings and the lower is a precision floating-type bearing. Cooling of the bearings is done by passing water through the outer bearing-race housing and by circulating oil in the hollow shaft to conduct the heat away from the inner race.

A labyrinth-type seal is installed between the blower impeller and the upper set of bearings to prevent oil from entering the primary-loop system. In addition to the seal, an auxiliary blower is used to purge the area between the seal and bearings with oilfree nitrogen.

A gear-type pump supplies oil for lubricating the bearings of the blower and auxiliary motors, and for cooling the blower shaft and bearings.

\section{Heat Exchanger}

The heat exchanger for cooling the nitrogen is a shell- and-tube-type unit composed of twenty-four 3/16-in. ID tubes and a 1-1/2-in, -diameter bypass tube contained in a water-cooled shell. The amount of heat removal can be controlled by a pneumaticdiaphragm-actuated valve on the gas bypass tube and by throttling the cooling-water flow through the shell. The heat-exchanger length is approximately $13 \mathrm{in.} \mathrm{Either} \mathrm{the}$ water pump in use or the standby unit will pump a maximum of $10 \mathrm{gpm}$ of coolant water.

\section{$\underline{\text { Test Section }}$}

The test section, which houses the test specimen, consists of three vertical concentric tubes. The outer tube, made from 4-in. aluminum pipe, is the pressure wall, while the two inner ones are thin-walled Inconel tubes that form the passages for the coolant gas.

The coolant gas flows to the test specimen through the annulus formed by the two Inconel tubes and the gas returns to the heat exchanger through the inside tube in which the test specimen is located. The annulus formed by the outer Inconel tube and the aluminum pressure wall contains static gas for insulation to reduce the heat losses from the system.

\section{Instrumentation and Control}

Instruments have been provided to measure loop-system conditions during operation and to provide the control required for safety purposes. Operating temperatures are recorded continuously to provide a permanent record for any future study of the tests and for use in the design of related or advanced loops. follows:

The operation of the loop has been divided into three controlled conditions, as

(1) During normal loop operation, the instrumentation will:

(a) Continuously record and control the fuel-element surface temperature at the outlet of the test specimen

\section{CONFIDENTIAL}




\section{CONFIDENTIAL}

93

(b) Continuously record the following temperatures:

(i) Inlet gas to test specimen

(ii) Outlet gas from test specimen

(iii) Inlet surface temperature of test specimen

(iv) Outlet surface temperature of test specimen

(v) Blower-bearing temperatures

(c) Control and indicate the gas pressure within \pm 10 per cent of the normal operating pressure

(d) Indicate the gas-flow rate

(e) Permit manual control of the gas flow from 100 per cent to 50 per cent of full flow

(f) Monitor the gas stream for activity

(g) Sample the gas stream

(2) Events causing the reactor to scram will include:

(a) Operating pressure high or low ( \pm 10 per cent)

(b) Test-specimen plate or gas temperatures too high (approximately $150 \mathrm{~F}$ above operating temperature)

(c) Loss of coolant-gas flow (below 50 per cent of full flow)

(d) Malfunction of the blower system caused by:

(i) Bearings being too hot (approximately $300 \mathrm{~F}$ )

(ii) Power failure to main blower, auxiliary blower, or lubricating pump

(e) Coolant-gas activity above accepted level

(3) The following events will take place after the reactor scrams:

(a) The valves controlling the nitrogen supply and exhaust will close

(b) The bypass valve to the heat exchanger closes

(c) The main blower and auxiliary equipment are shut down (after a 10-sec time delay).

\section{CONFIDENTIAL}




\section{CONFIDENTIAL}

94

The scram system is based on normally open relays associated with each control device. The relay is energized during loop operation when the specific control point is in normal operating range. If the relay de-energizes in performing its control function or because of any other loss of power, the contacts in the scram relay-coil circuit open and the reactor and loop scram.

The indicating system features lights showing which control points are out of operating range. Clocks will be placed in parallel with each control relay and will run during normal loop operation. All clocks will be started simultaneously. The malfunction causing the reactor to scram will be indicated by the clock showing the shortest elapsed time. By the method of requiring relay energization throughout the control system during normal operation, it is felt that maximum control safety has been attained.

Test-Specimen Assembly

The test-specimen assembly is composed of a square tube attached to a rod with a threaded plug-and-flange fitting on the end. The square tube serves as the holder for the fuel-element specimen and also as the inner wall of the annular inlet-gas-coolant passage. The test specimen is supported from the top by the rod. The whole assembly is supported from the top of the vertical-test-section leg of the loop.

Thermocouple leads for gas and fuel-plate temperature measurement are lead up parallel to the support rod and pass outside the loop through the plug-and-flange fitting.

\section{Test-Specimen-Transfer Equipment}

Test-specimen assemblies are transferred into and out of the loop as a unit. The transfer equipment is essentially an air bell open at the bottom. The procedure for a transfer is as follows:

(1) The air bell with a test-specimen assembly loaded inside is lowered into the pool to fit over the top end of the vertical leg of the loop. During this operation the air pressure in the bell is adjusted to keep the test-specimen assembly dry.

(2) With the bell in place, a mechanically operated arm inside the bell unscrews and removes the plug fitting at the top of the vertical leg.

(3) The test-specimen assembly is then lowered into the loop and secured by rotating the threaded-flange fitting into the top of the vertical leg. A reverse procedure is used for removing a test-specimen assembly. The shielded transfer cask contains identical fittings to the vertical-loop leg. Thus, transfers into the cask use the same procedure as outlined above. Obviously, the shielded transfer cask is located at the bottom of the pool during transfer operations. 


\section{CONFIDENTIAL}

Owing to the relative inaccessibility of the loop facility for minor maintenance and repair during operation in the reactor pool, it was considered necessary to perform fairly extensive operating tests prior to actual installation in the reactor.

For this purpose an 8 - $\mathrm{ft}$-diameter water tank $10 \mathrm{ft}$ high was constructed. Facilities were installed in order to operate the loop in the tank under simulated reactor conditions. A 50-kw electric heating element consisting of parallel Nichrome plates was constructed to simulate the in-pile test element. The test program in this out-of-pile facility includes flow- and temperature-calibration tests, simulated component or failure tests, and a continuous full-power operating period of about 4 weeks.

\section{Fuel-Element Test Specimen 1}

Fabrication was started on the initial fuel specimen to be tested in the loop. The specifications for this fuel-element subassembly are listed below:

(1) The subassembly contains seven active plates.

(2) The subassembly is $27 \mathrm{in.}$ long and contains plates $25 \mathrm{in}$. long, and grooved side plates $27 \mathrm{in.}$ long. The active plates are brazed into the side plates to form a rigid parallel-plate square subassembly.

(3) The grooved side plates are Type 347 stainless steel.

The fuel-plate specifications are as follows:

Dimensions
Minimum core width
1.000 in.
Core length
$24 \pm 0.250 \mathrm{in}$.
Core thickness
$0.050 \pm 0.002 \mathrm{in}$.
Element length
$25.000 \pm 0.001 \mathrm{in}$.
Element width
$1.180 \pm 0.001 \mathrm{in}$.
Element thickness
$0.060 \pm 0.002 \mathrm{in}$.

Core materials

$\mathrm{UO}_{2}$, hydrothermal
(fully enriched)
$\begin{aligned} & \text { Type } 347 \text { stainless } \\ & \text { steel }\end{aligned}$

Cladding material

Type 347 stainless steel 
The in-pile-loop facility is undergoing final assembly and leak testing. It is anticipated that out-of-pile tests with the complete loop will begin during June, 1957 . Unless unusual difficulties in debugging and operation are encountered in the out-of-pile tests, it is expected that the loop will be installed at the reactor and in-pile tests begun during July, 1957.

After fabricating the first in-pile-loop subassembly, tests will be initiated at the reactor to determine the actual reactor flux to be expected during operations. The assembly will be placed in a dummy tube which simulates the vertical leg of the loop and positioned at the face of the reactor core. Tin-antimony-alloy wires will be placed in the channels between the fuel plates. The reactor will be operated at low power for several hours to activate the wires. Counting of the wire activation after exposure will indicate the flux distribution throughout the test specimen.

DLK/ims:jms:pa:mmk 